\title{
Do unconscious threats give us the shivers? : a critical inquiry of Ohman's hypothesis about the pre- attentive elicitation of phobic fear
}

Citation for published version (APA):

Mayer, B. (2000). Do unconscious threats give us the shivers? : a critical inquiry of Ohman's hypothesis about the pre-attentive elicitation of phobic fear. [Doctoral Thesis, Maastricht University]. Universiteit Maastricht. https://doi.org/10.26481/dis.20000915bm

Document status and date:

Published: 01/01/2000

DOI:

10.26481/dis.20000915bm

Document Version:

Publisher's PDF, also known as Version of record

Please check the document version of this publication:

- A submitted manuscript is the version of the article upon submission and before peer-review. There can be important differences between the submitted version and the official published version of record.

People interested in the research are advised to contact the author for the final version of the publication, or visit the DOI to the publisher's website.

- The final author version and the galley proof are versions of the publication after peer review.

- The final published version features the final layout of the paper including the volume, issue and page numbers.

Link to publication

\footnotetext{
General rights rights.

- You may freely distribute the URL identifying the publication in the public portal. please follow below link for the End User Agreement:

www.umlib.nl/taverne-license

Take down policy

If you believe that this document breaches copyright please contact us at:

repository@maastrichtuniversity.nl

providing details and we will investigate your claim.
}

Copyright and moral rights for the publications made accessible in the public portal are retained by the authors and/or other copyright owners and it is a condition of accessing publications that users recognise and abide by the legal requirements associated with these

- Users may download and print one copy of any publication from the public portal for the purpose of private study or research.

- You may not further distribute the material or use it for any profit-making activity or commercial gain

If the publication is distributed under the terms of Article $25 \mathrm{fa}$ of the Dutch Copyright Act, indicated by the "Taverne" license above, 


\section{Omslag}

Sandra Daems, Open Universiteit Nederland

\section{Druk}

Unigraphic, Universiteit Maastricht

ISBN 90-5681-079-0 


\section{Do unconscious threats give us the shivers?}

A critical inquiry of Ohman's hypothesis about the pre-attentive elicitation of phobic fear

\section{PROEFSCHRIFT}

ter verkrijging wan de graad van doctor

aan de Universiteit Maastricht,

op gezag van de Rector Magnificus, Prof. dr. A.C. Nieuwenhuijzen Kruseman, volgens het besluit van het College van Decanen,

in het openbaar te verdedigen op

vrijdag 15 september 2000 om 16.00 uur

door

Birgit Mayer 


\section{Promotor}

Prof. dr. H.L.G.J. Merckelbach

\section{Beoordelingscommissie}

Prof. dr. A.T.M. Jansen (voonzitter)

Prof. dr. M.A. van den Hout

Dr. M. Jelicic

Dr. J.L. Kenemans (Universiteit Utrecht)

Prof dr. H.T. van der Molen (Open Universiteit Nederland)

Het onderzoek in dit proefschrift werd financieel gesteund door de Stichting Gedragswetenschappen (SGW), die wordt gesubsidieerd door de Nederlandse organisatie voor wetenschappelijk onderzoek (NWO; projectnummer 575-65-069). 


\section{Contents}

1. Introduction

Specinc phobia: Phenomenclogy and epidemology 7

The irrational character of phobia 8

Psychoanalytic account 9

Stress-induced recovery of phobias $\quad 10$

Ewolutionary origin of phobic fear

The uncontrollability of phobic fear $\quad 12$

Automatic information processing 13

Pre-attentive activation of fear 4

Psychophysiological responses to masked fearful stimui 15

Psychophysiological studies 15

Neurobiological support 21

2. Critral notes on Öhman's hypothesis 25

The irrationality of phobic responses reconsidered 25

Disgust sensitivity $\quad 26$

Feature detectors? $\quad 28$

Technical aspects of Ohman's experiments 28

$\begin{array}{ll}\text { Concluding comments } & 29\end{array}$

3. Research questions

4. Empincalustudies




masked phobic cuess


cognitive herterence





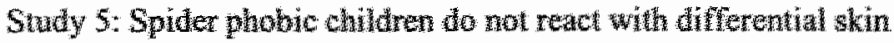
conductance responses to masked phobe stimu隹




Introduction

Psychodynamics, cognitive psychology, and folk psychology 103

The unconscious and the psychodynamic tradition 103

Unconscious processes and cognitive psychology 104

Subliminal messages and folk psychology 105

$\begin{array}{ll}\text { Subliminal perception and emotion research } & 107\end{array}$

Subliminal exposure therapy? $\quad \mathbb{1 0 7}$

$\begin{array}{ll}\text { Priming studies } & 107\end{array}$

A critical evaluation of priming studies 108

Subliminal perception and pathological anxiety 111

Pre-attentive origins of phobic responding $\quad 111$

Attentionall bias and anxiety $\quad 113$

$\begin{array}{ll}\text { Automaticity } & 114\end{array}$

$\begin{array}{ll}\text { Concluding remarks } & 115\end{array}$

$\begin{array}{ll}\text { Technical issues } & 115\end{array}$

$\begin{array}{ll}\text { Conclusion } & 117\end{array}$

6. General discussion

Recapitulation of the findings

$\begin{array}{ll}\text { How to handle contradictory results? } & 124\end{array}$

$\begin{array}{ll}\text { The saga of Smith and Jones } & 126\end{array}$

$\begin{array}{ll}\text { Technical obstacles } & 127\end{array}$

$\begin{array}{ll}\text { Automatic processes and psychopathology } & 129\end{array}$

Suggestions for future research 131

$\begin{array}{ll}\text { Final remarks } & 133\end{array}$

References

Summary

Samenvatting

Dank...

Curriculum vitae 


\section{Chapter 1}

\section{Introduction}

Specific phobia: Phenomenology and epidemiology

According to the fourth edition of the Diagnostic and Statistical Manual of Mental Disorders (DSM-IV; American Psychiatric Association, 1994, p.410), the core feature of specific phobia (formerly "simple phobia") is a "marked and persistent fear that is excessive or unreasonable, cued by the presence or anticipation of a specific object or situation". Exposure to the phobic object or situation almost invariably provokes an immediate fear response. DSM-IV assumes that phobic patients recognize that their fear is excessive or unreasonable. Despite this, phobics cannot control their fear responses. As a result of their uncontrollable and excessive fear, phobic patients will go at greath lenghts to avoid the phobic object or situation.

Specific phobias and their non-pathological counterparts, specific fears, have been the object of a number of surveys. These have consistently found that some fears (e.g., fear of snakes) are more prevalent than others (e.g., fear of electricity) (e.g., Agras, Sylvester, \& Oliveau, 1969; Costello, 1982). Factor analyses have shown that specific fears cluster together in a relatively small number of categories (Arrindell, Pickersgill, Merckelbach, Ardon, \& Cornet, 1991; Fredrikson, Annas, Fischer, \& Wik, 1996). Accordingly, DSM-IV (APA, 1994) differentiates between four types of specific phobia: animal type (e.g., spiders), natural environment type (e.g., heights), bloodinjection-injury type (e.g., receiving an injection), and situational type (e.g., enclosed spaces). Apart from these prevalent types, DSM-IV lists a residual type (e.g., choking phobia).

Phobia is the most common psychiatric disorder and within this category, specific phobia ranks highest in prevalence (see Chapman, 1997). Although epidemiological studies have come up with point prevalence estimates for specific phobia that vary from $2.3 \%$ (Myers et al., 1984) to $26.5 \%$ (Fredrikson et al., 1996), most studies reported lifetime prevalence rates circling around 12\% (Robins \& Regier, 1991; Kessler et al., 1994). Barlow (1988) found that animal phobias make up the largest part of the specific phobias (i.e., 14\%). This fits nicely with the finding of Bourdon, Boyd, Rae, Burns, Thompson, and Lacke (1988) that the most common phobias are phobias of spiders, bugs, mice, snakes, and so on (see also Chapman, 1997).

It is a well-established fact that there are marked sex differences in the prevalence of phobias. That is, prevalence rates are generally higher for women than for men (e.g., Myers et al., 1984; Bourdon et al., 1988; Fredrikson et al., 1996; Curtis, Magee, Eaton, Wittchen, \& Kessler, 1998). Sex differences in prevalence rates have been consistently found for agoraphobia and specific phobia, but not for social phobia (Bourdon et al., 
1988). As far as specific phobias are concerned, the skewed sex distribution has been observed for animal and situational phobias, but not for blood-injection-injury phobia (Fredrikson et al, 1996). It is unlikely that sex differences in specific phobia are the result of a self-report bias in men (Katkin \& Hoffman, 1976; Comelius \& Averill, 1983). For example, it has been noted that men appear to behave less fearfully under social pressure (Speltz \& Bernstein, 1976). Such "forced" exposure to feared situations may have a prophylactic effect and thus reduce the probability of developing a phobia. Probably, there are also other predisposing factors that contribute to the uneven sex distribution of specific phobias (e.g., sex hormones; see Merckelbach, De Jong, Muris, \& Van den Hout, 1996).

A substantial proportion of specific phobias begins in childhood (see Muris \& Merckelbach, 1998; 2000). For example, Thyer et al. (1985) noted that almost $47 \%$ of their specific phobia patients reported an onset of their complaints in their preteen years, with an additional $23 \%$ of the patients developing their phobia during their teens (median age: 12 years). Similarly, Öst (1987) found early onset ages for animal phobia (i.e., mean: 6.9 years), blood-injection-injury phobia (i.e., mean: 8.8 years), and dental phobia (i.e., mean: 11.7 years). For claustrophobia, however, this author reported a much later onset age (i.e., mean: 20.2 years).

Over the past 10 years or so, our understanding of phobias has steadily increased. The progress made in this domain concerns the developmental aspects of phobias and fears, etiological mechanisms that might be involved in phobias, and, perhaps most importantly, effective treatment of phobic fear (see e.g., Muris \& Merckelbach, 1998; 2000; Merckelbach, De Jong, Muris, \& Van den Hout, 1996; Stein \& Bouwer, 1997). However, researchers agree that some aspects of phobic disorders remain puzzling. A case in point is the irrationality that is ascribed to phobic fears.

The irrational character of phobia

There seems to be a broad consensus among students of phobia that the phobic patient recognizes the irrationality and excessiveness of his or her fear. This feature of phobias is not only listed in the DSM-IV (1994, APA), but it shows also up in many review papers. For example, Seligman $(1971 ;$ p.316) argues that "showing or telling a phobic that cats are not going to hurt him is rarely effective. Phobic fear is by definition not readily inhibited by rational means." Likewise, following the DSM-III (APA, 1987) definition, Sturgis and Scott $(1984 ; \mathrm{p} .92)$ contend that "the essential feature of the simple phobia is a persistent, irrational fear of ${ }_{*}$ and compelling desire to avoid, some objects or situations". Another example is provided by Hugdahl's (1989; p.295/296) technical comments on blood-injection-injury phobia: "A vasovagal reflex to slow down cardiovascular effectors would thus be instrumental in preventing excessive blood loss. To exhibit a similar response when viewing someone else bleeding is, however, an irrational phobic response." So, according to these and many other authors, the phobic patient is aware of the fact that ( $s$ )he does not have to be afraid of the phobic object or 
situation because there is no imminent danger. Still, the patient is afraid of the specific object or situation. Why? In literature, only a few hypotheses can be found that address this core feature of phobia:

\section{Psychoonalytic accoumt}

Freud (1909: 1984) argued that phobias are defences against internal and unconscious conflicts. He believed that repression of impulses from the Id causes anxiety. In order to handle this anxiety, individuals would transpose repressed feelings to an object or situation with which the anxiety is symbolically connected. These objects or situations would then become phobic stimuli. Avoidance of these symbolic feared objects of situations would enable the patient to ignore intemal conflicts.

In his well-known case-history of little Hans, Freud $(1909 ; 1984)$ made an attempt to illustrate his theory about phobias. The 5-year-old boy Hans developed a horse phobia after watching an accident of two horses with a horse car. In this accident, the horse car fell down and the horses seemed dead. According to Freud, Hans" fear of horses was a straightforward example of an Oedipal conflict disguised as a psychopathological symptom. More specifically, his phobia was symbolic of his fear of his father, his fear of being castrated ${ }^{3}$ and his deadwishes towards his newborn sister. By developing his horse phobia, little Hans could give expression to his fears and anger, while at the same time living peacefully together with his family. As well, Hans" phobia allowed him to stay at home with his mother for whom he had a sexual desire, according to Freud's Oedipus doctrine.

Freud's account of the development of phobias accords well with the irrationality that is often ascribed to phobias. That is, in his view, the phobic object is only feared because it is symbolically related to the internal conflicts and not because it is really dangerous. Although Freud's theory nicely explains the irrational character of phobias, it is flawed on several counts. In this context, it is worth referring to Wolpe and Rachman (1973) who have provided a damaging analysis of Freud's case history. Their analysis emphasized three points. The first is that on several occassions, little Hans was interviewed in a suggestive way, so as to obtain material that is highly consistent with the Freudian doctrine. The second point is that little Hians systematically denied the relationship between horses and his father, as he denied to possess feelings of fear to his father. Also, the idea that his phobia served the purpose of staying close to his mother is questionable given the fact that he experienced intense fear of horses even when he was out walking with his mother. Thirdly, there is an altemative view of Hans phobia, a view that is more parsimonious and better grounded in empirical evidence. According to this alternative view, Hans' phobia can best be conceptualized as the result of aversive classical conditioning: Hans once reacted with terror (unconditioned response; UCR) to an accident that involved horses and vans (unconditioned stimulus; UCS) and subsequently developed an intense fear (conditioned response; CR) of horses (conditioned stimulus; CS). This view is attractive because it explains why Hans was not only afraid of horses, but also of vans, a fact that is overlooked in Freud's interpretation of this case. To recapitulate, then, if cases like that of little Hans serve as 
the primary eviderice for the Freudian view on phobias, there is little reason to believe that the irrationality of phobias stems from unconscious conflicts that underlie these phobias.

\section{Siress-induced recovery of phobias}

Jacobs and Nadel (1985) tried to explain phobias and their irrational character in terms of "infantile" hippocampal functioning. Briefly, certain brain regions (i.e., parts of the neocortex, cerebellum, and hippocampus) are known to mature post-natally. As a result, these brain regions do not function optimally during early childhood. An immature hippocampus, for example, lacks the ability to form memories containing information about when and where events have occurred (i.e., context information; Squire \& ZolaMorgan, 1988).

In their dual-memory model, $O^{\prime}$ Keefe and Nadel (1978) draw a distinction between two types of learning systems: the local system and taxon systems. According to these researchers, the local system is necessary for the internal representation, and subsequent recognition, of environments the individual has previously experienced. In other words, the local system takes care of context-specific memories, a function that would be sustained by the hippocampus. On the other hand, taxon systems are responsible for the acquisition of context-free skills, rules, and S-S and S-R learning. Learning with taxon systems is learning without context. Thus, as O'Keefe and Nadel (1978) argued, learning that takes place in taxon systems and that is uninfluenced by the local system will not be tied to any given environmental context. As a consequence it will manifest itself broadly. According to Jacobs and Nadel (1985), this matches perfectly with what one sees in phobias. In their opinion, the relevant features of phobias "do bear a strong resemblance to the kind of learning predicted to occur in the absence of the local system" (p.517). They postulate that this situation can occur when "stress disrupts the function of the hippocampally based local system and its context-specific learning capacities while potentiating taxon systems and their context-free associations"' (p.518). More specifically, these authors believe that under certain stressful conditions, hormones are released that interfere with normal hippocampal functioning. This would lead to the breakdown of the inhibitory local control over taxon systems and, accordingly, fears that previously have extinguished would re-occur. To illustrate their poimt, they provide the example of an adult woman who develops an insect phobia after the stressful birth of her child. By this view, then, the irrationality of phobias reflects a stress-induced return to the pre-hippocampal state in which fear responses are context free, easily generalized, and difficult to extinguish.

There are studies that provide some support for certain parts of Jacobs and Nadel's hypothesis: for example, hormones released during stress are known to interfere with the development of long-term potentiation (Shors, Levine, \& Thompson, 1990; Foy, Stanton, Levine, \& Thompson, 1987), a form of neural plasticity that may significantly contribute to learning in the hippocampus (Teyler \& DiScenna, 1987). However, as McNally (1989) convincingly pointed out, Jacobs and Nadel (1985) based their theory on questionable assumptions about clinical phobias. For example, these authors assume 
that phobic people often are unable to report when and where the feared object or situation was specifically paired with a noxious event. Most phobics, however, can describe a frightening incident that precipitated their phobias (see McNally, 1989). In addition, their probably hypothetical example about the woman who develops an insect phobia after the birth of her child is atypical. This case intends to illustrate their hypothesis about the stress-induced nature of phobias, but as a matter of fact adults rarely develop animal phobias (McNally \& Steketee, 1985; Ost, 1987). Apart from these issues, some technical points can be raised that have to do with Jacobs and Nadel's (1985) assumption that the hippocampus sustains context-specific memory functioning. Most importantly, other authors have argued that it is the hippocampus that mediates primitive, procedural or implicit forms of memory, whereas the much more slowly developing pre-frontal areas sustain complex memory performance (e.g., Nelson, 1995). So, the idea that a dysfunctional hippocampus is the locus of irrational fear is questionable.

\section{Evolutionary origin of phobic fear}

With his preparedness hypothesis, Seligman (1970) tried to offer an evolutionary based account for the origin of phobias. The preparedness hypothesis states that some types of events are much more easily associated with aversive events than are other types of events, because such associations are functional from an evolutionary perspective. For example, rats have been found to associate tastes with malaise much quicker than tastes with footshocks (Garcia \& Koelling, 1966). Seligman argues that this makes evolutionary sense because it is of vital importance to relate a taste to malaise if potential poisoning should be avoided in the future. In line with this, Seligman (1971) proposed that a "genetic preparedness" causes humans to easily associate fear and avoidance with situations that were threatening to the survival of our ancestors. As a result, modern man would have a biological predisposition to develop phobias for "ancient" threats (e.g., snakes, heights). In contrast, fears of "modern" threats (e.g, traffic, electricity) would be "unprepared" and would require a series of conditioning trials to develop into a phobia. According to this analysis, the irrationality of phobias would derive from their evolutionary, non-cognitive origins. In Seligman's (1971) words "if phobias are seen as prepared classical conditioning, their one trial acquisition, their selectivity and their persistence may follow. The "irrationality" of phobias is also compatible with what data exists on prepared classical conditioning." (p.315). Furthemore, Seligman suggested that unprepared associations are learned and extinguish through cognitive operations, while prepared associations are acquired in a relatively automatic (i.e., non-cognitive) fashion.

Research on the preparedness hypothesis has been extensively conducted by Öhman and associates (e.g., Hugdahl \& Öhman, 1977; Öhman, Fredrikson, Hugdahl, \& Rimmö, 1976; Öhman, Erixon, \& Löfberg, 1975). In their conditioning studies, these researchers confronted normal subjects with either fear-relevant CSs (e.g., slides of snakes, angry faces) followed by an electric shock, or fear-irrelevant CSs (e.g., slides of flowers, happy faces) followed by a shock. The results showed that skin conductance responses 
(SCRs) conditioned to fear-relewant CSs extinguished more slowly than SCRs conditioned to fear-irrellevant CSs. To the extent that one assumes that the phobiarelevant CSs allude to prehistoric dangers, these findings seem to support the preparedness theory.

Apart from the fact that the findings of Ohman and co-workers appear to be difficult to replicate (e.g., McNally \& Foa, 1986; Merckelbach, Van der Molen, \& Van den Hout, 1987), there is a more fundamental point that can be raised. The preparedness hypothesis hinges on the notion that aversive leaming about stimuli such as spiders, snakes, and angry faces is non-cognitive, i.e., does not involve higher cognitive operations (e.g, expectancies, beliefs). However, as Davey (1991, 1995) has pointed out, the delayed extinctions of responses conditioned to spiders, snakes, and so forth is accompanied by persistent subjective expectancies about UCSs that could follow such stimuli. In a typical experiment, Davey (1991; Exp.1) exposed subjects with fearrelevant and fear-irrelevant slides (CSs) that were announced to be followed by shocks. Throughout the experiment SCRs to the CSs were recorded. Yet, subjects were also instructed to indicate with help of a lever pointer how much they expected an UCS (shock) whenever a CS occurred. Results showed that subjects shown fear-relevant pictures expected shocks more often than did subjects shown fear-irrelevant pictures. This expectancy effect was evident, even when shocks were never really presented during the experiment. Thus, this suggests that the delayed extinction of conditioned responses to spiders and snakes is far from non-cognitive and irrational, but may be under direct cognitive control. As Davey (1995) concludes, the readiness with which fear-relevant stimuli become associated with aversive outcomes arises from biases in the processing of information about threatening stimuli rather than from phylogenetically based associative predispositions or "biologically preparedness". This a priori expectancy bias reflects some initial general assessment of the danger or threatpotential of a stimulus. There is evidence that subjective estimates about the danger of stimuli are a significant predictor of people's fear of these stimuli, and hence of the emergence of UCS-expectancy biases. Therefore, danger seems to be a better predictor of fear than survival relevance (Merckelbach, Van den Hout, Jansen, \& Van der Molen, 1988). To sum the the idea that the irrationality of phobias is a function of the noncognitive and evolutionary nature of phobias is not very convincing precisely because phobic fear is intimately linked to cognitive operations (like expectations).

\section{The uncontrollability of phobic fear}

Besides the irrationality that is ascribed to phobic fear, phobias display another remarkable feature: the uncontrollability of the fear response. That is, although the phobic patient readily admits that his or her fear is excessive or irrational, (s)he cannot suppress the fear response. Why? 


\section{Automatic information processug}

The past 15 years have secti a burgeoning literature on infomaton processing in



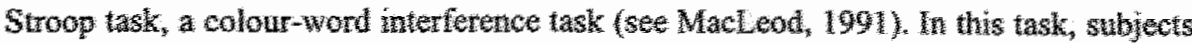

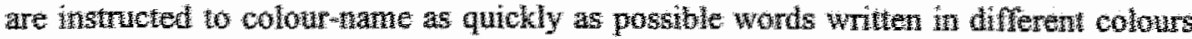
Whe ignoring the contens of the words. A common findmg is und colours or words of

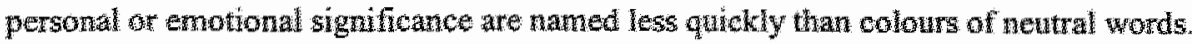




wotds. Moreover, patients slow-down on colom-naming words specifoaly retated to their anxiety disonder. That is, compared to nomal controbs, phobic putusts show enotiona inerference to words a

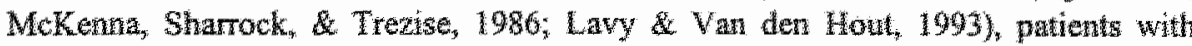
generalzed anxiety disorder wow-down on words describng danger (e.g.



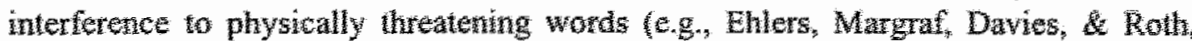


ignore the contents of the words, but chen so emotionaly stgnifican words made them


delay in colour-maming enotional words is that patents atomaticaly shin their




antomatically (i.e., involuntary; see MeNally, 1995). Yet, wh ben chined that wis bias is also automatic in the sense that it needs not be nedided by areness (Beod,

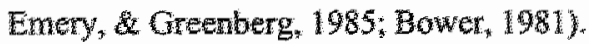

To find support for the hyothesis that anxety-related (i.e. theatening) stimu are processed automatically in the sense of unconsciously, it is necessary to demonstrate that such stimuli may evoke emotional interference (e.g., slowing-down of colournaming times) even when presented under conditions that prevent conscious perception. To this end, a number of studies have used the central visual masking technique (see Marcel, 1983). This technique makes use of stimulus-onset asynchrony and works in a backward manner. That is, two visual stimuli are briefly presented, one after the other, with the second stimulus masking the first one. It is assumed that such masking interferes with conscious perception of the first stimulus (i.e., target stimulus), but that preconscious processing is unaffected (Marcel, 1983). In the Stroop paradigm, this masking procedure has been applied as follows. Coloured words are flashed briefly (e.g., $20 \mathrm{~ms}$ ) and are then immediately followed by a pattem mask (i.e., XXXs, or a nonsense word like KPIDWR) of the same colour. Subjects are instructed to colourname the masks as quickly as possible.

Employing this so-called subliminal Stroop task, Mogg, Bradley, Williams, and Mathews (1993) investigated selective processing of emotional information in anxiety and depression. In their study, anxious, depressed, and normal control subjects had to name the background colours of anxiety-related, depression-related, positive, and 
neutrall words. Half of the words was presented subliminally (i.e, masked); the other half was presented supraliminally (i.e., unmasked). Compared to both depressed and control subjects, anxious subjects were found to colour-name the background of subliminal negative words (both the anxiety-related and the depression-related) more slowly. This suggests that there is, indeed, an unconscious (i.e, pre-attentive) processing bias in anxiety. However, as all subliminally presented negative words elicited an emotional interference effect, this bias appears to operate in a rather broad fashion rather than that it is restricted to anxiety-related stimuli. Thus, in contrast to supraliminal Stroop experiments demonstrating content specific slowing-down in collour-naming of anxious patients, subliminal Stroop studies indicate that anxious patients are only sensitive to valence (i.e. $e_{*}$ threat versus non-threat) and not to specific content.

In conclusion, studies relying on the subliminal emotional Stroop suggest that emotional (e.g., threatening) information can be processed without voluntary control and in the absence of conscious strategies. In other words, threatening information seems to be processed pre-attentively, at least in anxious people. However, it should be noted that some authors argue that these effects might be postconscious rather than preconsclous. For example, Fox (1996) found evidence for automatic processing of threat-related words only when masked (i.e., subliminal) trials were presented intermixed with or after unmasked (i.e., supraliminal) trials. According to Fox, this suggests that an unconscious processing bias on masked trials is dependent on prior conscious activation of threat-related material (i.e., a postconscious automatic effect). By this view, automaticity in the sense of unconscious processing as it occurs during subliminal Stroop set-ups, is context-dependent. Furthermore, the unconscious processing phenomena that have been obtained in various emotional Stroop studies primarily offer a description rather than an explanation for the uncontrollability of phobic fears.

\section{Pre-attentive activation of fear}

In accordance with the subliminal Stroop findings, Öhman (1988; 1993; 1994) proposes that stimuli can be processed pre-attentively. He even goes one step further and claims that under some circumstances such pre-attentively processed stimuli may elicit a fear response. However, Ohman (1988) states that this is only true for a certain category of stimuli. More specifically, humans would possess automatic information processing routines that serve to detect evolutionary threatening stimuli. This detection would occur at early perceptual stages and so, Öhman's hypothesis assumes that there exists a perceptual monitoring system that is sensitive to biologically fear-relevant stimuli (e.g., prepared stimuli), especially if these stimuli have been associated with aversive outcomes in the past. With this monitoring system, fear-relevant stimuli would be located automatically and simultaneously by many perceptual channels. As well, this system would operate independently of subjects' focus of attention. When the system identifies potential threat by recognizing specific key features, an automatic switch of attention would occur, the function of which is to bring the stimulus into focus of 
conscious attention and, thus, of strategic processing. Simultaneously, the defence response with its associated metabolic support, would be initiated. Thus, as Öhman (1994, p.211) states, "this analysis implies that fear responses are activated even before the eliciting stimulus is consciously perceived". Ohman claims that his account bears a special relevance to phobias. Indeed, according to Öhman, phobic responses are the product of the perceptual monitoring system's immediate activation of the arousal system. This would imply that the phobic object would always enter consciousness against a background of rising physiological activation. In Óhman's (1994, p.211) words: "In this perspective, it is easy to understand that phobic fear would have an automatic uncontrollable character to it, leaving the victim with few alternatives but head-on flight. The present analysis, therefore, provides a good theoretical account of the "irrationality" of phobias, that is, the inability of phobics to control their fear by means of rational reasoning".

Psychophysiological responses to masked fearful stimuli

In the previous sections, it was concluded that the traditional Freudian view of the imationality of phobic fears is highly problematic. The same is true for theoretical approaches that emphasize the alleged evolutionary and non-cognitive profille of phobias. With respect to the subliminal manifestations of attentional bias phenomena, it was argued that they lack explanatory power. At first sight, Öhman's line of reasoning seems to offer a fresh and innovative perspective on the irrational and uncontrollable nature of phobic fear. In the sections that follow, the empirical evidence for his account will be reviewed.

\section{Psychophysiological studies}

Öhman (1994) suggests that different mechanisms are involved in responding to fearirrelevant and fear-relevant stimuli. That is, responding to fear-irrelevant stimuli would be govemed by controlled, attentive information processing mechanisms. In contrast, responses to fear-relevant stimuli would be governed by pre-attentive information processing mechanisms. As a result, fear-relevant stimuli will be processed at an automatic, pre-attentive level with no need for a conscious representation of the stimulus before the phobic response is elicited. The defining feature of such automatic, pre-attentive processing is that, once elicited, it cannot be terminated voluntarily (see Esteves, Dimberg, \& Öhman, 1994).

To examine whether a pre-attentive analysis of threatening stimuli is sufficient for a physiological fear response to occur, Öhman and associates carried out a series of conditioning experiments using the backward masking technique (see Marcel, 1983). Basically, this technique involves two pictures that are flashed very briefly, with one picture (i.e., mask) immediately following the other (i.e., target). In this way, the target is overshadowed by the mask, and, consequently, is kept out of conscious awareness. At least, it is assumed that with the right temporal parameters (e.g., a stimulus onset asyn- 





chrony of $30 \mathrm{~ms}$ of target and mask), subjects remain unaware of the target stimuius. Table 1 presents an overview of the conditioning experiments that were carried out along these lines.

In one of his first studies, Öhman (1986) used pictures of angry faces and happy faces as emotional stimuli and pictures of neutral faces as masks. First, half of the subjects was conditioned to (supraliminal) angry faces (CSt), whereas happy faces served as non-reinforced control stimuli (CS-). The other subjects were conditioned to happy faces ( $\mathrm{CS}+$ ), with angry faces serving as control stimuli (CS-). Conditioning was achieved with a brief electric shock to the fingers following the CSt. After this acquisition phase, subjects underwent an extinction procedure. That is, $C S+5$ and $C S-s$ were presented without shock. Yet, this time, angry and happy faces were presented for $30 \mathrm{~ms}$, immediately backwardly masked by a $30 \mathrm{~ms}$ neutral face. This masking procedure should prevent subjects from perceiving the angry and happy faces consciously. Skin conductance responses (SCRs) to the masked pictures were measured. Results showed that for subjects previously conditioned to angry faces, differential SCRs to $\mathrm{CS}$ t and $\mathrm{CS}$ - occurred during early extinction trials, even though these trials consisted of backwardly masked stimuli. That is, on early extinction trials, SCRs to backwardly masked angry faces were larger than those to backwardly masked happy faces, suggesting that these backwardly masked faces may directly imitiate emotional responses provided they have been paired with aversive UCSs. This differential effect was not obtained in the group conditioned to happy faces. Thus, masked CSts did not elicit larger SCRs than did masked CS-s when happy faces served as CS+s. According to Öhman (1988), these data demonstrate that biologically fear-relevant stimuli may trigger an emotional response even if their access to awareness is blocked through backward masking.

In a follow-up experiment, Esteves, Dimberg, and Öhman (1994, Exp. 1) used similar stimuli (facial expressions) and temporal parameters (i.e., $30 \mathrm{~ms}$ targets and $30 \mathrm{~ms}$ masks) as in the 1986 experiment. However, this time, masked presentations of angry and happy CSt stimuli were interspersed among unmasked acquisition trials of CSt (paired with shock) and CS- (unpaired with shock). Results clearly showed that during the first two masked test trials, SCRs to masked CS+s were larger than those to masked CS-s for subjects conditioned to angry faces ( $\mathrm{CS}+$ ), but not for subjects conditioned to happy faces (CSH). This suggests that masked fear-relevant stimuli may trigger physiological responses, but the authors also acknowledge that the effect was small, probably because masked trials were presented during the acquisition phase. With this in mind, they ran a second experiment which involved unmasked habituation and acquisition trials, followed by masked extinction trials. It was found that masked angry face CS $+s$ elicited larger SCRs than did masked happy face CS-s, a finding which the authors take to mean that fear-relevant stimuli of which subjects are unaware nevertheless may provoke a physiological response (see also Parra, Esteves, Flykt, \& Öhman, 1997; Exp.1 \& Exp.2). Note, however, that interpretation of this finding is complicated by the fact that masked $\mathrm{CS}+$ presentations always involved angry faces, whereas masked CS-presentations always consisted of happy faces. 
In the experiments described above, subjects were first conditioned to unmasked presentations of the $\mathrm{CS}^{+}$and then confronted with masked trials of the CS+. In general, the results show that once an association between full-blown CS+s and UCSs has been established, degraded (i.e., masked) versions of the CS+ may trigger conditioned responses, but only so if the CS+ is an angry face. In a more recent series of experiments, Öhman and co-workers (Esteves, Parra, Dimberg, \& Öhman, 1994; Exp. 1 \& 2) tested whether it is possible to acquire conditioned SCRs to masked stimuli. These studies relied on a sequence of masked and unmasked presentations that was the reverse of that used in previous studies. That is, first masked $\mathrm{CS}+\mathrm{s}$ were paired with shock and then unmasked CS+ and CS- extinction trials were given. Basically, the results show that it is possible to condition SCRs to masked presentations of $\mathrm{CS}+\mathrm{s}$, provided that these CSt-s are angry faces (i.e., fear-relevant). Speculating about the theoretical ramifications of this finding, Öhman (1996; p.268) remarked that "the formation of associations between anxiety responses and non-consciously perceived cues may be important for the understanding of anxiety disorders. For example, panic patients appear to be interoceptively highly sensitive, so that bodily sensations may trigger panic (e.g., Ehlers, 1993). Such triggering could be the result of Pavlovian conditioning in which an initial panic attack became associated with some bodily changes (e.g., heart rate increase, sweating) that were not within the attentional focus at the time (i.e., they were outside of the person's awareness)."

Öhman and coworkers (1993; Soares \& Öhman, 1993a, 1993b) pursuited this line of research with pictures of spiders and snakes as fear-relevant stimuli. For example, Öhman and Soares (1993; Exp. 2) conditioned subjects to supraliminal versions of fearrelevant (i.e., spiders or snakes) or fear-irrelevant stimuli (i.e., mushrooms or flowers). Thus, one group was conditioned to a fear-relevant stimulus ( $\mathrm{CS}+$; e.g., a spider) by pairing it with shock (US), whereas another fear-relevant stimulus (CS-; e.g., a snake) was never paired with shock. The other group was conditioned to a fear-irrelevant stimulus (CS+; e.g., a mushroom), while another fear-irrelevant stimulus (e.g., a flower) served as control stimulus (CS-). In the extinction phase of this experiment, all CS $+s$ and CS-s. were presented for $30 \mathrm{~ms}$ and backwardly masked for $100 \mathrm{~ms}$. In this case, masks were randomly cut, reassembled and rephotographed pictures of spiders, snakes, mushrooms, and flowers. SCRs to the CSs were measured. Results showed that for the backwardly masked fear-irrelevant stimuli, CS+s failed to elicit larger SCRs than CS-s. In contrast, SCRs to backwardly masked fear-relevant stimuli were found to be reliably larger for the CSt than for the CS-. So, again, although subjects presumably were not consciously aware of the presented stimuli, they responded with larger SCRs to the CS+ than to the CS-, but only if these stimuli were fear-relevant and had a prior history of finding. In their words (Öhman \& Soares, 1993; p.129): "To the extent that conditioned SCRs to pictures of snakes or spiders can serve as laboratory models of phobic responses (Öhman, 1979), the results from this study suggest a theoretical explanation for the irrationality of phobias. According to this explanation, phobics are unable to 
under the control of conscious intentions. This implies that the autonomic arousal, which provides a central component of the phobia, may be already under way when the stimulus information that defines the phobic object reaches conscious, controlled levels of information processing."

The results of the studies reviewed so far provide support for the hypothesis that autonomic responses can be elicited after an automatic, unconscious analysis of fearrelevant stimuli. Furthermore, the finding that differential responding to the masked $\mathrm{CS}+$ was found for fear-relevant stimuli, but not for fear-irrelevant stimuli suggests that this automatic, unconscious analysis mechanism only exists for a certain class of stimuli. That is, the finding that differential responses to fear-irrelevant stimuli disappeared as a result of masking suggests that responses to fear-irrelevant stimuli require controlled, conscious processes.

Already in their earlier studies, Hugdahl (1978) and Hugdahl and Öhman (1977) found some striking indications for a differentiation between processing of fear-relevant stimuli and that of fear-irrelevant stimuli. More specifically, they found that verbal instructions had different effects on the extinction of SCRs conditioned to supraliminal fear-relevant stimuli and those conditioned to fear-irrelevant stimuli. In these experiments, subjects were first conditioned to fear-relevant or fear-irrelevant stimuli and then they received the instructions that the CS would no longer be followed by a shock. Next, shock electrodes were removed and a number of CS extinction trials followed. Whereas responses to fear-irrelevant stimuli were completely abolished by instructions eliminating the expectancy of future UCSs (i.e., shock), responses to fearrelevant stimuli appeared not to be influenced by this procedure. In other words, conditioned responses to fear-relevant stimuli may have been automatically emitted, whereas responses to neutral stimuli seem to be cognitively mediated. In a follow-up study, Soares and Öhman (1993b) manipulated both masking and instruction. Subjects were allocated to a masked (i.e., unconscious) or a non-masked (i.e., conscious) extinction condition. Half of the subjects in both groups was conditioned to supraliminal (i.e., unmasked) fear-relevant stimuli (i.e., spiders or snakes) by means of a shock (UCS). The other half was conditioned to supraliminal (i.e., unmasked) fear-irrelevant stimuli (i.e., mushrooms or flowers). In the extinction phase, half of the subjects conditioned to fear-relevant stimuli and half of the subjects conditioned to fearirrelevant stimuli were informed that they would receive no shock anymore and electrodes were removed (i.e., instruction condition). The other half of the subjects was not informed and electrodes remained in place (i.e., control condition). Results showed that differential responding to $\mathrm{CS}+$ and $\mathrm{CS}$ - still accurred both for subjects conditioned to fear-relevant and subjects conditioned to fear-irrelevant stimuli when these stimuli were presented without mask and without "no more shock"-instruction. However, in the mask and "no more shock"-instruction condition, differential responding to fearirrelevant stimuli, but not to fear-relevant stimuli, disappeared. Thus, although subjects knew that no shocks would be administered, they responded with larger SCRs to masked CS + s than to masked CS-s, but only so if CS+ and CS- were fear-relevant. This suggests that conscious processes such as expectancies do not play a role in the 
activation of physiological responses to fear-relevant stimuli, but that they do matter in the activation of responses to fear-irrelevant stimuli. In Ohman and Soares ${ }^{2}(1993 ; \mathrm{p} .93)$ words: "The dissociation between expectancy and autonomic responses in the fearrelevant $\mathrm{CS}$ group is consistent with the hypothesis, which indicates that these responses were elicited from an automatic level of information processing not manipulable by instructions. This suggests that differential responding to fear-relevant CSs may be mediated by a hedonic shift in negative direction for the CS+ rather than by UCS expectancy."

A study that complicates Öhman and Soares conclusion about the absence of UCS expectancies in the "nonconscious" elicitation of a previously conditioned response was conducted by Wong, Shevrin, and Willians (1994). In that study, subjects were confronted with masked presentations of an angry CS+ and a happy CS- face, after the supraliminal version of the CS+ had been paired with shock. Unlike Ohman and colleagues, Wong et al. established individual threshold durations for the targets, a procedure which resulted in extremely short exposure times (mean threshold duration was $2.35 \mathrm{~ms}$ ). And unlike Öhman and colleagues, Wong et al. used an energy rather than a pattern mask technique. Evenso, the findings of this study were remarkable. To begin with, Wong et al. found no evidence that magnitude of the SCR was higher with masked CS+ angry faces than with masked CS- happy faces. Only with probability and amplitude measures of the SCR was such an differential effect found, although the authors added that "the effect was small in view of the lack of significance found in the magnitude measure" (Wong et al, 1994; p.98). The authors also recorded ERP parameters and found evidence that slow wave activity occurred after masked stimuli, particularly after the masked CSt angry face. They concluded: "it seems that an expectancy process can be elicited entirely without awareness" (Wong et al., 1994; p.97).

According to Ohman (1994), the finding that fear responses to fear-relevant stimuli appear to originate at unconscious and purely perceptual levels of information processing provides an explanation for the uncontrollability and irrationality of phobias. That is, at the moment the phobic patient becomes consciously aware of the phobic object, his or her body is already responding with fear. This makes the fear feel uncontrollable and irrational. More specifically, Soares and Öhman (1993b, p.93) contend that "phobic fear responses are inaccessible to voluntary control once elicited because they are rooted in ancient information processing mechanisms outside the control of conscious intentions and evaluations. Thus, they resist cognitive conscious manipulations appealing to rational thought simply because rational thought cannot access the information processing mechanisms behind the fear response".

Ohman and Soares made a further attempt to test the unconscious origins of phobic fear. They reasoned that if phobic responses occur via automatic processes, one would expect that they can be elicited in fearful subjects by confronting them with backwardly masked versions of their feared stimulus. Accordingly, Öhman and Soares (1994) selected spider-fearful, snake-fearful, and non-fearful subjects and exposed them to backwardly masked fear-relevant (i.e., spiders and snakes) and neutral (i.e., mushrooms 
and flowers) stimuli. Results showed that spider-fearful indiwiduals responded with larger SCRs to masked spider pictures, snake-fearful individuals responded with larger SCRs to masked snake pictures, while the non-fearful controls did not respond specifically with large SCRs to any of the masked pictures. The authors claimed that although subjects were not consciously aware of the target stimuli, they responded with larger SCRs to specifically their feared stimulus. These findings suggest, indeed, that autonomic responses associated with fear can be elicited merely after a pre-attentive analysis of the eliciting stimulus.

In what follows, the Öhman and Soares (1994) experiment will be considered as the most critical study because it comes so close to testing the central tenets of Öhman's view on the automatic origins of phobias. While the studies conducted by Öhman and co-workers have yielded impressive results, severall critical points can be raised as to their interpretations. We will turn to these critical points in Chapter 2.

\section{Neurobiological support}

Research about the neural basis of fear heavily depends on classical conditioning in rats. With the lesion method and modern neuro-anatomical tracing techniques, many studies have looked at pathways involved in aversive, classical conditioning processes. For example, LeDoux, Sakaguchi, and Reis (1984) found that lesions of the midbrain and the auditory thalamus prevented conditioning of fear reactions to auditory stimuli. Thus, these subcortical regions appear to be necessary to obtain fear conditioning. In contrast, lesions of the auditory cortex had no effect on conditioning of fear responses to auditory CS stimuli. Apparently, the cortex is not necessary for fear conditioning.

Lesion studies have attributed a crucial role in fear conditioning to the amygdala (e.g., Iwata, LeDoux, Meeley, Arneric, \& Reis, 1986; LeDoux, Sakaguchi, Iwata, \& Reis, 1986; LeDoux, 1987, 1990, 1992; Davis, Hitchcock, \& Rosen, 1987; Davis, 1992; Kapp, Pascoe, \& Bixler, 1984). Likewise, electrical stimulation of the amygdala has been found to produce fear-like behaviours (Davis, 1992). In other words, the amygdala seems to play a central role in the conditioning and expression of fear.

According to the traditional view, the amygdala receives sensory input through cortical mediation. By this view, sensory input is relayed via the thalamus to cortical regions and from there it is transferred to the amygdala. However, with anatomical tracing techniques, LeDoux, Ruggiero, and Reis (1985) showed that the auditory thalamus projects not only to the cortex but also directly to the amygdala. Thus, the amygdala receives sensory input from both the cortex and the thalamus (see also LeDoux, 1986). The thalamus may address the amygdala quickly, but provides only a gross representation of the input. In contrast, the cortex is able to acquire detailed stimulus information, yet relays its information to the amygdala more slowly (LeDoux, 1986). Thus, lower-order thalamic inputs may be useful for producing rapid responses on the basis of limited stimulus information, whereas higher-order cortical inputs are needed for emotional reactions coupled to perceptually complex stimulus features. As rapid responses to danger have obvious survival value, a quick-and-dirty subcortical pathway for threatening information would be of great significance (Öhman, 1986; 
LeDoux, 1990). Interestingly, LeDoux (1995; p.229) also emphasizes the other (i.e., psychopathological) side of the coin: "If, for genetic or experiential reasons, the lowerorder pathways are more efficient at triggering the amygdala than are the higher-order pathways in some individuals, we would expect those individuals to have rather limited insight into the nature of their emotional reactions".

That a quick and lower-order initiation of the amygdala response (i.e., outcome of an unconscious, subcortical analysis) may also occur in humans, is further underlined by the study of Whalen et al. (1998). These researchers noted that while their subjects reported sceing only neutral faces (i.e., masks), activity in their amygdala (as indexed by blood oxygen level-dependent FMRI signals) was significantly higher during exposure to masked fearful faces than during exposure to masked happy faces. This difference was the result of both significant signal increases to masked fearful faces and signal decreases to masked happy faces. Thus, level of amygdala activation is affected differentially by the emotional valence of the masked stimuli. Similarly, in their PET study, Morris, Ohman, and Dolan (1998) found significantly more amygdala activity to masked CS+ angry faces than to masked CS- angry faces. This activity was found in the right half of the amygdala. This right half activity was absent in the unmasked (i.e., supraliminal) condition. As a matter of fact, unmasked CS+ faces appeared to activate the left half of the amygdala (see also Morris, Öhman, \& Dolan, 1999).

In conclusion, for emotional stimuli, there seems to be a quick-and-dirty processing woute from the thalamus directly to the amygdala. As a result, it is conceivable that a fear response is already initiated by the amygdala, before the stimulus information has reached the cortex where conscious identification takes place.

Although LeDoux's theory has attracted considerable attention and has been cited as a new and innovative view on a host of psychopathological phenomena (e.g., McNally, 1998), among which the uncontrollability of phobic fears, some critical remarks are in order. To begin with, LeDoux's approach is not new. The idea that aversive conditioning depends on the integrity of subcortical rather than cortical areas was already advocated by the Dutch Pavlov disciple Ten Cate, who published about his findings well before World War II (see e.g., Merckelbach \& Overduin, 1993). Secondly, and more importantly, not all neuro-anatomists agree with LeDoux's two pathways. For example, Parrot and Schulkin (1993) argue that LeDoux"s claim that there are two emotional pathways in brain - one purely emotional and the other allowing for cognitive-emotional interactions - , is highly questionable. According to these authors, emotional pathways are characterized by centrifugal organisation in which, for example, the amygdala may inhibit or excitate sensory and attentional processes in other parts of the brain: "In such a system, there would be no neurological basis for distinguishing emotion and cognition on the grounds of anatomical or functional independence" (Parrott \& Schulkin, 1993; p.53). Other neurobiologists have emphasized that the dominant role that LeDoux ascribes to the amygdala in fear conditioning might be true as long as non-specific responses are concerned (heart rate, blood pressure, etc.) However, when the job is to account for the origins of specific avoidance responses that involve motor movements, the cerebellum seems to play a decisive role (Lavond, Kim, 
\& Thompson, 1993). Yet, it remains to be seen to what extent LeDoux's two pathways can be generalized to cerebellum action.

A third point that can be raised has to do with one basic assumption of LeDoux's model, namely that for evolutionary reasons our brain structure has evolved such that negative emotions allow for quick decision making. While the idea that negative emotions promote fast decision making is certainly attractive from a evolutionary perspective, some authors have argued that it is positive rather than negative affect that allows for quick and flexible decision making. For example, Isen, Daubman, and Nowicki (1987) confronted participants who were aroused by exercise or whose affects were induced positively (induced by a comedy film or a small gift of candy) or negatively (induced by a documentary film depicting Nazi concentration camps), with a problem to solve. That is, participants were asked to affix a candle to a corkboard in such a way that it will burn without dripping wax on the ground. For this purpose, participants were equipped with a candle, a book of matches, and a box of tacks. The problem can be solved if the box is emptied, tacked to the wall, and used as a platform for the candle. Results showed that, whereas negative affect or arousal induced by exercise had no effect on creative problem-solving, positive affect facilitated the creative problem-solving process. Further evidence that positive stimuli may possess such automatic qualities comes from subliminal studies (e.g., Murphy \& Zajonc, 1993). For example, effects of subliminal positive stimuli have been documented in priming studies. In these studies, neutral stimuli are evaluated more positively after priming the subjects with subliminal positive stimuli (e.g., Murphy \& Zajonc, 1993). There are good reasons to believe that such priming effects of positive subliminal stimuli represent a robust phenomenon, yet it has no obvious place in LeDoux's model.

A final comment concerns modern neuro-imaging findings that have been cited as rather strong support for LeDoux's model (e.g., Morris et al., 1998, 1999). While these studies documented right amygdala activation following exposure to subliminal angry faces, they are silent about the precise neuronal pathways that were involved in this phenomenon. This point has, of course, to do with the low temporal resolution of modern techniques such as PET. So, theoretically, it cannot be ruled out that the right amygdala activation was a consequence of high-level, neocortical processes. 



\section{Chapter 2}

\section{Critical notes on Öhman's hypothesis}

Öhman's hypothesis about the uncontrollability of phobic fear is based on a number of empirical findings, in particular findings that were obtained with a combination of conditioning and backward masking techniques (see Table 1). As well, his formulations nicely fit with the attentional bias literature and LeDoux's neurobiological studies. Nevertheless, a close look at his work makes plain that a number of shortcomings and critical points can be raised. Some of these are of a fundamental nature. For example, a basic question is whether phobias can be conceptualized in terms of uncontrollable and irrationall responses. Likewise, one could question whether an evolutionary analysis of phobic fears in terms of threat provides a good approach for understanding phobias of say spiders or snakes. Apart from these fundamental issues, there is a number of technical points that can be raised about the evidence that Öhman provides in support of his formulations. For example, Öhman's theory is thought to be of relevance to phobias, but all his experiments relied on normal subjects. Furthermore, Öhman claims that he and his co-workers demonstrated emotional responding as a result of subliminal threat stimuli. But, then, is the SCR a good index of emotional responding and were the stimuli genuinely subliminal? In this chapter, these points will be considered in detail.

\section{The irrationality of phobic responses reconsidered}

A widely held belief is that phobias are characterized by an irrational (unreasonable) fear of a certain object or situation (see DSM-IV, APA, 1994). Phobic fear is defined as irrational because the phobic patient would admit that the particular object or situation that he or she fears, in fact, is harmless. However, there are indications that the irrational character that is ascribed to phobic fear can be questioned.

McNally and Steketee (1985) found that animal phobics do not only fear stimulus characteristics (e.g., movement, physical appearance) of the feared anima, but also consequences (e.g., panic) of confrontation with the animal. This suggests that phobics have atypical beliefs. Arntz, Lavy, Van den Berg, and Van Rijsoort (1993) systematically investigated the beliefs involved in spider phobia. To this end they constructed a Spider Phobia Beliefs Questionnaire which addresses various beliefs about spiders and about subjects" reactions during encounters with spiders. It was found that phobics strongly endorse negative and irrational ideas about spiders (i.e. "the spider jumps onto me"; "the spider is mean"). In addition, phobic patients indicated that they had strong negative ideas about their own reactions when confronted with a spider (e.g., "I will not stand it"; "I will become crazy because of anxiety"). Accordingly, the authors concluded that spider phobic patients do not only fear the danger that spiders may represent, but also their own reactions to the spiders. 
A comparable study was carried out by Thorpe and Salkovskis (1995). These atuthors investigated whether in phobic patients, cognitions could be identified that clarify the logic of phobic problems in a similar way as catastrophic misinterpretations in panic disorders account for panick attacks. Their results show that a considerable percentage of phobics believe statements that have to do with possible physical harm caused by being in the presence of the phobic object. Thorpe and Salkovskis argue that these beliefs might even be essential for the maintenance of the phobic anxiety state. All in all, it can be argued that to the extent phobics endorse such negative beliefs about spiders and their own reactions to spiders, it is by all means rational for them to fear spiders. As a consequence, Thorpe and Salkovskis (1995; p.815) propose that "the definition of phobias as "irrational' may be unsound".

While Thorpe and Salkovskis (1995) argue that phobic fear might be conceptualized as rational behaviour given the negative beliefs that phobics have about their feared object, others have reasoned that the dichotomy of rational versus irrational is completely irrelevant to phobic behaviour. For example, McNally (1987) states that the concept of (ir)rationality only applies to voluntary behaviour. The phobic patient, however, does not choose to respond with fear. Therefore, his or her behaviour is involuntary and, consequently, standards of rationality do not apply. McNally argues that phobic fear is like a toothache: these responses have causes, not reasons. Whether or not one appreciates McNally's (1987) line of reasoning, the fact remains that phobic patients report catastrophic cognitions about their feared object. Some have argued that these cognitions may play a critical role in the maintenance of phobic disorders (e.g., Last, 1987). We do not know whether such cognitions possess a causative power or whether they are just epiphenomena of being phobic (e.g., Merckelbach, De Jong, Muris, \& Van den Hout, 1996). What is clear, however, is that these maladaptive cognitions refute the popular notion of phobics readily admitting the harmless nature of the phobic object and the irrationality of their fear. As things stand, this popular notion is a naive conceptualization of their fear:

\section{Disgust sensitivity}

Ohman's theory about the pre-attentive origins of phobic fear is predicated on the belief that phobic objects represent evolutionary challenges that once required immediate action. Implicit in this evolutionary approach is the idea that spiders, snakes, and other small animals that may serve as objects of animal phobia, once were dangerous to our prehistoric ancestors (cf., preparedness; Seligman, 1971). However, a number of findings is difficult to reconcile with an evolutionary interpretation of phobias (see also Chapter 1). First, most of the assumptions of the preparedness theory are questionable (see McNally, 1987). Assumptions of this theory are ease of acquisition of the fear, irtationality of the fear, belongingness between the fear and threats of prehistoric origin, and high resistance to extinction of the fear (Seligman, 1971). In his review article, McNally (1987) extensively points out that there is very little experimental support for these assumptions. For example, the preparedness theory predicts that SCRs should be more easily established to fear-relevant than to fear-irrelevant stimuli. Thus, if the 
degree of conditioning is held constant, responses conditioned to fear-relevant stimuli should be larger than responses conditioned to fear-irrelevant stimuli. However, such differential acquisition pattern fails to show up in most conditioning studies (e.g., Hugdahl, Fredrikson, \& Öhman, 1977; Dimberg \& Öhman, 1983). Another example has to do with the alleged resistance to extinction of responses conditioned to fear-relevant stimuli. As noted earlier, several authors found that responses conditioned to fearrelevant stimuli extinguish more slowly than those conditioned to fear-irrelevant stimuli (e.g., Fredrikson, Hugdahl, \& Öhman, 1976; Öhman \& Dimberg, 1978). However, there are also authors who were unable to obtain a differential extinction pattern for fearrelevant and fear-irrelevant stimuli (e.g., McNally \& Foa, 1986; Öhman \& Soares, 1993, Exp. 2). All in all, the assumptions on which the preparedness theory of phobias rests are questionable.

Second, a number of authors (e.g., Davey, 1992; 1995; Matchett \& Davey, 1991; Merckelbach, De Jong, Arntz, \& Schouten, 1993) has argued that small animal phobias can better be understood in terms of a disease-avoidance model than in terms of preparedness. The disease-avoidance view emphasizes that specific phobias and fears often pertain to animals that are perceived as disgusting rather than dangerous. The disgust-evoking status of these animals would derive from their association with disease, dirt, and/or contamination. In line with this, Matchett and Davey (1991) noted that heightened disgust/contamination sensitivity is related to a stronger fear of animals that generally do not attack or harm humans (e.g., spider, cockroach). These authors also found that disgust/contamination sensitivity is not linked to fear of predatory animals (e.g., tiger, shark). Note that the latter category of animals only rarely becomes the target of a specific phobia. In line with this, there is a significant relationship between parents' disgust sensitivity and offsprings' animal fears (Davey, Forster, \& Mayhew, 1993). But this is only true for offsprings' fear of animals known to be associated with disgust and not for offsprings" fear of animals known to be related to violent attack or physical harm. Furthermore, Mulkens, De Jong, and Merckellbach (1996) showed that spider phobics are, indeed, more sensitive to disgust than are nonphobics (see also Tolin, Lohr, Sawchuk, \& Lee, 1997).

There is also evidence to suggest that disgust sensitivity acts as a causal antecedent of animal fears. Webb and Davey (1992) measured subjects' fears of a variety of animals both before and after three different treatment conditions. Subjects watched either a video depicting extreme violence, a video depicting revulsive scenes from a hospital operation, or a video showing neutral landscape scenes. The results showed that exposure to violent material produced an increase in fear ratings only for animals normally considered predatory (e.g., a lion). In contrast, exposure to revulsive material produced an increase in fear ratings exclusively for disgust-relevant or fear-relevant animals (e.g., spiders). Thus, self-rated fear of certain (phobia-relevant) animals can be inflated by increases in disgust sensitivity.

To sum up, then, there are good reasons to believe that disgust sensitivity is an important antecedent of small animal phobias and fears. Meanwhile, the feature of 
disgust sensitivity is difficult to reconcile with the evolutionary determined dangerousness that is emphasized in Ohman's automatic activation model.

\section{Feature detectors?}

The idea that humans automatically screen their environment for physical features of threatening stimuli is a core assumption of Ohman's theory about the automatic origins of phobic fear. According to Ollman's theory, it is the early detection of physically defined characteristics of prepared stimuli that may trigger an autonomic response (Ohman, 1993; 1996). Ohman (1993) assumes that the alarm reaction that eventually surfaces as an anxiety response, is started to be recruited immediately when the perceptual system encounters a sign of a survival-relevant stimulus. These so-called feature detectors are assumed to operate primarily on physical input. By this view, things should be quite different when degraded threat words are presented to subjects. With verbal material, arousal responses should not occur unless such material becomes the object of conscious perception. The implication of this line of reasoning is clear: according to Öhman's theory, subliminal presentations of threat words are not expected to produce heightened SCRs. This prediction was recently tested by Van den Hout, De Jong, and Kindt (in press). These authors exposed spider phobic patients to spider words (e.g., SPIDER), general threat words (e.g., DEAD), and neutral words (e.g., HOUSE). Words were presented both supraliminally and subliminally while SCRs were measured. Van den Hout et al. (in press) found that under supraliminal conditions, SCRs to spider words exceeded those to general threat words while both SCRs to spider and general threat words were larger than SCRs to neutral words. Under subliminal conditions, subjects responded equally to spider words and general threat words, but SCRs to these stimuli were larger than those to neutral words. Thus, spider phobic patients responded with heightened SCRs to subliminal fear-related words. This indicates that the arousal system can be activated by stimuli that share no perceptual characteristics with the feared cues. Apparently, the arousing effects of subliminally presented threat words must have been due to some intermediate semantic analysis (Van den Hout, De Jong, \& Kindt, in press). Obviously, these results cast doubts on the idea of automatic feature detectors that exclusively focus on the physical dimensions of survival stimuli.

\section{Technical aspects of Ohman "s experiments}

Öhman"s hypothesis seeks to explain clinical phobias. However, in their experiments, Ohman and associates never included clinical phobic patients. Instead their studies relied on non-fearful and fearful undergraduates. One could argue that testing Ohman"s automatic activation hypothesis in fearful subjects is suboptimal because information processing in phobics may be quite different, precisely because they are phobic. For instance, it is conceivable that phobic patients possess extreme low thresholds for consciously processing phobic cues because they give high priority to these cues. Another technical issue is that in Öhman and Soares' (1994) crucial experiment, one cannot be sure that the masked stimuli of fear-relevant and neutral objects remained. 
genuinely subliminal. Although these authors were able to show in a pillot-study with another sample that their stimuli were not detected above chance level, they did not carry out awareness check trials during the crucial experiment. As a result; it cannot be ruled out that fearful participants responded to the masked fear-relevant pictures because they perceived them consciously. To establish that all stimuli remain truly subliminal, it is necessary to obtain physiological and awareness check data in one and the same sample.

A technical issue that is closely related to this point pertains to expectancy ratings of subjects exposed to masked fear-relevant and neutral CS+s. A number of studies have documented that individuals will only react with a conditioned SCR to a CS+ when they have become aware of the CSt - UCS contingency. That is, conditioned SCRs closely parallel subjective expectancies of the UCS (e.g., Dawson, Schell, \& Filion, 1990). This intimate connection between higher cognitive operations such as expectations and electrodermal conditioning has been taken to mean that subjective UCS expectancies are a prerequisite for conditioning to occur. At first sight, the studies of Öhman and coworkers seem to represent a straightforward exception of this rule However, Ohman and Soares (1998; Exp. 2) presented evidence that further complicates rather than elucidates this issue. In their study, subjects were confronted with 30 ms masked fearrelevant $\mathrm{CS}+\mathrm{s}$ and $\mathrm{CS}-\mathrm{s}$. During the acquisition phase of the experiment, $\mathrm{CS}+\mathrm{s}$ were followed by a mill electric shock after a 4 s interval. During the extinction phase, subjects saw masked presentations of CS+ and CS- in the absence of a shock (UCS). A subgroup of subjects was instructed to rotate a lever pointer indicating their UCS expectancy after each masked presentation. During extinction, masked presentations of fear-relevant $\mathrm{CS}+\mathrm{s}$ elicited larger SCRs than masked presentations of $\mathrm{CS}-\mathrm{s}$, a finding that replicates earlier findings. Curiously enough, however, subjects gave higher shock expectancy ratings during masked CS+ than during CS- trials. Öhman and Soares explain this phenomenon in terms of subliminal information "leaking through" to higher cognitive systems (see also Ohman, 1996). But, of course, an alternative interpretation is also possible, namely that their masking procedure was not completely effective, allowing for at least some amount of consciously perceived CS + UCS contingencies.

A final technical comment concerns the strong preference of Ohman and co-workers for SCR as the primary dependent variable. As a matter of fact, most of their studies relied on SCR (see also table 1). SCR is a rather crude and peripheral measure of arousal and orienting (e.g., Dawson, Schell, \& Filion). Therefore, SCR is not uniquely linked to fears and phobias. Nevertheless, Ohman's hypothesis relates to these clinical phenomena.

\section{Concluding comments}

This chapter has raised a number of critical points about Ohman's idea that phobic responses originate from automatic activation of arousal systems. The most crucial and most convincing study in this respect is the Öhman and Soares (1994) experiment. Recall that in this experiment, spider-fearful, snake-fearful, and non-fearful control subjects were exposed to masked presentations of spiders, snakes, and neutral material 
while SCRs were measured. The results of this study were "quite dramatic" (Ohman, 1994, p.16; 1996, p.263): spider-fearfuls reacted with heightened SCRs to masked spider pictures, snake-fearfuls reacted with heightened SCRs to masked snake pictures, whereas contro: subjects did not react with any specific SCRs. The qualifier "dramatic" suggests that we deal with huge effects that will easily stand up to further empirical tests. But, then $n_{y}$ why should one want to test such a dramatic effect? There are two considerations. To begin with, the field of automatic processing has a bad track record when it comes to replicating and interpreting certain phenomena. The Hansen and Hansen (1988) face-in-the-crowd-effect is a case in point. In their experiments (1988; Exp. 1 to Exp.3), these authors confronted subjects with pictures of "crowds" (i.e., photographs consisting of a matrix of four or nine faces). On half of the trials, all faces in the crowds displayed the same emotional gesture; on the other half, one of the faces displayed a different emotion. Subjects had to indicate as fast as possible whether or not a discrepant face had been present. Results showed that an angry face in a happy crowd was detected more efficiently than a happy face in an angry crowd. Moreover, an angry face was detected as quickly in crowds of four faces as in crowds of nine faces. According to Hansen and Hansen, these findings support their hypothesis that features of facial threat can be processed pre-attentively, in a parallel search. However, research of Purcell, Stewart, and Skow (1996) strongly suggests that this pop-out effect reported by Hansen and Hansen was merely a contrast artifact. That is, the pictures used by Hansen and Hansen had distinctive local features that were especially prominent for the angry faces but at the same time were independent of the anger expression per se (e.g., dark patch in the neck). Purcell et al. (1996) demonstrated that the pop-out effect of angry faces was not a result of a high-level emergent facial attribute (i.e., anger), but of a low-level visual feature (i.e., the artifact). In their study, Hampton, Purcell, Bersine, Hansen, and Hansen (1989) had removed the dark patch in the neck and found that angry faces were detected more quickly. Yet, reaction times varied with the position of the target face in the crowd. In other words, the faster detection of angry faces seemed to be due to a faster but controlled search through happy crowds, and not to a fully automatic pop-out effect (but see De Jong \& Kindt, 1999).

Secondly, Ohman's hypothesis is not about trivial issues, but about phobic patients with serious symptoms. His formulations capitalize on the idea that the roots of maladaptive symptoms lie in an inaccessible, automatic perceptual system that has been shaped by evolutionary pressures. The characteristics of this system would explain the irrationality and uncontrollability of phobic fear (Ohman, 1993). From this perspective, phobias are non-cognitive and physiologically driven phenomena. To be sure, this is far removed from cognitive approaches that emphasize the causal status of higher cognitive operations in phobias (e.g., Shafran, Booth, \& Rachman, 1993). 


\section{Chapter 3}

\section{Research questions}

In Öhman and Soares' (1994) crucial experiment, they demonstrated that spider-fearfuls and snake-fearfuls responded differentially with large SCRs to masked spider and snake pictures, respectively, while non-fearful controls did not respond to any of the masked pictures. This finding provides support for Öhman's theory that a pre-attentive analysis of fear-relevant stimuli is sufficient for a fear response to occur. However, as their study is pioneer work, and, more importantly, some critical comments can be made about the theoretical and technical aspects of this experiment (see Chapter 2), further research on the presumed pre-attentive elicitation of phobic fear is warranted.

The basic assumption of Öhman's view is that phobics cannot control their fear because their bodily response precedes the conscious recognition of the feared object. If this is correct, one would expect that phobics, indeed, experience their fear as an uncontrollable response. Curiously enough, no systematic information about this matter has been gathered. Furthermore, as Thorpe and Salkovskis (1995) proposed, from the phobic patient's point of view, fear responses might not be that irrational. To study this issue in more depth, a questionnaire was developed to investigate to what extent phobics ascribe (un)controllability and (ir)rationality to their fear responses. The results of this study are described in section 4.1 .

A second point is that Öhman and co-workers tested their hypothesis about the preattentive elicitation of phobic fear in fearful undergraduates. Obviously, it is of crucial importance to examine whether the same results can be obtained in clinical phobic patients. After all, Öhman's theory offers an explanation for the phobic response. Furthermore, in their critical experiment, Ohman and Soares (1994) failed to carry out concurrent awaremess checks. As a result, one cannot be entirely sure about the subliminal character of the presented stimuli. Therefore, it would be important to measure physiological responses to pre-attentive stimuli and check awareness in one and the same sample. These points will be addressed in section 4.2.

Thirdly, skin conductance responses are known to be orienting responses rather than defensive responses (i.e., measures of anxiety). An index that is more directly linked to fear responses is the eye blink startle reflex. With this in mind, a study was conducted that sought to examine whether masked phobic pictures are able to elicit differential eye blink startle refiexes in phobic patients. In addition, this study explored whether masked phobic stimuli evoke cognitive interference (cf., emotional Stroop task, see MacLeod, 1991). That is, if masked phobic pictures produce physiological responses whereas they fail to elicit cognitive interference, less sensory input seems required for physiological responses to occur. This would support Öhman's hypothesis about the pre-attentive origins of fear. Alternatively, if masked phobic pictures produce cognitive interference 
whereas they fail to induce physiological responses, Ohman's hypothesis is less likely to be true. Both issues will be addressed in section 4.3 .

A fourth point is that Olmman's theory emphasizes the evolutionary relewance of a rapid analysis mechanism for fear-relevant stimuli. His finding that fearful adults respond with heightened SCRs to subliminal versions of their feared object seems to underline this point. However, this can also be explained in terms of a fear responding system that has become automatized due to extensive leaming experiences with the phobic object. Therefore, if the assumption of an evolutionary based pre-attentive fear system is correct, one would expect this system to operate also in phobic children. Children with specific phobia are close to the onset of their phobia and thus only a few learning experiences will have taken place yet. If they would display physiological responses to subliminal stimuli, an evolutionary interpretation would be much stronger. This point will be addressed in section 4.4 .

In Öhman's experiments, participants were confronted with small subliminal pictures (i.e., $21 \times 14 \mathrm{~cm}$, at $1 \mathrm{~m}$ distance). It could be argued that in this line of research, size of picture is crucial to obtain differential effects. That is, a picture probably must fall completely into foveal vision to be processed pre-attentively. In section 4.5 , the role of picture size is examined.

Öhman's hypothesis capitalizes on the notion that the pre-attentive processing of information is biased towards negative or threatening material. This would be especially true for phobics. However, from a quite different perspective, Murphy and Zajonc (1993) argued that both positive and negative subliminal information might affect preferences. According to their analysis, subliminal affective information may prime behaviour, irrespective of precise valence. Note that the issue of whether subliminally presented positive valenced material might influence people's behaviour has not yet received much attention from researchers. Meanwhile, this issue is interesting because it may provide us with clues as to how positive information can be used in a therapeutic way. 
Chapter 4

Empirical studies 



\section{Study 1}

\section{Self-reported automaticity and irrationality in spider phobia*}

\section{Summary}

Spider phobic $(n=39)$ and non-fearful control $(n=41)$ women completed a 20 -item questionnaire measuring the extent to which they experience their fear reactions to spiders as automatic and irrational. For the phobic sample, therapy outcome data were also collected. Results suggest that spider phobics tend to view their attitude to spiders as irrational and in this respect, they do not differ from control subjects. Furthermore, compared to control subjects, phobics more often perceive their responses to spiders as automatic i.e., not under intentional control. Contrary to expectation, no robust correlation was found between automaticity and irrationality. Interestingly, automaticity was not related to treatment outcome, while irrationality to some extent predicted therapy outcome (i.e., the more phobics experienced their fear as rational, the less they profited from exposure treatment).

\section{Introduction}

Phobias are characterized by intense fear and avoidance of specific objects or situations. More precisely, the latest edition of the Diagnostic and Statistical Manual of Mental Disorders (DSM-IV; APA, 1994, p.410) states that a person with a specific phobia "recognizes that the fear is excessive and unreasonable". DSM's portrayal of specific phobias as unreasonable or, in other words, irrational has become conventional wisdom among clinicians and researchers. For example, Page (1991, $\mathbb{1}$.183) claims that "[...] simple phobics can acknowledge the fear to be unreasonable $[. . .]^{\mathrm{m}}$. In a similar vein, Soares and Ohman (1993a, p.460) argue that "rational arguments about the actual harmlessness of phobic stimuli [....] are largely ineffective. This irrationality indicates that the phobic fear is not amenable to intentional conscious cognitive control". According to these authors, the irrational character of phobias would originate from certain pre-attentive (i.e., unconscious) mechanisms that operate in phobias. More specifically, Soares and Öhman (1993a; see also Ohman \& Soares, 1994) assume that during the first milliseconds of a confrontation with the phobic object, pre-attentive processing of phobogenic information would immediately trigger physiological fear reactions (i.e., sympathic arousal). As a result, phobics would become fully aware of the phobic object at a point in time when physiological fear responses are already activated and this would explain why phobics experience their fear

\footnotetext{
* This study will appear as an article (Mayer, Merckelbach, \& Muris) in Psychological Reports (in press).
} 
as irrational and uncontrollable.

In a series of experiments, Soares and Öhman (1993a; Öhman \& Soares, 1994; Öhman, Esteves, \& Sorares, 1995) monitored phobics' physiological reactions to subliminally presented phobic pictures (i.e., spiders, snakes), and found support for the idea that phobic responding is triggered by pre-attentive information processing. However, other authors (e.g., Globisch, Weike, \& Hamm, 1996; Mayer, Merckelbach, De Jong, \& Leeuw, 1999) were unable to replicate these effects. Apart from that, surprisingly few studies have addressed the issue of whether phobics actually experience their fear as an automatic, involuntary response. If a phobic response is, indeed, activated before conscious reflection comes into play, one would expect that phobics describe the phenomenology of their fear in terms of an automatic response that is not under intentional control.

As to the irrational character that the DSM-IV ascribes to phobias, it remains to be seen whether phobics really experience their fear in this way. For example, Arntz, Lavy, Van den Berg, and Van Rijsoort (1993) noted that spider phobics have a range of negative cognitions about spiders. These authors found that spider phobics strongly endorse all sorts of negative ideas about spiders (e.g., "The spider will attack me") and about their reactions during an encounter with spiders (e.g., "I will die because of fear"). Similar results were obtained by Thorpe and Salkovskis (1995), who found that phobics strongly believe that harm will befall them if confronted with a spider (e.g., "I would make a fool of myself" or "I would feel faint"). These findings suggest that from the phobic patient's point of view, it is rational to react with intense fear to the phobic object. In the words of Thorpe and Salkovskis (1995; p.815): "Overall, these data lead to the conclusion that the definition of phobias as 'irrational' may be unsound".

The present study was a first attempt to clarify to what extent phobics experience their fear as automatic (i.e., involuntary) and irrational and whether there is a connection between these two features. To this end, a questionnaire was developed, the Automaticity Irrationality Questionnaire (AIQ). AIQ items were formulated in such way that they referred to spider fear. It is worth noting that the aim of the present study was not to develop a new clinical tool, but to assess and evaluate in a systematic fashion certain aspects (i.e., automaticity and irrationality) of the phenomenology of phobic fear. Spider phobics and normal controls completed the AIQ and group differences in automaticity and irrationality of spider fear were tested. Furthermore, the association between automaticity and irrationality was analysed in more detail. If, as Öhman and Soares (1994) claim, automaticity underlies irrationality, one would expect a robust connection between these two features. Finally, we examined whether irrationality and automaticity are predictors of therapy outcome. In their study on exposure effects in spider phobia, Ost, Salkovskis, and Hellström (1991; p.421) concluded that "the most important factor in one-session treatment is making explicit the patients" catastrophic thoughts concerning the phobic situation". To the extent that exposure therapy is effective because it corrects a set of elaborated and articulated misconceptions that phobics have (see also, Foa \& Kozak, 1986), one would expect that phobics who experience their fear as highly automatic andior irrational (in the 
sense of acknowledging that spiders are hamnless) will benefit less from this treatment. On the other hand, there are some indications that phobics who are convinced of the rationality of their fear profit less from therapy (e.g., Thorpe \& Salkovskis, 1995).

\section{Method}

\section{Participants}

Participants were 39 spider phobic women who applied for treatment at the University Spider Phobia Project of Maastricht University, and 41 control women. Phobic participants were only included if they fulfilled DSM-IV (APA, 1994) criteria for specifio phobia, animal type. Diagnoses were made by a trained psychologist. Phobics did not suffer from significant other mental disorders. Mean age of the phobic group was 31.5 years $(S D=8.8)$. Control women were selected from a large pool of individuals recruited by advertisements in a local newspaper. Control women were only included in the final sample if they did not exhibit a fear of spiders. They received a financial compensation for participation in the study. Mean age of the control group was 31.2 years $(S D=8.1)$. Groups were matched as much as possible for educational level.

\section{Assessment}

Subjective fear of spiders was measured with the Fear of Spiders Questionnaire (FSQ; Szymanski \& O’Donohue, 1995; Muris \& Merckelbach, 1996) and the Spider Beliefs Questionnaire (SBQ; Arntz et al., 1993). The FSQ consists of 18 items that refer to a restricted time period (e.g., "If I encounter a spider now, I would have images of it trying to get me"). Items are evaluated on 7 -point Likert scales $(1=$ strongly disagree; $7=$ strongly agree). Accordingly, FSQ scores range between 18 and 126, with higher scores reflecting higher levels of spider fear. The $\mathrm{SBQ}$ comprises two scalles that assess the strength of negative beliefs about spiders (i.e., SBQ-spider; e.g., "The spider will attack $\mathrm{me}^{\mathrm{x}}$ ) and about reactions of the individual during confrontation with a spider (i.e., SBQself; e.g., "I will loose control"). Items of both subscales range from 0 (absence of negative beliefs) to 100 (very strong beliefs). A Behavioural Approach Test (BAT) was used to measure actual avoidance of spiders. During the BAT, participants had to approach a live spider in a stepwise manner. Scores on the BAT range from 0 (spider at $3 \mathrm{~m}$. distance) to 8 (spider on hand). Thus, high scores on the BAT reflect better performance (i.e., less spider fear).

Phobics and control subjects also completed the Automaticity Irrationality Questionnaire (AIQ). The original wersion of the AIQ consisted of 23 items referring to automaticity (e.g., "When I see a spider, I am not able to suppress my fear response") or irrationality (e.g., "When I notice a spider, I know that, in fact, I do not have to be afraid of it") involved in responses to spiders. Each item was scored on a 5 -point Likert scalle $(1=$ strongly disagree; $5=$ strongly agree). High scores on automaticity items indicate that respondents feel that 
they have little intentional control over their reactions to spiders. High scores on irrationality items imply that respondents readily acknowledge the harmlessness of spiders, whille low scores indicate that respondents are not sure about this. The co-existence of high irrationality scores and a strong fear of spiders, means, by implication, that individuals view their spider phobia as irrational.

As anticipated, initial factor analysis of the AIQ (principle components with VARIMAX rotation) revealed two factors (i.e., automaticity and irrationality), but also showed that three irrationality items (i.e., "I can imagine that many people dare to touch a spider", "I can imagine that fear of spiders passes off after a while", and "I think of spiders more as disgusting than as dangerous") had low loadings (i.e., loadings below 0.3) on the irrationality factor (i.e., $0.27,0.19$, and -0.19 , respectively). Therefore, these items were removed from the AIQ, leaving a total of 20 items in the final AIQ version (i.e., 13 automaticity items and 7 irrationality items). Items of the final AIQ version are listed in Table 1.

\section{Procedure}

All participants came to the laboratory individually. Before treatment, spider phobics filled out the FSQ, SBQ, and AIQ, and underwent the BAT. Treatment consisted of 3 hours exposure in wivo (for details, see Öst, 1989). After treatment, spider phobics carried out the BAT and filled out the FSQ and SBQ again. For practical reasons, control participants only completed the FSQ and the AIQ, and underwent the BAT once.

\section{Resuilts.}

\section{General statistics}

An exploratory factor analysis (principle components with VARIMAX rotation) of the final AIQ version confirmed the two-factor structure. Table 1 shows AIQ items, their loading on the two factors after rotation, and the mean scores of phobics and controls on the individual items. As can be seen, automaticity items loaded convincingly on the first factor (eigenvalue 10.36 , explained variance $51.8 \%$ ), whereas irrationality items loaded clearly on the second factor (eigenvalue 2.66, explained variance 13.3\%). Cronbach's alphas for AIQ automaticity and AIQ irrationality in the total sample were 0.97 and 0.70 , respectively. For the phobic sample, these coefficients were 0.68 and 0.77 , respectively. For the controls, coefficients were 0.82 and 0.69 , respectively.

\section{Phobics us controls}

As expected, phobics had higher scores on the FSQ than controls, means being $98.0(S D$ $=13.6)$ and $1.5(S D=3.2)$, respectively: adjusted $t(42.1)=43.1, p<0.001$. Phobics also displayed more avoidance behaviour on the BAT than controls, mearns being $3.6(S D=1.9)$ and $7.7(S D=0.8)$, respectively. adjusted $t(48.2)=12.7, p<0.001$. 
Furthermore, phobics and controls differed in terms of their mean scores on the automaticity dimension of the AIQ, means being 55.0 $(S D=5.3)$ and $20.2(S D=6.9)$, respectively: $t(78)=25.3, p<0.001$. Post-hoc $t$-tests revealed that signifucant differences between phobics and controls were present on all automaticity items (see Table 1). In other words, phobics perceived their responses to spiders as more automatic in nature than did controll subjects.

A t-test revealed no significant difference between phobics and controls with regard to the AIQ irrationality subscale, means being $24.6(S D=5.7)$ and $24.7(S D=4.4)$, respectively: $t(78)<1.0$. Thus, spider phobics did not have a stronger belief in the dangerousness of spiders than controls.

\section{Correlations between AIQ automaticity and AIQ irrationality}

Pearson product-moment correlations were computed between automaticity and irrationality. In line with the two-factor solution suggested by the factor analysis, automaticity and irrationality were not found to be correlated $\left(r=-0.09, \mathrm{n} . \mathrm{s}_{\text {. }}\right)$ in the total sample (i.e., phobics and controls). For the non-fearful control group, there was a small, negative correlation between automaticity and irrationality $(r=-0.35 ; p<0.05)$. That is, the more control subjects experienced their 'fear' as automatic (i.e., involuntary), the less they tended to depict spiders as harmless animals. For the phobic group, no such an association between automaticity and irrationality was evident $(r=-0.17$, n.s. $)$.

Correlations between $A l Q$ and severity of spider fear

Pearson product-moment correlations were computed between AIQ irrationality and AIQ automaticity, on the one hand, and measures of spider fear, on the other hand. This was done for the total sample, but also for phobic and non-phobic groups separately. As for the total sample, AIQ automaticity was significantly associated with FSQ $(r=0.94, p<0.001)$ and BAT $(r=-0.78, p<0.001)$. There were no significant correlations between AIQ irrationality, on the one hand, and FSQ or BAT, on the other hand ( $r$ 's were -0.08 and 0.14 , respectively). In other words, only automaticity was related to spider fear and avoidance behaviour.

In the control group, AIQ automaticity correlated with self-reported spider fear as indexed by the FSQ $(r=0.43, \mathrm{p}<0.005)$. There was no significant correlation between AIQ automaticity and BAT $(r=-0.28, n . s$.$) . Moreover, AIQ irrationality was not associated$ with any measures of spider fear (i.e., FSQ and BAT).

In the phobic group, no significant associations between AIQ automaticity and measures of spider fear were observed. AIQ irrationality, however, was negatively correlated with FSQ $(r=-0.47, p<0.005)$ and SBQ $(r=-0.45, p<0.005)$ (see upper part of Table 2 ). That is, in phobics, a tendency to portray spiders as harmless animals (i.e., high irrationality scores) was accompanied by relatively low levels of spider fear and a relatively weaker tendency to endorse negative beliefs about spiders. 


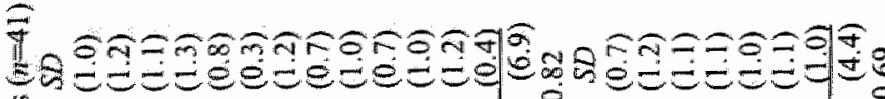
ह

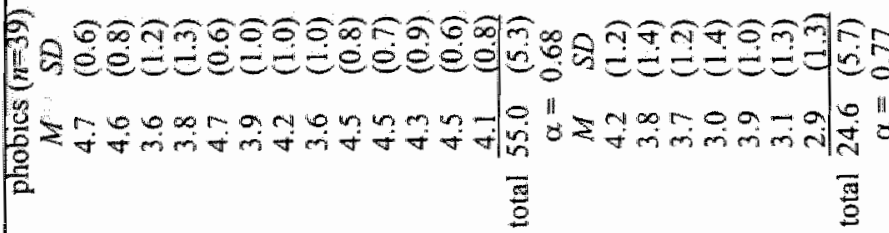

舟

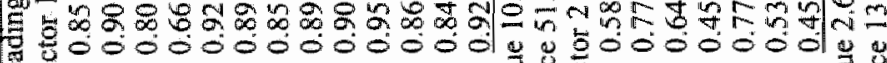
送

$E$ 要总

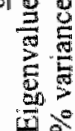

宊

营





接

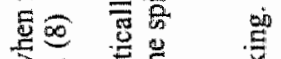

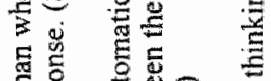
O)

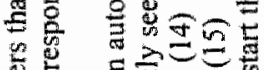

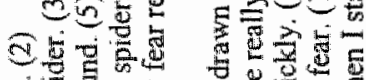

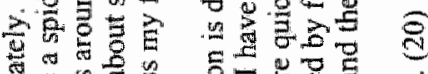

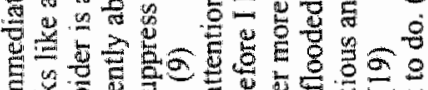

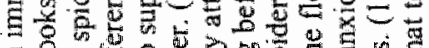

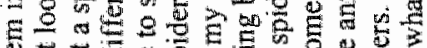
E

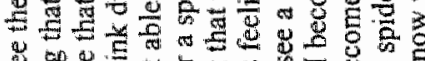

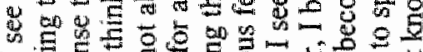
- E

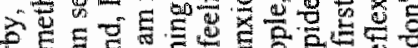

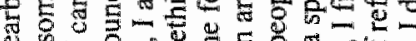

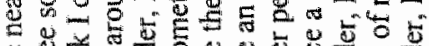
㟧 2.

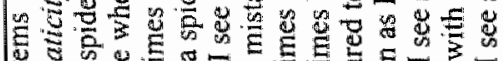

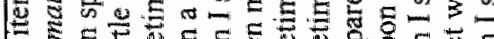




\section{AIQ automaticity, AIQ irrationality and therapy outcome}

Correlations between $\mathrm{AIQ}$ subscales and therapy outcome measures in phobics are shown in the lower rows of Table 2. As can be seen, AIQ automaticity did not correlate with any of the ontcome measures. In contrast, AIQ irrationality was associated with post-treatment $\mathrm{SBQ}$ spider $(r=-0.41, p<0.0125)$ and post-treatment BAT $(r=0.41, p<0.0125)$. When pre-treatment scores on FSQ, SBQ, and BAT were partialled out, only the correlation of AIQ irrationality with post-treatment BAT remained marginally significant (partial $r$ $0.34, p<0.05$ ). The direction of this correlation indicates that the more phobics describe spiders as harmless animals, the more a subsequent exposure session will reduce their avoidance behaviour. Altogether, these results suggest that automaticity is not related to treatment outcome, while irrationality to some extent predicts therapy outcome as measured at the behavioural level.

Table 2: Pearson product-moment correlations between AIQ automaticity and AIQ irrationality, on the one hand, and pre-and post-treatment spider phobia measures, on the other hand, for the phobic group $(n=39)$

\begin{tabular}{lcc}
\hline & $\begin{array}{c}\text { AIQ } \\
\text { Automaticity }\end{array}$ & $\begin{array}{c}\text { AlQ } \\
\text { Irrationality }\end{array}$ \\
FSQ pre-treatment & 0.19 & $-0.47 * *$ \\
SBQ spider pre-treatment & 0.23 & $-0.45 * *$ \\
SBQ self pre-treatment & 0.15 & -0.21 \\
BAT pre-treatment & 0.17 & 0.23 \\
FSQ post-treatment & -0.08 & -0.18 \\
SBQ spider post-treatment & 0.04 & $-0.41 *$ \\
SBQ self post-treatment & -0.03 & -0.19 \\
BAT post-treatment & -0.05 & $0.41 *$
\end{tabular}

Note. FSQ $=$ Fear of Spiders Questionnaire; $\mathrm{SBQ}=$ Spider Beliefs

Questionnaire; BAT = Behavioural Approach Task

* $p<0.05 ; * *$ significant when applying Bonferroni correction $(p<0.05 / 8=p<0.00625)$

\section{Discussion}

The DSM-IV assumes that individuals with specific phobias acknowledge that their fears are irrational. The present study examined whether this assumption is correct. In addition, an attempt was made to determine whether at the phenomenological level, the alleged irrationality of phobic fear is a function of automaticity, as Öhman and Soares (1994) claim. The main results of the present study can be summarized as follows. To begin with, in line with the DSM-IV description, spider phobics felt that their fear reactions to spiders were not justified by the dangerousness of spiders. In other words, phobics tended to view their 
reactions to spiders as irrational and they did not differ in this respect from normal control persons: both groups tended to view fear of spiders as irrational. Whille these findings support the DSM-IV position, they are difficult to reconcile with the results reported by Arntz et al. (1993) and Thorpe and Salkovskis (1995). These researchers noted that phobics strongly believe that harm will befall them when confronted with spiders. Clearly, endorsing such a belief implies that spider fear is rational. The discrepancy between the current findings and the results of Amtz et al. (1993) and Thorpe and Salkovskis (1995) might be related to the fact that the AIQ irrationality items tap globall ideas and attitudes about spiders, while measures as the SBQ ask for detailed and idiosyncratic cognitions about spiders and the fear reactions they elicit. Possibly, a global measure of the sort used in the current study is less sensitive to idiosyncratic danger expectations that some phobics might have. A related issue is that 2 of the 7 irrationality items used in the present study evaluate the irrationality of spider fear from the point of view of other people (i.e., public notions of irrationality). Yet, it is possible that at least some spider phobics believe that confrontation with a spider will have catastrophic results (internal irrationality) and at the same time acknowledge that other people will not share this view (external irrationality). The present study also found that spider phobics' Irrationality scores correlate negatively with their scores on the Spider Beliefs Questionnaire. Thus, low irrationality scores are accompanied by strong negative beliefs about spiders. Apparently, as a group, spider phobics do not differ from non-fearful controls in qualifying fear of spiders as irrational, possibly because most phobics are able to adopt public notions of irrationality. However, within the phobic group, there is a subgroup of phobics who strongly belief various negative ideas about spiders and who are less willing to define their spider fear as irrational or unreasonable.

A second finding of the current study that deserves some comment is that phobics experienced their reactions to spiders as more automatic (i.e., more involuntary) than did control subjects. This is, of course, in line with the position of Öhman and Soares (1994), as is the finding that higher levels of automaticity were positively related to spider fear and avoidance. However, in the present study, no substantial correlation was found between automaticity and irrationality. Thus, at least at the phenomenological level, there is no straightforward connection between the self-reported absence of intentional control over fear responses and the tendency to view this fear as unreasonable. This finding can be taken as an argument against Ohman and Soares, who claim that the irrational character of phobias is a function of the automaticity (involuntariness) of phobic responses. One could counter that their automaticity hypothesis pertains to physiological processes rather than phobics' self-reports. On the other hand, automaticity and irrationality refer to metacognitive judgements and this makes the present study"s reliance on self-report measures legitimate.

A third finding of the present investigation is that, in contrast to our expectations, pretreatment automaticity ratings were not related to therapy outcome. It was anticipated that for a phobic person who responds highly automatically to the feared object, it is more 
difficult to profit from the corrective information offered by exposure in vivo. While this was not bome out by the data, our failure to find a connection between automaticity and therapy outcome might be due to a restriction-of-range problem. That is, all phobics reported high levels of automaticity and there was relatively little variance within this group $(M=55.0 ; S D=5.27$; range 0-65). In line with previous findings of Thorpe and Salkovskis (1995), the present study found a connection between AIQ irrationality and post-treatment avoidance of spiders such that the more phobics were convinced of the dangerousness of spiders (i.e., the rationality of their fear), the less they profited from behaviour therapy. This implies that those phobics who endorse strong danger expectations about spiders respond less to therapy, a finding that underlines the idea that it might be valuable to include cognitive elements in exposure treatment (e.g., Foa \& Kozak, 1986; Öst, Salkovskis, \& Hellström, 1991).

In sum, then, the findings described here support the idea that, on the whole, spider phobias are experienced as irrational and automatic in nature (Öhman \& Soares, 1994). They do not show, however, that automaticity and irrationality are related to each other, as implicated by Öhman and Soares' proposal. Furthermore, automaticity was not found to be related to treatment outcome, whereas irrationality to some extent predicted therapy outcome. More specifically, phobics who were more convinced of the dangerousness of spiders profited less from exposure in vivo. Clearly, the role that "rational' and 'irrational" beliefs play in exposure treatment deserves further study. 
. 


\section{Study 2}

\section{Skin conductance responses of spider phobics to backwardly masked phobic cues *}

\section{Summary}

The present study was carried out to test Öhman's (1994) hypothesis that a pre-attentive analysis of phobic stimuli is sufficient for a fear response to occur. Spider phobic $(n=47)$ and non-phobic $(n=41)$ subjects were exposed to phobic slides (spiders) and control sides (flowers, mushrooms, and snakes) that were presented for $30 \mathrm{~ms}, 20 \mathrm{~ms}$, or $15 \mathrm{~ms}$. Slides were backwardly masked for $100 \mathrm{~ms}$. This technique was used to prevent conscious identification. During each trial, SCRs were measured. Following each trial, subjects indicated what they had seen (forced choice awareness check). Awareness check data revealed that only $15 \mathrm{~ms}$ stimuli remained genuinely subliminal. No convincing evidence was found to suggest that masked spider pictures elicit stronger SCRs in spider phobics than neutral control pictures. All in all, the present data fail to provide straightforward support for the idea that subliminal phobic cues elicit differential autonomic reactions in phobics.

\section{Introduction}

According to the Diagnostic and Statistical Manual of Mental Disorders (DSM-IV, APA, 1994), a phobia is a persistent and excessive fear that is cued by specific objects or situations. Exposure to the phobic stimulus provokes an immediate fear response in phobic patients. Patients experience these fear responses as irrational and uncontrollable. As a result, patients will go at great lengths to avoid the phobic object. Why are phobics not able to control their fears, while at the same time they seem to recognize that their fear is irrational? OHhman (1994) proposed that phobias are experienced as involuntary because the fear response is initiated before conscious, controlled processes come into play. By this view, phobias are characterized by an automatic analysis of phobia-relevant cues that operates outside attention and triggers physiological responses. At the time the phobic patient consciously identifies the phobic object, (s)he already feels bodily sensations. This, then, would explain why phobics experience their fear as uncontrollable.

Neurobiological findings of LeDoux (1994) nicely fit with Ohman's interpretation. In

* This study appeared as an article (Mayer, Merckelbach, De Jong, \& Leeuw) in the Journat of Psychophysiology, 13 (1999), 152-159. 
his animal studies, LeDoux demonstrated that two different pathways contribute to emotional processing: a slowly operating cortical pathway and a quickly operating subcortical pathway. In the first pathway, a thalamo-cortical route relays information to the cortex. At the cortical level, a full analysis of the stimuli is carried out and information is then transmitted along a cortico-amygdala route. Eventually, the amygdala activates an emotional response. The second pathway operates in a "quick and dirty" fashion. Here, information by-passes the thalamo-cortical and the cortico-amygdala pathway. Information is directly passed on from the thalamus to the amygdala, at which point the fear response is immediately initiated ("quick"). However, by-passing the cortex implicates that emotional stimuli are not fully analysed ("dirty"). Clearly, the quick and dirty thallamoamygdala route has survival value in dangerous situations that call for immediate action. It is conceivable that in phobics, this thalamo-amygdala pathway is hypersensitive to certain classes of stimuli.

Evidence to support this view comes from two sources. First, using cognitive tasks such as the masked modified Stroop test, a number of studies have demonstrated that phobias are accompanied by an automatic tendency to focus on threatening cues, even if these cues are masked and task-irrelevant (e.g., Mogg, Bradley, Williams, \& Mathews, 1993; Van den Hout, Tenney, Huygens, \& De Jong, 1997). However, most of these studies relied on verbal stimuli (e.g., threatening words in a modified Stroop task). Obviously, verbal threats are far removed from the stimuli that phobics fear.

The second source is a series of studies carried out by Öman and co-workers (see, for a review, Öhman, 1994). Unlike the Stroop studies, their experiments employed pictorial stimuli that were either threat-relevant or neutral. In the critical experiment, Öhman and Soares (1994) examined whether fearful and non-fearful undergraduates differed in their skin conductance responses (SCRs) to phobic and non-phobic cues which were presented either sub- or supraliminally. When a phobic response is, indeed, initiated before conscious controlled processes come into play, one would expect that fearful persons react to phobic stimuli even when these stimuli are presented sublimimally (i.e., outside awareness). In agreement with this, Ohman and Soares (1994) found that spider-fearful subjects responded with relatively large SCRs to backwardly masked spider pictures, snake fearful subjects responded with relatively large SCRs to backwardly masked snake pictures, while nonfearful control subjects did not respond differentially to any of these pictures.

This finding seems to sustain the idea that a pre-attentive analysis of phobic stimuli is already sufficient for a fear response to occur. However, the Öhman and Soares' experiment has some limitations that preclude any firm conclusion. Before one can conclude on the basis of this type of experiment that the "quick and dirty" route plays a crucial rolle in the phenomenal experiences of phobic fear (i.e., uncontrollability and irrationality), it is necessary to document 1) that target stimuli are genuinely subliminal (i.e., cannot be detected above chance; cf., objective threshold, Cheesman \& Merikle, 1986), and 2) that the basic findings can be obtained in clinical phobics. As to the first point, Öhman and Soares assumed that the $30 \mathrm{~ms}$ backwardly masked pictures used in their experiment were 
genuinely subliminal. Yet, they provide only indirect support for this assumption. More specifically, Öhman and Soares did not carry out direct awareness check trials along with $\mathrm{SCR}$ recordings. Admittedly, the authors were able to show in pilot experiment with a separate sample that $30 \mathrm{~ms}$ backwardly masked stimuli are not detected above chance. Still, extrapolating from this pilot to subsequent samples is not without problems. Establishing adequate thresholds for subliminal perception is notoriously difficult (Holender, 1986; Miller, 1991; see also Mayer \& Merckelbach, 1999a). The second point has to do with the fact that the Öhman and Soares experiment relied on fearful undergraduates rather than clinically diagnosed phobic patients. Note, however, that Öhman's (1994) theory pertains to clinical phobias as defined in the DSM-IV. Testing such a theory with fearful undergraduates is suboptimal because one could always speculate that fearful subjects may process threatening information in an automatic fashion, while phobics may have extreme low thresholds for consciously processing phobic cues, precisely because they give hight priority to these cues. Thus, it remains to be seen whether similar or even stronger effects of subliminal stimulation can be obtained in severe phobics.

The purpose of the present experiment was to test Öhman's (1994) hypothesis that preattentive phobic stimulation is sufficient for a fear response to occur. The procedure employed in the current study deviated in three important ways from that of Ohman and associates. To begin with, the current study relied on clinically diagnosed spider phobic patients rather than fearful students. Secondly w awareness check data were obtained along with SCRs in one and the same sample. Thirdly, as we had no a priori reasons to believe that $30 \mathrm{~ms}$ presentations would remain subliminal, we included two additional presentation times of shorter duration. More specifically, we used stimulus durations of $30 \mathrm{~ms}, 20 \mathrm{~ms}$, and $15 \mathrm{~ms}$. The $20 \mathrm{~ms}$ and $15 \mathrm{~ms}$ durations were included because these durations are frequently employed in subliminal Stroop studies (e.g., Van den Hout, Tenney, Huygens, \& De Jong, 1997; Mogg, Kentish, \& Bradley, 1993).

Method

\section{Subjects}

In accordance with the highly skewed sex distribution of the animall type of specific phobias (e.g., Merckelbach, De Jong, Muris, \& Van den Hout, 1996), subjects were 47 female spider phobics and 41 female control subjects. After reading magazine or journal articles about our Spider Phobia Project, spider phobics applied for treatment at our department. They received a "free" 3-hour exposure in wivo treatment in return for participating in the Project. The spider phobic women met the DSM-IV (APA, 1994) criteria for specific phobia, with spider phobia as their main problem. These diagnoses were made by a trained psychologist. Their average score on the Spider Phobia Questionnaire (SPQ; Klorman, Weerts, Hastings, Melamed, \& Lang, 1974) was 23.1 (SD=3.1), which comes cllose to scores of clinical spider phobics reported in other studies (e.g., Lavy \& Van den Hout, 
1993; De Jong, Merckelbach, \& Arntz, 1995). The non-fearful controls were recruited through advertisement in local newspapers and were given a financial compensation for participating in the study. Their average SPQ score was $2.5(S D=2.1)$, which indicates that the control subjects were genuinely non-fearful of spiders. Spider phobics and control subjects were matched as much as possible on age (means being 27.8 and 31.9 , respectively; $t(86)=2.26, p<0.03$ ). Participants' level of education was similar for both groups; means being 6.4 and 6.1 , respectively $[t(86)<1]$, on a scale ranging from only primary school (1) to university completed (9).

\section{Apparatus and stimulus material}

Subjects were seated in a sound-isolated, dark chamber. The target stimuli were $34 \mathrm{~mm} \mathrm{x}$ $22 \mathrm{~mm}$ colour slides of spiders, snakes, mushrooms, and flowers. The majority of these slides (i.e., all spider, snake, and mushroom pictures) were taken from the International Affective Picture System (IAPS; Lang, Öhman, \& Vaitl, 1988). Pictures were selected at face validity. As LAPS did not contain sufficient flower pictures for the present study, some new slides were derived from photographs in gardening books. As for the masks, we followed the procedure described by Öhman and Soares (1994). That is, masks were randomly cut, reassembled and rephotographed pictures of the original spiders, snakes, mushrooms, and flowers. However, rather than using 4 separate types of masks (constructed from spiders, snakes, mushrooms, or flowers, respectively), each mask contained unrecognizable parts of each type of stimulus (i.e., small pieces of spiders, snakes, mushrooms, and flowers). As a result, the 12 different masks used in the present study were highly similar. Uniform masks can be expected to reduce stimulus novelty and in this way may promote habituation of orienting SCRs to these masks (Dawson, Schell, \& Filion, 1990). Note that responses to the masks may blur critical responses to the target slides. Thus, using similar masks may enhance the sensitivity to detect SCRs to the target slides.

Targets and masks were projected by two Kodak Carousels (Ektapro) equipped with Compur high-speed shutters (EVS-3). To ensure that projection fields of targets and masks would be overlapping, the size of the mask $(120 \mathrm{~cm} \times 80 \mathrm{~cm})$ was slightly larger than that of the target $(110 \mathrm{~cm} \times 70 \mathrm{~cm})$. A low-intensity auditory probe signalled the onset of each new trial. The onset and offset of probes, targets, and masks were controlled by a Compaq deskpro 486 personal computer. SCRs were measured with a Schwartzer Skin Conductance Coupler (type EDA 48). The method of constant voltage ( $0.5 \mathrm{~V})$ was used. The coupler was connected to two Beckman $\mathrm{Ag}-\mathrm{AgCl}$ electrodes (diameter $8 \mathrm{~mm}$ ) that were filled with isotonic electrode gel. Electrodes were attached to the middle phalanges of the second and third fingers of the non-dominant hand. Respiration was measured with a Schwartzer respiration belt fastened around the waist of the subject. The respiration belt was connected to a Picker-Schwartzer ED14 Polygraph. Both respiration and SCRs were recorded on a Picker-Schwartzer ED14 Polygraph and sampled $(1000 \mathrm{~Hz})$ with a National Instruments AT-mio 16 A/D-converter. 


\section{Design}

The main factors in the experiment were group (between-subjects: spider phobics vs controls), presentation time (between-subjects: $30 \mathrm{~ms}$ vs $20 \mathrm{~ms}$ vs $15 \mathrm{~ms}$ ), and type of target picture (within-subjects: spider vs snake vs mushroom vs flower). Both phobic and control women were assigned to one of the three conditions in order of application. More precisely, phobics and controls who responded to advertisements appearing on several days in various newspapers and magazines, were sent a set of questionnaires and forms which they were asked to complete at home. When subjects returned these questionnaires, they were contacted by phone in order to schedule an appointment. In this way, the first 15 phobic women were subjected to the $30 \mathrm{~ms}$ condition, the following 16 to the $20 \mathrm{~ms}$ condition, and the last 16 to the $15 \mathrm{~ms}$ condition. A similar procedure was followed for the control participants. For practical reasons having to do with the scheduling of behavioural treatments, phobics and controls were tested on different days and the experimenter was not blind to the testing condition. Targets were presented for $30 \mathrm{~ms}, 20 \mathrm{~ms}$, or $15 \mathrm{~ms}$ and then backwardly masked for $100 \mathrm{~ms}$ with a stimulus onset asynchrony (SOA) of $30 \mathrm{~ms}, 20 \mathrm{~ms}$, or $15 \mathrm{~ms}$, respectively. Three different versions of each of the 4 types (spiders, snakes, etc.) of pictures were used. The order of these 12 pictures varied in a quasi random fashion. That is, no more than two successive presentations of the same slide type occurred. Each picture was presented 3 times. Accordingly, there were 36 trials. Twelve different, but equivalent masks were used. Each of them was presented 3 times and always masked the same target picture. The intertrial intervall was $26 \mathrm{~s}$. To ensure that SOAs were identical for sessions in which phobics and controls were tested, regular checks were performed on the calibrations of the shutters.

\section{Pracedure}

Subjects were seated in front of a white wall, at a distance of approx. 2 m. Kodak Carousels, shutters, polygraph, and computer were located in an adjacent room. Targets and masks were flashed through a small window on the white wall. After subjects had been told that the purpose of the experiment was to measure physiological responses to different types of pictures, respiration belt and electrodes were attached. Subjects were informed that a warning sound would signal the occurrence of each picture. As soon as they heard the warming signal, they had to sit quiet and fixate on that part of the wall where the pictures would appear (i.e., the centre of the stimuli). Subjects were told that following each waming signal, two pictures would be flashed, the first being a flower, mushroom, snake, or spider, and the second being a meaningless picture. Subjects were instructed that the presentation times of the meaningful pictures would be ultrashort, but that their task was nevertheless to identify these pictures. Before the experiment proper, they were shown 4 straightforward sample photographs of the pictures used (i.e., one of each category) In the $4 \mathrm{~s}$ period before and $6 \mathrm{~s}$ period after target onset, respiration and SCRs were measured. Subjects were instructed to remain silent during this period. After the $6 \mathrm{~s}$ period, subjects were asked through an intercom which of the 4 pictures they had seen. They had to make 


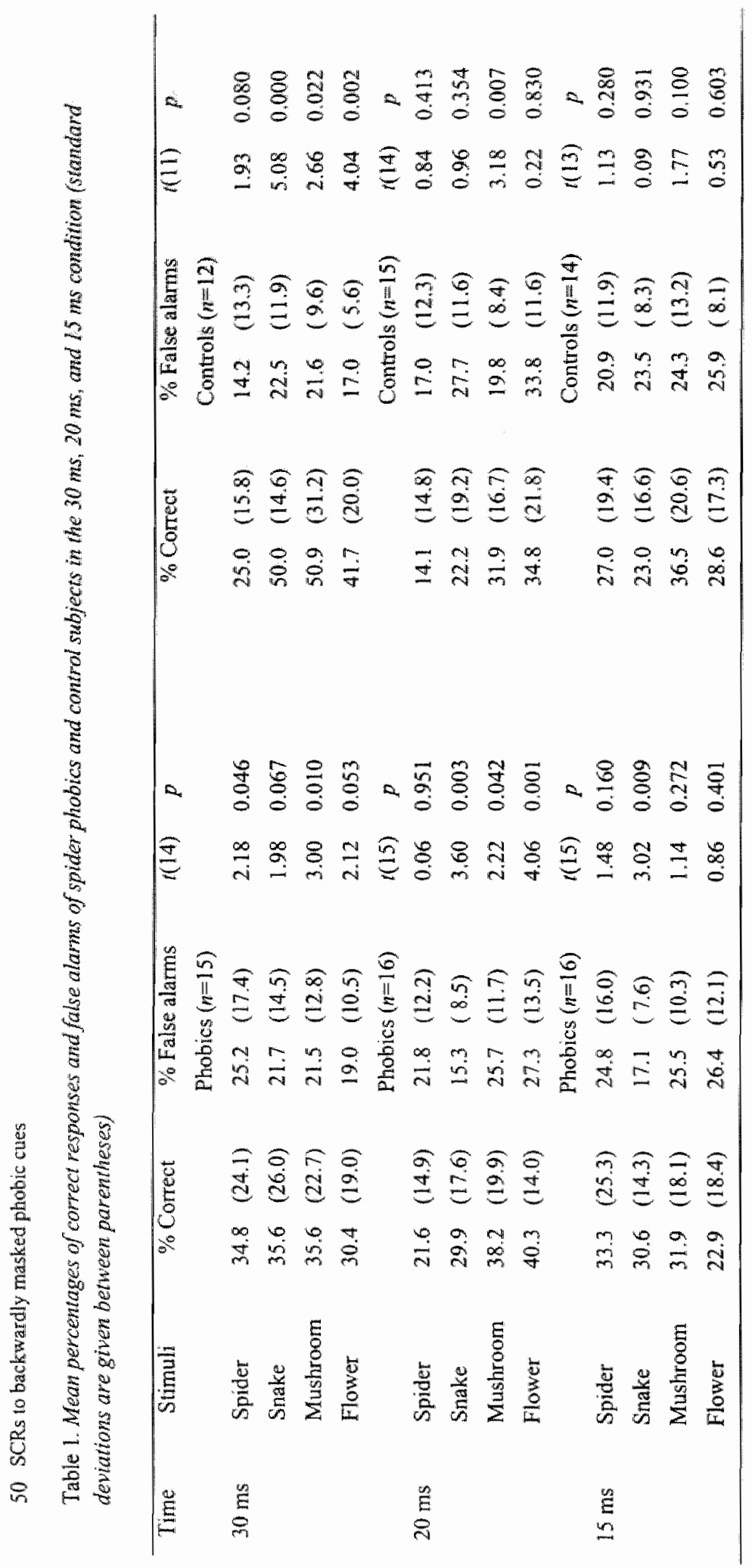


a cholice (forced choice procedure). In this way, data about hits (e.g., number of spider pictures identified as spiders) and false allarms (e.g., number of non-spider pictures identified as spiders) were collected.

\section{Data reduction and analysis}

The forced choice identification data were used to evalluate whether subjects were able to identify target pictures above chance (i.e., above $25 \%$ ). To assess identification performance, both percentages hits and percentages false alarms should be taken into account (Snodgrass, Levy-Berger, \& Haydon, 1985). Consider a subject who says "spider" on all trials. While this subject would reach the $100 \%$ hit asymptote for spiders, his or her performance would not indicate correct identification of spiders, simply because he or she also displays a $100 \%$ false alarm rate. In fact, subjects do not perform above chance until percentage hits exceeds both the $25 \%$ hit level (i.e., chance level) and the percentage false alarms. Thus, to establish whether target stimuli reach awareness or remain subliminal, it is essential to subject percentage hits and false alarms to within-subject comparisons. With this in mind, a 2 Group (spider phobics / controls) x 3 Time $(30 \mathrm{~ms} / 20 \mathrm{~ms} / 15 \mathrm{~ms}) \times 4$ Picture (spiders / snakes / mushrooms / flowers) $\times 2$ Awareness (percentage hits / percentage false alarms) Analysis of Variance (ANOVA), with repeated measures on the last two factors, was carried out. In case of significant interaction effects, pencentages hits and false alarms of each picture category were compared with paired $t$-tests for each time condition separately. Because $12 t$-tests were carried out, alpha was Bonferroni corrected and set at $p<0.05 / 12$.

SCR magnitude was measured by scoring the maximal deflection in conductance (in $\mu$ S) starting in the 1 to $4 \mathrm{~s}$ interval after onset of each target picture. As even extremely subile changes could reliably be detected by computer, no minimum response criterion was adopted. Following the criteria of Stern, Ray, and Davis (1980), SCRs associated with respiratory irregularities were not scored. These missing SCR data were estimated by taking the mean value of adjacent trials with similar pictures. When nore than two missing SCR values occurred for one type of picture, the subject's record was excluded. For this reason, data of one subject in the control group were excluded. The total percentage of estimated SCRs was $1.9 \%$. In order to normalize the distributions, SCR data were square-root transformed.

SCR data were subjected to a 2 Group (spider phobics / controls) x 3 Time ( $30 \mathrm{~ms} / 20$ ms / $15 \mathrm{~ms}$ ) x 4 Picture (spiders / snakes / mushrooms / flowers) Analysis of Variance (ANOVA), with repeated measures on the last factor. In case of significant main or interaction effects, separate ANOVA"s and follow-up $t$-tests were carried out. Given the large number of comparisons possible with this design, elevated confidence levels were used to guard against spurious findings. Because we had clear expectations about the SCR data, alpha was not Bonferroni corrected (as was done for the forced choice data), but set at $p<0.01$. 
Results

\section{Forced choice identification data}

The awareness check data of the forced choice procedure are summarized in Table 1. Percentages hits and percentages false alarms are shown separately for both phobics and controls. As can be seen in Table 1, various hit scores exceeded chance probability (i.e., 25 $\%$ ). A 2 Group (phobics / controls) $\times 3$ Time ( $30 \mathrm{~ms} / 20 \mathrm{~ms} / 15 \mathrm{~ms}$ ) x 4 Picture (spider / snake / mushroom / flower) $\times 2$ Awareness (percentage hits / percentage false alarms) ANOVA yielded a main effect of Awareness: $F(1,82)=56.92, p<0.001$. That is, percentages hits were larger than percentages false alarms, which indicates that, in general, target pictures were identified above chance. Furthermore, a significant interaction was found between Awareness and Time $[F(2,82)=9.46, p<0.001]$ and between Awareness and Picture $[F(3,246)=3.53, p=0.02]$. The interaction between Awareness and Group did not attain significance: $F(1,82)<1$. Likewise, the interaction between Awareness, Group, and Picture failed to reach significance $[F(3,246)=1.98, p=0.12]$. In other words, correct identifications differed across time condition and across pictures. However, there were no significant differences between phobics and controls in identifying target pictures above chance. To locate the origins of the significant interactions between Awareness and Time and between Awareness and Picture, follow-up t-tests were carried out for each picture in each time condition separately.

For the $30 \mathrm{~ms}$ condition, paired $t$-tests revealed that subjects performed significantly above chance in detecting flowers $[t(26)=4.15, p<0.001]$, mushrooms $[t(26)=3.71, p=$ $0.001]$, and snakes $[t(26)=4.26, p<0.001]$. Yet, spider pictures were not identified above chance: $t(26)=2.96, p>0.001$. For the $20 \mathrm{~ms}$ condition, the awareness check data indicated that subjects were aware of mushrooms $[t(30)=3.64, p=0.001]$. However, flowers $[t(30)=2.47, p>0.01]$, snakes $[t(30)=1.27, p>0.2]$, and spiders $[t(30)<1]$ were not detected above chance. For the $15 \mathrm{~ms}$ condition, no stimuli were identified above chance: all $r(29)$ 's $<2.10$, all $p$ 's $>0.04$. Overall, the awareness check data indicate that in the $30 \mathrm{~ms}$ and $20 \mathrm{~ms}$ condition certain target stimuli survived backward masking, i.e., were identified above chance.

\section{SCRs}

Mean SCRs of phobic and control subjects are shown in Table 2.

The ommibus ANOVA did not yield a main effect of Group $[F(1,82)=1.83, p=0.18]$, but there was a main effect of Picture $[F(3,246)=4.32, p<0.01]$. In addition, a significant interaction of Group $x$ Picture was found: $F(3,246)=7.75, p<0.001$. This interaction was due to a differential Picture effect in the phobic group $[F(3,132)=7.81, p<0.001]$, which was not significant in the control group $[F(3,114)=3.59, p=0.02]$. Post-hoc $i$-tests showed that phobics exhibited smaller SCRs to mushrooms than both to snakes $\llbracket t(46)=3.21, p<$ $0.01]$ and flowers $[t(46)=3.03, p<0.01]$. Yet, the critical differential response to spiders did not occur. 
Table 2. Mean square-root transformed SCRs (standard deviations in parentheses) of spider phobic and control subjects in three conditions (30 ms, $20 \mathrm{~ms}$, and $15 \mathrm{~ms}$ )

\begin{tabular}{|c|c|c|c|c|c|c|c|c|c|}
\hline \multirow{3}{*}{$\frac{\text { Time }}{30 \mathrm{~ms}}$} & \multirow{3}{*}{$\begin{array}{l}\text { Group } \\
\text { Phobics }\end{array}$} & \multicolumn{6}{|c|}{ Stimull } & & \\
\hline & & \multicolumn{2}{|c|}{ Spider } & \multicolumn{2}{|c|}{ Snake } & \multicolumn{2}{|c|}{ Mushroom } & \multicolumn{2}{|c|}{ Flower } \\
\hline & & 0.35 & $(0.29)$ & 0.44 & $(0.28)$ & 031 & $(0.20)$ & 0.41 & $(0.28)$ \\
\hline & Controls & 0.33 & $(0.18)$ & 0.32 & $(0.19)$ & 0.36 & $(0.16)$ & 0,35 & $(0.16)$ \\
\hline \multirow[t]{2}{*}{$20 \mathrm{~ms}$} & Phobics & 0.14 & $(0.09)$ & 0.13 & $(0.07)$ & 0.13 & $(0,08)$ & 0.13 & $(0.06)$ \\
\hline & Controls & 0.08 & $(0.05)$ & 0.10 & $(0.05)$ & 0.10 & $(0.06)$ & 0.10 & $(0.04)$ \\
\hline \multirow[t]{2}{*}{$15 \mathrm{~ms}$} & Phobics & 0.08 & $(0.05)$ & 0.09 & $(0.07)$ & 0.08 & $(0.05)$ & 0.11 & $(0.07)$ \\
\hline & Controls & 0.05 & $(0.02)$ & 0.04 & $(0.03)$ & 0.06 & $(0.03)$ & 0.06 & $(0.04)$ \\
\hline
\end{tabular}

Furthermore, the omnibus ANOVA yielded a main effect of Time: $F(2,82)=40.39, p$ $<0.001$. Overall, subjects reacted with larger SCRs to $30 \mathrm{~ms}$ pictures than to $20 \mathrm{~ms}$ pictures $[F(1,56)=37.24, p<0.001]$, and with larger SCRs to $20 \mathrm{~ms}$ than to $15 \mathrm{~ms}$ pictures $[F(1,59)$ $=8.08, p<0.01]$.

The interaction of Group $\mathrm{x}$ Time did not attain significance $[F(2,82)<1]$. Likewise, no significant interaction could be obtained for Time $\mathrm{x}$ Picture $[F(6,246)=2.42, p=0.03]$. However, a significant interaction was found for Group $\times$ Time $\times$ Picture $[F(6,246)=5.30$, $p<0.001$. The origins of these interactions were examined with separate ANOVAs for the three time conditions (i.e., $30 \mathrm{~ms}, 20 \mathrm{~ms}$, and $15 \mathrm{~ms}$.).

In the $30 \mathrm{~ms}$ condition, there was neither a main effect of Group $[F(1,25)<1]$ nor of Picture $[F(3,75)=3.36, p=0.02]$. However, there was a significant interaction between Group and Picture $[F(3,75)=7.06, p<0.001]$. Follow-up ANOVAs showed that this interaction effect was carried by a main effect of Pictures in the phobic group $[F(3,42)=$ $8.02, p<0.001]$ that was not evident in the control group $[F(3,33)=1.63, p=0.20]$. For the phobic group, post-hoc $t$-tests indicated that flowers elicited larger SCRs than did mushrooms $[t(14)=2.85, p=0.01$.$] . In addition, \mathrm{SCRs}$ to snakes were larger than SCRs to mushrooms $[t(14)=4.17, p<0.01]$ and spiders $[t(14)=3.10, p<0.01]$.

For the $20 \mathrm{~ms}$ condition, the ANOVA yielded neither a main effect of Group $[F(1,29)$ $=2.97, p=0.10]$, nor of Picture $[F(3,87)<1]$. Likewise, the critical interaction of Group $x$ Picture failed to reach significance: $F(3,87)=2.30, p=0.08$. In other words, phobic subjects did not respond with larger SCRs to spider pictures than controls. Neither did phobics react with larger responses to spiders than to the other pictures.

For the $15 \mathrm{~ms}$ condition, the ANOVA showed neither a main effect of Group $[F(1,28)$ $=6.25, p=0.02]$, nor of Picture $[F(3,84)=2.70, p=0.05]$. Again, the critical Group $\mathrm{x}$ Picture interaction was not significant: $F(3,84)=1.12, p>0.3$.

\section{Discussion}

The main results of the present study can be summarized as follows. First, $30 \mathrm{~ms}$ and 20 
ms backwardly masked pictures were not subliminal in the strict sense of the word. That is, during the forced choice task, subjects in the $30 \mathrm{~ms}$ and $20 \mathrm{~ms}$ condition were able to identify some stimulus categories above chance. Thus, strictly speaking, only the $15 \mathrm{~ms}$ condition is appropriate for the issue at stake (i.e., do subliminal phobic stimuli elicit stronger autonomic reactions than neutral stimuli?). Secondly, the overall analysis of SCRs did not support the idea that degraded phobic cues elicit differential SCRs in phobic subjects. Thirdly, in the $30 \mathrm{~ms}$ condition, SCRs to flowers and snakes were significantly larger than SCRs to mushrooms and spiders. A possible explanation for this unexpected finding has to do with a technical issue in the experimental set-up: pictures were presented in a quasi-random but fixed sequence starting with a flower trial and followed by a snake trial. Orienting responses to these first pictures could have caused the higher mean values for these stimulus categories. One could speculate that this may have contributed to our failure to find differential responses to phobic pictures. However, excluding the first trials of each picture category from the analyses, basically yielded similar results. That is, there was a significant Group $x$ Picture interaction due to a significant main effect of Picture in the phobic group which was not evident for the control group. Post-hoc $t$-tests showed that phobics responded with larger SCRs to snakes than to mushrooms $[t(46)=2.67, p=0.01]$. Other comparisons did not attain significance: $t(46)$ 's $<2.2, p$ 's $>0.01$. In sum, the posthoc ANOVA showed that the exclusion of the first SCRs did not change our finding that spider phobics did neither respond with larger SCRs to spiders than control subjects, nor with larger SCRs to spiders than to neutral pictures.

Taken together, the present results do not sustain Öhman and Soares" proposal that a pre-attentive analysis of phobic stimuli is already sufficient for a physiological fear response to occur. However, as the present study was not an exact replication of the Öhman and Soares (1994) study, one could counter that our failure to obtain similar results is due to procedural differences. Indeed, the present study deviates in two important respects from the procedure employed by Öhman and Soares (1994). First, the inclusion of a forced choice identification task might have affected the sensitivity of the SCR measure in a negative way. Germane to this issue is a study by Esteves, Dimberg, and Öhman (1994) who found that instructions to attend to the mask interfered with psychophysiological responding to the target stimulus. Note, however, that in the present study, subjects were asked to attend to the target stimuli rather than to the masks. One could even argue that directing attention to the target stimulus enhances rather than attenuates subjects' responses. That is, with the present set-up, subjects are typically trying to ignore the (meaningless) mask and focus on the (meaningful) target. This is substantiated by the fact that in the 20 $\mathrm{ms}$ and $30 \mathrm{~ms}$ condition some pictures did survive the backward masking procedure (i.e., were identified above chance). Interestingly, in a recent study, Öhman and Soares (1998; Exp. 2) exposed normal subjects to backwardlly masked conditioned stimuli ( $\mathrm{CS}+$ ) while SCRs and forced choice recognition performance were measured. They found no indications that the forced choice task undermined or contaminated SCRs to masked target stimuli. 
A second difference is that the sizes of the target and mask stimuli used in the present study were larger than those in the Ohman et al. studies (i.e., $110 \times 70 \mathrm{~cm}$ versus $21 \times 14$ $\mathrm{cm}$ ). One could speculate that detecting effects of subliminal stimuli may be more difficult with large than with small target pictures, simply because in the former case more portions of the target scene fall in peripheral retinal locations. Yet, on a more careful inspection, such an interpretation of our failure to obtain robust effects of subliminal phobic stimuli is hardly convincing (see also Study 4). To begin with, our subjects were seated at a greater distance of the targets and masks than subjects in the Öhman and co-workers studies ( $2 \mathrm{~m}$ versus $1 \mathrm{~m}$ ). As well, in the current study, subjects were instructed to fixate on a little cross on the wall where the centre of the target would appear. Thus, target stimuli were alway's within foveal vision. Again, the fact that under 20 and $30 \mathrm{~ms}$ presentation conditions, certain targets were detected above chance underlines this point. Note further that, in their study on subliminal priming of subjective evaluations, Murphy and Zajone (1993) documented robust priming effects with an intermediate stimulus size $(45 \times 60 \mathrm{~cm})$ at a distance of $1.5 \mathrm{~m}$ and even shorter presentation time (i.e., $4 \mathrm{~ms}$ ). Taken together, it is unlikely that the size of the stimulus pictures in the present study is responsible for our failure to cross validate the basic findings of Öhman and Soares (1994).

Is it possible that phobic patients recognised fragments of spiders in the masks and that this elicited SCRs that obscured differential responding to the target pictures? While this possibility cannot be ruled out definitively, it appears highly unlikely. After the experiment, participants were asked to describe the stimuli they had seen. Nearly all subjects reported autumn leaves, woodland soill, and coloured pieces (cf. Ohman \& Soares, 1994). A small minority of the participants mentioned spiders, snakes, mushrooms, or flowers. As a rule, these participants performed above chance during the forced choice task.

While the present study yielded disappointing results, it is important to emphasize its strenghts. For one thing, in the present study, SCR data were collected along with forced choice awareness check data. Furthermore, several stimulus presentation times were included. Also, the 12 different masks that we used were highly similar, thereby reducing orienting responses to the masks and enhancing the sensitivity to detect autonomic responses to target stimuli. Finally, and most importantly, it should be stressed that the present study relied on a large sample of phobic patients $(n=47)$ rather than fearful undergraduates. As said earlier, Öhman's (1994) hypothesis about the pre-attentive antecedents of phobic responding is, indeed, an hypothesis about phobias.

In sum, then, the present experiment found no convincing evidence to support the idea that degraded phobic stimuli are effective in eliciting the autonomic components of fear in phobics. Although it is tempting to accept Öhman's theory about a "quick and dirty" route playing a crucial role in phobics" experience of uncontrollability and irrationality of their" fear, the current findings do not llend unequivocal support for this idea. 


\section{Study 3}

\section{Subliminal phobic stimuli, fear-modulated eyeblink startle reflex, and cognitive interference *}

\section{Summary}

The present study examined 1) whether subliminal phobic stimuli potentiate eye blink startle reflexes, and 2) whether such stimuli are able to provoke cognitive interference on a Stroop-like task. Fourty-six spider phobic patients and 43 non-fearful control participants were exposed to subliminal (i.e., masked) or supraliminal (i.e., unmasked) target (i.e., phobic, negative, neutral, and positive) slides. On $60 \%$ of the trials, affective and neutral slides were accompanied by acoustic startle probes and eye blink startle reflexes were measured. The same series of slides was presented for a second time followed by coloured masks. Colour-naming latencies were recorded as a measure of cognitive interference.

Exposure to supraliminal phobic slides resulted in an affect-modulated startle reflex in the phobic, but not in the control group. Such an effect was not found under subliminal viewing conditions. Likewise, in the supraliminal condition, phobics tended to exhibit more colour-naming interference when phobic or negative slides preceded the colour masks than control participants. Yet, in the subliminal condition, such an effect did not occur. Thus, unlike supraliminal phobic stimuli, subliminal phobic stimuli failled to elicit startle potentiation or cognitive interference.

\section{Intraduction}

An important criterion for phobias is that the patient admits that his or her fear of the phobic object or situation is unreasonable (DSM-IV, APA, 1994). However, despite the knowledge that the feared object is not dangerous, phobics react with intense fear as soon as they are confronted with their phobic object. According to Öhman (1993), this uncontrollable character of phobic fear results from pre-attentive automatic processing of threatening information. Öhman argues that phobic information is analyzed by fast, subcortical information processing mechanisms that operate outside the control of conscious intentions. These pre-attentive information processes would initiate a fear response before the phobic stimulus is consciousiy recognized.

\footnotetext{
* Submitted for publication
} 
Neurobiological findings of LeDoux (1994) support the pre-attentive processing hypothesis of Öhman (1993). In his animal work, LeDoux (1994) found evidence for a subcortical pathway linking the thalamus and the amygdala. This direct thalamo-amygdala pathway is shorter and faster ("quick") than thalamo-cortical pathways, but its capacity to process the stimulus is more limited ("dirty"). In other words, the "quick and dirty" subcortical fear pathway is sufficient for rapid analysis of simple stimulus features and for producing an immediate fear response.

In their experiments, Öhman and Soares $(1993,1994)$ found support for the idea that phobic stimuli may elicit physiological responses in the absence of conscious identification of these stimuli. For example, Öhman and Soares (1994) exposed spider-fearful students, snake-fearful students, and non-fearful controls to brief presentations of fear-relevant (i.e., spiders, snakes) and fear-irrelewant (i.e., mushrooms, flowers) slides. Slides were presented ultra short (i.e., $30 \mathrm{~ms}$ ) and backwardly masked. The authors argued that under these conditions, subjects are not able to consciously recognize the stimulus pictures. Nevertheless, spider-fearful subjects reacted with skin conductance responses (SCRs) to spider slides, snake-fearfuls reacted with SCRs to snake slides, and non-fearful controls did not react to any of the slides. Öhman and Soares (1994) take these findings as evidence that pre-attentive analyses of fearful stimuli may evoke a fear response.

Attempts to replicate the SCR effects of Öhman and Soares (1994) have not been uniformly successful (Mayer, Merckelbach, De Jong, \& Leeuw, 1999; see Study 2). But, apart from that, it should be noted that the SCR measure employed in the Öhman and Soares (1994) study is an index of orienting and arousal rather than a measure of fear per se (e.g., Ohman, 1979). Modulation of the eyeblink startle response would seem to provide a more direct measure of emotion (Vrana, Spence, \& Lang, 1988). Indeed, a large number of studies conducted by Lang, Bradley, and Cuthbert (1990, 1992; Bradley, Cuthbert, \& Lang, 1993) have demonstrated that the startle reflex is particularly sensitive to emotional walence of a background stimulus (i.e., the more negative an emotion is, the larger the eyeblink startle reflex; see also De Jong, Merckelbach, \& Arntz, 1991). In contrast, the SCR can best be conceptualized as an index for emotional intensity (i.e., equally intense stimuli, regardless of valence, provoke similar responses). For example, Hamm, Cuthbert, Globisch, and Vaitl (1997) recently showed that animal-fearfuls display larger SCRs to their phobic pictures than controls, while SCRs of mutilation-fearfuls to their phobic pictures do not differ from those of controls. Yet, both animal- and mutilation-fearfuls exhibit on their phobic trials a similar pattem of startle reflex potentiation which differ significantly from that of controls. Findings such as these indicate that the startle response is a more direct and specific measure of fear than SCRs.

A related line of research demonstrates that the amygdala plays a critical role in the fearmodulated startle response (e.g., Hitchcock \& Davis, 1991). Inspired by this finding, Merckelbach, De Jong, Leeuw, and Van den Hout (1995) attempted to extend the findings of Öhman and Soares (1994), using eyeblink startle response rather than SCR as the dependent measure. In their experiment, startle responses of spider phobic patients and non- 
fearful controls were measured during exposure to uitra short $(30 \mathrm{~ms})$ and backwardly masked phobic and neutral slides. Compared to controls, phobics tended to react with larger startles during the second block of spider slides, while no such differential pattern was found for neutral slides. However, overall, spider phobics did not react with larger startle reflexes on spider trials than did control participants. Thus, these findings, at best, provide only partial support for Öhman's theory. Meanwhile, a potential limitation of the Merckelbach et al. (1995) study concerns the time interval between target slides and startle probes. It might well be the case that the interval time employed in that study (i.e., $2.4 \mathrm{~s}$ ) was too long to detect startle potentiation by masked phobic slides. Perhaps; then, a more robust startle potentiation would have been obtained with shorter interval times.

Another startie-probe study that has been cited as providing indirect support for the automatic origins of fear was conducted by Globisch, Harm, Esteves, and Öhman (1999). In that study, fearfuls but not non-fearful controls were found to react with a startle potentiation to $150 \mathrm{~ms}$ fear-relevant pictures (e.g., spiders). This potentiation was evident as early as $300 \mathrm{~ms}$ after stimulus onset. Accordingly, the authors concluded that "fear can be activated very rapidly, requiring only minimal stimulus input" (Globisch et al., 1999; p.66). Thus, the authors assume that a $150 \mathrm{~ms}$ stimulus duration does not allow for a full perceptual analysis of the fear-relevant cue, an assumption that can be questioned.

The primary aim of the present study was to replicate and extend the findings of Öhman and Soares (1994) and those of our previous study (Merckeibach et al., 1995). Because the optimal time interval for auditory probes to elicit fear-potentiated startle responses in a subliminal set-up is yet unknown, the present experiment relied on three different time intervals rather than one. A second aim of the present study has to do with the cognitive effects of phobic stimuli. There are reasons to believe that subliminal phobic stimuli may produce effects in several domains. Apart from the psychophysiological effects reported by Öhman and Soares (1994), several authors using subliminal Stroop paradigms have found that subliminal phobic words produce cognitive interference (e.g., MacLeod \& Hagan, 1992; Van den Hout, Tenney, Huygens, \& De Jong, 1997). That is, conpared to normal controls, anxious persons are slower in colour-naming a mask (i.e., a meaningless string of coloured letters, like RGTYPRZ) when it is preceded by subliminal fear-relevant words (e.g., spider) than when it is preceded by subliminal neutral words (e.g., pencil). This suggests that information processing systems give priority to the (semantic) analysis of threatening information. So far, subliminal Stroop studies have relied exclusively on verbal stimuli. It would be interesting to see whether subliminal pictorial phobic stimuli are able to provoke such a cognitive interference. From supraliminal Stroop studies, it is known that pictorial fear-relevant stimuli produce less interference than linguistic fear-relevant stimuli (Lavy, Van den Hout, \& Arntz, 1993; Merckelbach, Kenemans, Dijkstra, \& Schouten, 1993). Thus, it seems plausible to assume that much the same is true for subliminal set-ups. If, however, subliminal phobic pictures were found to produce cognitive interference whereas they fail to induce physiological responses (e.g., startle potentiation), this would suggest that relatively more intense sensory input is required to elicit such physiological 
effects. Such a pattern of results wrould cast doubts on Öhman's claim that subliminal phobic stimuli are sufficient to trigger the physiological components of fear. Alternatively, if subliminal phobic pictures were found to evoke physiological effects, but no cognitive interference, this would suggest that physiological fear components are more readily triggered by the information processing system. Such a pattern of findings would support the credibility of Ollman"s hypothesis.

To evaluate the physiological and cognitive effects of phobic stimuli, the present study obtained both startle potentiation and cognitive interference data in clinical phobics and non-fearful participants. Stimuli were presented subliminally and supraliminally to investigate whether or not conscious awareness is a prerequisite for startle potentiation and cognitive interference to occur.

Method

\section{Participants}

Participants were 46 spider phobics (mean age: 30.8 yrs, range $18-51$ yrs) and 43 nonfearful controls (mean age: 31.3 yrs, range 18 - 50 yrs). Phobic patients applied for treatment at our department. They agreed to participate in our Spider Phobia Project in exchange for one-session exposure in vivo treatment. Phobic participants were only included if they fulfilled DSM-IV criteria for specific phobia, animal type. Diagnoses were made by a trained psychologist. Control participants were recruited through an advertisement in a local newspaper and were paid for their participation. Phobics scored higher on the Fear of Spiders Questionnaire (FSQ; Szymanski \& O'Donohue, 1995) than controls, means being $96.7(S D=14.3)$ and $1.5(S D=3.2)$, respectively; adjusted $t(50.9)$ $=44.6, p<0.001$. Both phobics and controls underwent a standardized Behavioural Approach Test (BAT; see for details, De Jong, Visser, \& Merckelbach, 1996) that was scored on a 8 mpoint scale $(1=$ spider at $2 \mathrm{~m}$ distance; $8=$ spider walking on the hand $)$. Mean scores on the BAT for phobics and controls were $3.7(S D=1.9)$ and $7.7(S D=0.7)$, respectively; adjusted $t(54.3)=12.7, p<0.001$. Note that high scores on the BAT indicate more approach behaviour. Phobics and controls did not differ with respect to age $[t(88)=$ $0.26, p>0.7]$ or education $[t(88)=1.3, p=0.19]$.

\section{Stimulus materials and apparatus}

Fourty colour slides $(22 \times 34 \mathrm{~mm})$ were used in the experiment. Most slides (i.e., 31) were taken from the International Affective Picture System (IAPS; Lang, Öhman, \& Vaitl, 1988). The other slides (i.e., 9) were selected from magazines and postcards or prepared by a photographer. There were 4 categories of slides, each category containing 10 slides: phobic stimuli (i.e., spiders), negative stimuli (e.g., mutilated bodies), neutral stimull (e.g., household anticles), and positive stimuli (e.g., babies). Masks were reassembled and 
rephotographed pieces of pictures (ci,. Öhman \& Soares, 1993). There were 20 differemt, but highly similar masks. All masks contained a coloured (i.e., red, yellow, blue, or green) dot in the centre.

Slides were presented with two Kodak Carousels that were located in a room adjacent to the sound-attenuated experimental room. They were projected on a white wall, approximately $1.5 \mathrm{~m}$ in front of the participant. The projected targets were $75 \times 50 \mathrm{~cm}$, while masks were $80 \times 80 \mathrm{~cm}$.

Acoustic startle probes were $50 \mathrm{~ms}$ bursts of $100 \mathrm{~dB}$ white noise with an instantaneous rise time, presented binaurally through Sony CD 750 stereo headphones. Startle responses were recorded with 4 Beckman miniature $\mathrm{Ag}-\mathrm{AgCl}$ electrodes filled with salt free electrically conductive gel (Hewlett Packard Redux cream). Startle responses were measured by recording EMG activity from the $m$. orbicularis oculi beneath both eyes. The EMG signal was fed to a Picker Schwartzer ED14 coupler and sampled with a frequency of $1000 \mathrm{~Hz}$. A notch filter was used to eliminate $50 \mathrm{~Hz}$ interference.

A Compaq $48633 \mathrm{mHz}$ personal computer controlled the shutters as well as the presentation of slides, masks, and auditory probes. A second Compaq 486 computer was used for on-line storage of EMG and reaction time data.

\section{Designt}

For each group (i.e., phobic and control), halif of the participants was assigned to the subliminal condition, whereas the other half participated in the supraliminal condition. For both conditions, the experiment involved various phases. The series of 40 target slides was presented 4 times in succession. During the first and third slide series, startle responses were obtained, while during the second and fourth slide series, colour-naming latencies were recorded in a Stroop-like task (see below). Within both the supraliminal and the subliminal condition, there were 4 different, quasi-random sequences of the 40 target slides. In order to obtain reliable eye blink startle measures, the series of slides was presented twice (i.e., phase 1 and 3). Consequently, there were 80 trials, with $60 \%$ of the slides of each category (i.e, 12 phobic, 12 negative, 12 neutral and 12 positive slides) being accompanied by a startle probe. To reduce the temporal predictability of the startle probe, 12 additional probes were presented during inter-trial intervals. In the subliminal condition, target slides had a duration of $25 \mathrm{~ms}$ and at slide offset a mask with a duration of $100 \mathrm{~ms}$ occurred $(\mathrm{SOA}=25 \mathrm{~ms}$ ). Mean inter-trial interval was $25 \mathrm{~s}$ (range $20-30 \mathrm{~s}$ ). For each participant, 16 startle probes were presented $1,3 \mathrm{~s}$ following target side onset, 16 startle probes were presented $1.9 \mathrm{~s}$ following target slide onset, and 16 startle probes were presented $2.5 \mathrm{~s}$ following target slide onset. In the supraliminal condition, each target slide was presented for $6 \mathrm{~s}$ and mean inter-trial interval was also $25 \mathrm{~s}$ (range $20-30 \mathrm{~s}$ ). In this condition, 16 startle probes were presented $3.5 \mathrm{~s}$ following slide onset, 16 startie probes were presented $4.2 \mathrm{~s}$ following slide onset, and 16 startle probes were presented $4.9 \mathrm{~s}$ following slide onset. These different time intervals for subliminal and supraliminal conditions were based on the following considerations: In order to avoid pre-pulse 
inhibition phenomena, time intervals were always above the 1 s interval (cf., Bradley et al., 1993; Globisch et al., 1999). Because it seems safe to assume that in the subliminal condition, startle potentiation reaches its maximum in a short time window following stimulus presentation, a relatively short time interval was incorporated (i.e., 1.3 s). Furthermore, as we were able to obtain at least smal] effects in a previous study with the relatively long 2.4 s interval (Merckelbach et al., 1995), such an interval was also used in the current study (i.e.s 2.5 s). Additionally, an intermediate interval (i.e., 1.9 s) was included. For the supraliminal condition, 3 time intervals were chosen which are known to produce reliablle fear-potentiation (i.e., $3.5 \mathrm{~s}, 4.2 \mathrm{~s}$, and $4.9 \mathrm{~s} ; \mathrm{cf}$., Bradley, Cuthbert, \& Lang, 1993). As for the Stroop-like task (phase 2 and 4), in both the subliminal and the supraliminal condition, target slides were immediately followed by masks that had a coloured dot in the centre. Participants had to name the colour of the dot as quickly as possible and latencies were recorded. For the subliminal condition, the 4 phases were followed by a forced-choice identification task that evaluated whether the masked target pictures were genuinely subliminal. During the final phase, participants in both conditions were asked to evaluate on $100 \mathrm{~mm}$ Visual Analog Scales (VASs) each slide in terms of pleasantness, fearfulness, and arousal.

\section{Procedure}

Participants came to the laboratory individually. They were seated in a dimly lit, soundattenuated and electrically shielded room. Participants were informed that the experiment consisted of various phases. They were told that muscle tension around the eye was measured while pictures (with a brief duration) were presented. Furthermore, it was explained that auditory probes were delivered throughout the experiment. Next, physiological sensors and headphones were attached. Following this, participants were given test trials of startle probes and EMG activity was checked. Participants were explicitly told that during the experiment, startle probes would be delivered over the headphones and that they should ignore these probes. Furthermore, participants were asked to sit quiet and to attend to that part of the wall where target slides would appear. They were instructed that each target slide would be preceded by a low intensity, but clearly audible warning signal that occurred $2 \mathrm{~s}$ before the target. To reduce orienting effects, 10 startle probes were administered before the experiment proper started. Following this, the first experimental phase began. After presentation of the 40 slides, headphones were removed and participants were told that the second experimental phase would start and that during this phase, no auditory probes would be delivered and no physiological data would be obtained.

During the second phase, colour-naming latencies were recorded. Participants were placed before a microphone that was connected to a woice level detector. This detector stopped the computer's clock at the initiation of the participant's vocal response. Like the first phase, the second phase of the subliminal condition consisted of $25 \mathrm{~ms}$ target pictures, 
immediately followed by $100 \mathrm{~ms}$ masks. The second phase of the supraliminal condition involved $75 \mathrm{~ms}$ target pictures followed by the same $100 \mathrm{~ms}$ mask that was used in the subliminal condition. Participants were asked to name the coloured dot in the mask as quickly as possible. After this Stroop-like task, headphones were re-attached and a second series of startle measurements were obtained (cf., phase 1). Again, it was stressed that participants should sit quiet and attend to the wall. During the fourth phase of the experiment, a second series of the colour-naming trials was presented (cf, phase 2). Once more, participants were instructed to name the colour as quickly as possible.

Following these 4 phases, participants in the subliminal condition underwent a forcedchoice identification task. This task consisted of 40 trials, during which participants were exposed to either $25 \mathrm{~ms}$ target slides followed by $100 \mathrm{~ms}$ masks or $25 \mathrm{~ms}$ masks followed by $100 \mathrm{~ms}$ masks. Participants had to indicate whether stimuli preceding the masks were real pictures or meaningless masks (cf., forced-choice identification task in the subliminal Stroop paradigm; e.g., Van den Hout et al., 1997). Participants were informed that there was a $50 \%$ chance of a real target picture being presented on each trial. They were instructed to guess when they were uncertain about the correct response. Finally, each target picture was presented supraliminally and participants in both conditions were asked to rate its emotional valence on $100 \mathrm{~mm}$ VASs. More specifically, they rated how much they liked each picture, how frightening they found each picture, and how aroused they were by each picture.

\section{Data analysis and reduction}

Data of two phobic patients were lost because they preferred not to complete the experiment. Data of one phobic and one control participant were lost due to technical failures. Furthermore, the records of 5 phobics and 3 controls were removed from the data set because they had too many unscorable eye blink startle responses (i.e., more than $15 \%$ of their responses).

Forced-choice identification data were employed to evaluate whether masked target pictures were truly subliminal. Thus, for each participant, forced-choice identifications were subjected to binomial calculations to analyze whether they significantly exceeded chance level (ie., 50\%).

Enotional VAS scores of the target pictures were log transformed to nomalize the distribution. For each VAS measure (i.e., pleasantness, fearfulness, and arousal), mean scores were subjected to separate 2 (Group: phobic vs control) $\times 4$ (Slide: phobic vs negative vs neutral vs positive) analyses of variance (ANOVAs), with repeated measures on the last factor.

Startle data were analyzed off line using a $60 \mathrm{~Hz}$ highpass filter. The digitized signal was then rectified and integrated (time constant: $20 \mathrm{~ms}$ ). Magnitude of the startle reaction was scored in arbitrary units (a.u.'s) in the $100 \mathrm{~ms}$ interval after probe onset. To enhance reliability, reflex magnitude was averaged over both recording sites (i.e., left eye, right eye). Trials with an unstable baseline constituted $5.9 \%$ of all trials. The missing startle 
values of these trials were estimated by averaging trials of the same affective valence and with the same probe interval. To normalize the distribution, magnitudes were square-root transformed. Mean startle magnitudes were subjected to a 2 (Group: phobics vs controls) $\times 2$ (Condition: subliminal vs supraliminal) $\times 4$ (Slide: phobic vs negative vs neutral vs positive) ANOVA, with repeated measures on the last factor.

Latencies of the colour-naming task were square-root transformed to nomalize the distribution. Latencies below $300 \mathrm{~ms}$ or above $3000 \mathrm{~ms}$ were deleted. Likewise, errors and outliers (i.e., latencies that were more than three standard deviations above each participant's mean) were not taken into account. The extent to which slide content interfered with latencies was calcullated by subtracting colour-naming latencies on neutral trials from colour-naming latencies shown on phobic or negative trials (cf., MacLeod \& Hagan, 1992). Between-group differences were evaluated by means of $t$-tests.

Results

Forced-choice identification data and affective judgments

Each participant in the subliminal condition gave 40 forced identifications. Binomial calculation indicates that the number correct identifications must be 27 before it significantly $[p<0.05]$ exceeds chance level (i.e., 50\%). In other words, when a participant correctly identified 27 slides or more, the masking procedure was not reliably effective in blocking the pictures from awareness. Therefore, participants who identified significantly above chance level (i.e., one control and three phobics) were removed from further analyses.

Table 1: Mean (log transformed) VAS ratings of spider phobics $(n=30)$ and controls $(n$ 22) for each category of target slides

\begin{tabular}{|c|c|c|c|c|c|c|c|}
\hline \multirow[b]{2}{*}{ Target } & \multirow[b]{2}{*}{ Group } & \multicolumn{2}{|c|}{ Pleasantness } & \multicolumn{2}{|c|}{ Fearfulness } & \multicolumn{2}{|c|}{ Arousal } \\
\hline & & $M$ & $S D$ & $M$ & $S D$ & $M$ & $S D$ \\
\hline \multirow[t]{2}{*}{ Phobic } & Phobics & 3.02 & 1.12 & 2.70 & 1.25 & 2.45 & 1.45 \\
\hline & Controls & -0.40 & 0.96 & -2.76 & 1.28 & -2.27 & 1.63 \\
\hline \multirow[t]{2}{*}{ Negative } & Phobics & 1.87 & 0.98 & 0.60 & 1.30 & 1.04 & 0.89 \\
\hline & Controls & 1.77 & 1.08 & 0.21 & 1.45 & 0.66 & 1.54 \\
\hline \multirow[t]{2}{*}{ Neutral } & Phobics & -0.60 & 1.04 & -3.37 & 1.17 & -2.57 & 1.16 \\
\hline & Controls & -0.95 & 1.09 & -3.27 & 0.87 & -2.56 & 1.27 \\
\hline \multirow[t]{2}{*}{ Positive } & Phobics & -3.02 & 1.18 & -3.89 & 0.63 & 1.05 & 1.90 \\
\hline & Controls & -2.98 & 1.26 & -3.73 & 0.86 & 0.83 & 1.50 \\
\hline
\end{tabular}

Note: higher scores on pleasantness, fearfulness, and arousal indicate a less favourable evaluation of the slides (i.e., less pleasant, more frightening, more arousal) 
Affective judgments of the target slides by spider phobics and controls are presented in Table 1. As can be seen, for all three VAS measures (i.e., pleasantness, fearfulness, and arousal), there was a main effect of Group $[F(1,50)$ 's $>27.0, p$ 's $<0.001]$. Similarly, for all dimensions, there was a main effect of Slide $[F(3,150)$ 's $>78.0, p$ 's $<0.001]$ and a significant interaction between Group and Slide $[F(3,150)$ 's $>31.0, p$ 's $<0.001]$. Post-hoc $t$-tests showed that the VAS ratings followed the expected pattern. For example, the phobic group rated spider slides as less pleasant, more frightening, and more arousing than other slides [all $t$ 's $>5.0$, all $p$ 's $<0.001$ ]. For the control group, spider slides and neutral slides did not differ in terms of the three VAS dimensions [Bonferroni corrected $p$ s $s>0.001$ ]. As a matter of fact, controls rated the phobic slides as more pleasant, less frightening, and less arousing than negative slides [Bonferroni corrected $p$ 's $<0.001$ ].

\section{Startle response magnitude}

Figure I shows the mean startle responses of spider phobics and controls to probed phobic, negative, neutral ${ }_{x}$ and positive slides presented subliminally (left panel) or supraliminally (right panel).
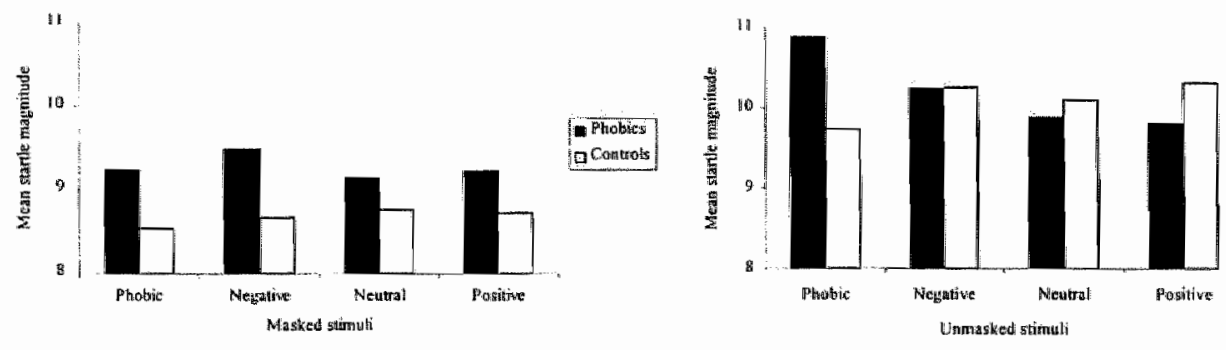

Figure 1: Mean square-root transformed eyeblink startle responses (in arbitrary units) in the masked (left panel) and unmasked (right panel) condition for spider phobics $(n=36)$ and controls $(n=37)$ for each category of target pictures

The overall Group $x$ Condition $\times$ Slide ANOVA revealed no significant main effect of Condition: $F(1,69)=2.32, p>0.1$. That is, startle magnitudes were not larger in the supraliminal condition than in the subliminal condition. In addition, no significant main effect of Group $[F(1,69)<1]$ or interaction effect of Group $x$ Condition $[F(1,69)<1]$ was found. Thus, spider phobics did not react with larger startles than controls. There was no significant main effect of Slide: $F(3,207)=1.14, p>0.3$. Neither was there a significant interaction between Condition and Slide: $F(3,207)=1.12, p>0.3$. However, there was a significant interaction between Group and Slide $[F(3,67)=6.71, p<0.001]$, and between Group, Slide, and Condition $[F(3,67)=3.89, p=0.01]$. Thus, phobics and controls showed a different response pattern to the slides.

To examine the origins of these interaction effects, subliminal and supratiminal 
conditions were analyzed separately. For the subliminal condition, neither a significant main effect of Group $[F(1,39)<1]$, nor a significant main effect of Slide $[F(3,117)=1.05$, $p>0.3]$ was found. There was no significant interaction between Group and Slide $[F(3,117)=1.67, p>0.1]$. That is to say, the critical interaction effect that would have indicated larger startle responses of phobics to specifically phobic slides did not occur. For the supraliminal condition, the ANOVA revealed neither a main effect of Group $[F(1,30)$ $<1]$, nor a main effect of Slide $[F(3,90)<1]$. However, the interaction between Group and Slide reached significance: $F(3,90)=5.41, p<0.01$. That is, the eyeblink response pattern of spider phobics differed from that of controls. To further investigate this effect, we subjected both groups to separate ANOVA's. For the phobic group, there was a significant effect of Slide $[F(3,48)=4.65, p<0.01]$ in the expected direction (i.e., fear potentiated startle), whereas for the control group such an effect was not evident $[F(3,42)=1.58, p>$ $0.2]$.

\section{Colour-naming latencies}

Table 2 shows the phobic and negative interference in the masked and unmasked condition. Interference scores for both phobic and negative stimulus trials were subjected to $t$-tests. Separate tests were performed for the subliminal condition and supraliminal condition. These tests yielded the following results: for the subliminal condition, no differences between phobics and controls were found [t(39)'s < 1]. Thus, phobics did not show more interference than controls when subliminal phobic or negative pictures preceded the coloured mask. For the supraliminal condition, phobics displayed a (marginally significant) larger phobic interference score than controls: $t(33)=1.98, p=0.06$. A similar result was found for the negative interference score, with phobics exhibiting larger interference than controls: $t(33)=2.00, p=0.05$. In other words, compared to controls, phobic patients in the supraliminal condition tended to display more interference in colour-naming when phobic pictures (i.e., spiders) or negative pictures (e.g., mutilated bodies) preceded the mask.

Table 2: Phobic and negative interference latencies (in ms; square-root transformed) in the masked and unmasked condition for spider phobics $(n=35)$ and controls $(n=41)$

\begin{tabular}{lllll}
\hline & \multicolumn{2}{c}{ Masked } & \multicolumn{2}{c}{ Unmasked } \\
& Phobics & Controls & Phobics & Controls \\
\hline Phobic interference & 0.139 & 0.109 & 0.821 & -0.114 \\
Negative interference & 0.145 & 0.064 & 0.279 & -0.188 \\
\hline
\end{tabular}

\section{Discussion}

According to OHman (1993), physiological fear responses can be initiated by pre-attentive information processing mechanisms that operate at a subcortical level. Öhman argues that 
these fast and unconscious information processing mechanisms underlie phobics" phenomenological experience of their fear as uncontrollable and irrational (see also Mayer, Merckelbach, \& Muris, 1999a; see Study 1). Evidence for Öhman's position comes from analog studies showing that spider- or snake-fearful undergraduates react with SCRs to subliminal spider or snake pictures, respectively (e.g., Ohman \& Soares, 1994). However, one limitation of these studies is that it remains unclear to what extent SCRs can be linked to fear or anxiety. There is convincing evidence indicating that the eyeblink startle component is more closely linked to the affective dimensions of fear and anxiety than the SCR (e.g., Balaban \& Taussig, 1994; Hamm et al., 1997). Therefore, the major aim of the present study was to examine whether subliminal phobic stimuli are able to provoke eyeblink startle potentiation.

The current study found no fear-potentiated startles in phobics after subliminal phobic slides. It should be noted that previous attempts to induce in phobic or fearful participants startle potentiation by presenting subliminal phobic stimuli also yielded disappointing (Globisch, Weike, \& Hamm, 1996) or inconchusive (Merckelbach et al ${ }_{\text {, }} 1995$ ) results. As a matter of fact, much the same is true for attempts to replicate the basic phenomenon (i.e., heightened SCRs to subliminal phobic stimuli) reported by Öhman and Soares (1994) (see Mayer, Merckelbach, De Jong, and Leeuw, 1999; see also Study 2).

The current study's failure to detect fear-potentiated startles under subliminal conditions raises the question whether it was plausible to anticipate such an effect in the first place. Admittedly, there is an important difference between traditional startle studies (e.g., Bradley et al., 1993; Lang et al., 1990; Vrana et al., 1988) and the current study. This difference has to do with the fact that in these traditional studies, startle reactions were obtained against a background of continuously present visual stimuli. In contrast, in the subliminal condition of the present study, probes were administered when visual stimuli had already disappeared. It may well be the case that fear-potentiated startle effects were interrupted because startle probes occurred in the absence of a fear-relevant background. Note, however, that Öman's theory is founded on the idea that fear responses may be initiated by subliminal phobic stimuli and once initiated, run their own course even after termination of the fear stimulus. The recent Globisch, Hamm, Esteves, and Ohnan (1999) study indicates that this line of reasoning is not entirely implausible. In that study, fearful and control participants were confronted with fear-relevant and fear-irrelevant pictures presented for $6 \mathrm{~s}$ or for $150 \mathrm{~ms}$. Acoustic probes were administered $120,300,800,1.300$, or $3.800 \mathrm{~ms}$ after slide onset. Results displayed that fearful participants showed potentiation of the eyeblink responses during the viewing of feared pictures. More importantly, this potentiation also occurred when feared stimuli were presented for only $150 \mathrm{~ms}$, and, consequently, probes were administered more than $3 \mathrm{~s}$ after slide offset.

These findings suggest that it might be possible to detect fear-potentiated startles in a subliminal set-up, an expectation that is not borne out by the data. Still, one could argue that interval times between target slides and startle probes were too long for subliminal phobic stimuli to initiate startle potentiation (see also Merckelbach et al., 1995). However, 
in one of their older experiments that relied on a highly similar design as the current study - albeit it with both shorter and longer interval times (i.e., 120, 300, 800, 1300, and 3800 ms) - Globisch and colleagues (1996) also failed to obtain fear-potentiated startles to subliminal phobic pictures. Taken together, the results of the present study and those of Globisch et al. (1996) suggest that it is hard to obtain fear-potentiated startle modulation under subliminal conditions. Possibly, this is inherent to subliminal set-ups. That is, it may well be the case that subliminal conditions raise visual vigilance of participants. Heightened visual vigilance, in turn, is known to reduce startle potentiation (e.g., Boelhouwer \& Blumenthal, 1993; Britt \& Blumenthal, 1993). However that may be, in the final analysis, it is hard to escape the conclusion that physiological fear responses (e.g., SCRs or startle potentiation) evoked under subliminal conditions, are at best fragile phenomena that depend on largely unknown parameters. This makes it difficult, if not impossible, to evaluate the merits of Öhman's theory.

A subsidiary aim of the present study was to examine whether subliminal pictorial phobic stimuli elicit cognitive interference in a Stroop-like set-up. Our failure to document startle potentiation during subliminal phobic trials, was paralleled by the absence of interference effects due to subliminal phobic cues. Again, this effect is by and large in line with findings from previous studies. Thus, for example, Lavy, Van den Hout, and Arntz (1993) and Merckelbach, Kenemans, Dijkstra, and Schouten (1993) reported that under supraliminal conditions, interference effects of pictorial phobic stimuli are much weaker than those of verbal phobic stimuli. Given the weak interference effects of pictorial stimuli, one can easily imagine that under subliminal conditions these effects disappear altogether.

Note that for the supraliminal conditions, the present study did find differences in interference effects between phobics and normal controls. That is, compared to normals, phobics were relatively slower in colour-naming after they had been exposed to phobic stimuli. Likewise, the current study did replicate a fear-potentiated startle response to supraliminal phobic or negative stimuli. Thus, supraliminal phobic or negative pictures were found to potentiate startle reflexes of phobics when acoustic probes were administered, while positive pictures attenuated the reflex. In contrast to the results typically obtained by Lang, Bradley, and Cuthbert $(1990 ; 1992)$, the present study found no evidence for such startle differentiation in the control group. However, the finding that phobic and negative pictures potentiated starlles in phobics, but not in control participants is in line with other studies. For example, Cook, Hawk, Davis, and Stevenson (1991) found a fear-potentiated startle in high-fear subjects, but not in low-fear subjects. Interestingly, Cuthbert. Bradley, and Lang (1.996) argued that negative affect modulates eyeblink startle responses only ander high arousal conditions. Under low arousal conditions, eyeblink startles would not differentiate between negative or positive material. Keeping in mind that the controls in the current study scored considerably lower on the arousal dimension (i.e., VAS scores) than did the phobics, it becomes understandable why the controls failed to exhibit a potentiated startle response. 
In conclusion, in the current study, subliminal phobic stimuli were not found to be able to elicit physiological fear responses. Neither did subliminal phobic stimuli elicit cognitive interference. The null findings of the subliminal condition stand in contrast to the effects in the supraliminal condition: supraliminal phobic stimuli did elicit larger startle responses and more cognitive interference in phobics than in controls. The present study's failure to obtain straightforward physiological and cognitive effects of subliminal phobic stimuli in phobics is, of course, difficult to reconcille with Öhman"s (1993) idea of fast, subcortical processing routines that are responsible for phobics immediate fear reactions to phobic cues. Apparently, then, physiological fear responses evoked by subliminal cues represent a fragile phenomenon. One could go even further and argue that while subliminal stimuli at best elicit small-scale effects, supraliminal stimuli are able to produce straightforward and robust effects. Obviously, from a psychopathological point of view, the latter are more interesting. After all, psychopathology is about strong emotions and radical behaviour. 



\section{Study 4}

\section{Do differential SCRs to masked fear-relevant stimuli depend on stimulus size? *}

\section{Summary}

To examine whether picture size is a critical factor in obtaining differential skin conductance responses (SCRs) to degraded phobic stimuli, the present experiment had 29 spider-fearful and 29 non-fearful women exposed to small (i.e., $38 \times 25 \mathrm{~cm}$ ) and relatively large (i.e., $90 \times 58 \mathrm{~cm}$ ) backwardly masked fear-relevant (i.e., spider) and neutral (i.e., snake, mushroom, and flower) slides, while recording their SCRs to the slides. Results showed that picture size was not a critical factor in obtaining differential SCRs to masked fear-relevant slides. In fact, neither large nor small degraded fear-relevant pictures elicited differentiall SCRs in spider-fearful women. Thus, no evidence was found to suggest that a pre-attentive analysis of threatening stimuli is sufficient for a physiological fear response to occur. This casts doubts on the idea that pre-attentive processes heavily contribute to small animal phobias.

\section{Introduction}

According to the Diagnostic and Statistical Manual (DSM-IV, APA, 1994), a phobia is a persistent and unreasonable fear of a certain object or situation. The phobic patient readily admits that his or her lear response is irrational, but at the same time (s)be perceives it as involuntary (see also Mayer, Merckelbach, \& Muris, 1999a; see Study 1). According to Ohman (1994), the involuntary nature of phobias can be explained by pre-attentive information processing mechanisms. Ohman argues that, as a result of evolution, threatening information can be located very fast and without focus of attention. Consequently, a fear response can be set in motion immediately and even before the threatening object is consciously recognized. Phobic fears would represent radical manifestations of such unconsciously mediated anxiety. By this view, the desynchrony between automatically induced physiological fear and conscious processing would explain why the patient experiences his or her phobic reactions as uncontrollable.

In their crucial study, Öhman and Soares (1994) tested this hypothesis by presenting presumably subliminal (i.e., $30 \mathrm{~ms}$ and backwardly masked) fear-relevant and control stimuli to spider-fearful $(n=16)$, snake-fearful $(n=16)$, and non-fearful control $(n=16)$

\footnotetext{
* Submitted for publication
} 
subjects while measuring their skin conductance responses (SCRs). Spider-fearfuls were found to react specifucally with large SCRs to subliminal spider pictures, snake-fearfuls reacted specifically with large SCRs to subliminal snake pictures, and non-fearful controls failed to react specifically to any of the pictures. Thus, although subjects were exposed to presumably subliminal (i.e., pre-attentive) stimuli, they responded selectively to their feared stimulus. These findings provide sirong support for the idea that a pre-attentive analysis of fear-releyant stimuli is sufficient to elicit a physiological fear response. A recent study from our lab sought to provide a conceptual replication of these findings (Mayer, Merckelbach, De Jong, \& Leeuw, 1999; see Study 2). Following the procedure of Öhman and Soares (1994), we measured SCRs in 47 spider phobic patients and 41 control participants who were exposed to masked phobic and neutral pictures. Masked pictures had a duration of 30 , 20 , or $15 \mathrm{~ms}$, and were always backwardly masked for $100 \mathrm{~ms}$. In contrast to the findings of Öluman and Soares, our study failed to obtain differential responding to masked phobic stimuli. This discrepancy is remarkable given the large sample size and therefore strong statistical power of our study.

However, one technical difference between the Öhman and Soares (1994) study and our study (Mayer et al., 1999) has to do with the size of the presented target pictures. Whereas the Öhman and Soares study relied on small presentations (i.e., $21 \times 14 \mathrm{~cm}$ ), we used relatively large presentations (i.e., $110 \times 70 \mathrm{~cm}$ ). Although participants in our study were seated at a larger distance from the projected slides than in the Öhman and Soares study ( 2 $m$ versus $1 \mathrm{~m}$ ), the visual angle in the latter study was smaller. Thus, one could argue that in our study, presentation times were too short to allow full foveal vision. This, then, may have contributed to our failure to obtain differential SCRs to masked phobic pictures.

To examine whether size of the phobic target material is crucial for obtaining differential psychophysiological effects in fearful or phobic subjects, the present study manipulated picture size. That is, spider-fearful and non-fearful control subjects were exposed to degraded fear-relevant and neutral target material that had either relatively large or small proportions. Picture size was manipullated within-subjects.

Method

\section{Participants}

Participants were 29 spider-fearful women (mean age: 32.6 years, range 18 - 56 years) and 29 non-fearful control women (mean age: 32.9 years, range $19-53$ years). Participants were recruited through advertisements in local newspapers that invited women extremely fearful of spiders and women without spider fear to participate in our research project. Fearfuls and controls were carefully screened and were matched for age $[t(56)<1]$ and education [means being 8.0 and 8.4 , respectively, with $l=$ primary school and $I 1=$ university; $t(56)<1]$. Participants were paid the equivalent of 12 euro's for their participation. 


\section{Assessment and apparatus}

Subjective fear of spiders was measured with the Fear of Spiders Qnestionnaire (FSQ: Szymanski \& O'Donohue, 1995; see also Muris \& Merckelbach; 1996). Participants also underwent a Behavioural Approach Test (BAT; for details see De Jong, Visser, \& Merckelbach, 1996). Furthermore, anxiety and depression levels were measured with the Spielberger State Trait Anxiety Inventory (STAI; Spielberger, Gorsuch, \& Lushene, 1974) and the Beck Depression Inventory (BDI; Beck \& Steer, 1987), respectively. Target stimuli were $34 \times 22 \mathrm{~mm}$ colour slides of spiders, snakes, mushrooms, and flowers. All pictures were clearly recognizable. Masks were randomly cut, reassembled, and rephotographed pictures of snakes, mushrooms, and flowers (cf., Öhman \& Soares, 1994). SCRs were measured with a Schwartzer Skin Conductance Coupler (type EDA 48). The method of constant voltage $(0.5 \mathrm{~V})$ was used. The coupler was connected to two Beckman $\mathrm{Ag} / \mathrm{AgCl}$ electrodes (diameter $8 \mathrm{~mm}$ ) which were filled with isotonic electrode gel. Electrodes were attached to the middle phalanges of the second and third fingers of the non-dominant hand. Respiration was measured with a Schwartzer respiration belt which was fastened around the waist of the participant and connected to a Picker-Schwartzer EDI4 Polygraph. Both respiration and SCRs were recorded on a Picker-Schwartzer ED14 Polygraph and sampled $(1000 \mathrm{~Hz})$ with a National Instruments AT-mio $16 \mathrm{~A} / \mathrm{D}$-converter.

\section{Design}

Main factors in the present study were group (between-subjects: spider-fearful vs control), picture category (within-subjects: spider vs snake vs mushroom vs flower), and picture size (within-subjects: small vs large). Within each of the 4 picture categories, 5 different slides were used (e.g., there were 5 different spider slides, and so on). All pictures were shown twice and this was true for large and for small target presentations. Thus, participants were confronted with 40 small and 40 large masked pictures. Sizes of small and large pictures were $38 \times 25 \mathrm{~cm}$ and $90 \times 58 \mathrm{~cm}$, respectively. Projected images were observed from a 2 $\mathrm{m}$. distance. Pictures were presented in a block of small pictures and a block of large pictures that were counterbalanced. That is, half of the subjects started with small pictures followed by large pictures, while the other half had the reverse order. Furthermore, 4 different sequences for picture presentation were used. Picture sequences varied in a quasirandom fashion. That is, no more than 2 successive presentations of the same slide type occurred. Across block 1 (e.g., small presentations) and block 2 (e.g., large presentations), orders were held constant. In addition, there were 5 different, but highly similar masks. All masks were presented 8 times per picture size. Mean inter-trial interval was 26 s.

\section{Procedure}

Participants were seated in a sound proof, dimly lit, electrically shielded chamber. The apparatus was located in an adjacent room. Targets and masks were flashed through a small window and presented on a white wall approximately $2 \mathrm{~m}$. in front of the participants. Subjects were told that the purpose of the experiment was to measure physiological 
responses to different types of briefly presented pictures. They were also informed that a soft noise would signal the occurrence of a picture. They were asked to sit quietly and focus on a cross on the wall where the centre of the picture would appear, as soon as they heard the noise signal. Then, respiration belt and electrodes were attached. In the $4 \mathrm{~s}$ period before and $6 \mathrm{~s}$ period after onset of the target pictures, respiration and SCRs were measured. After the first block, participants were asked to fill out a set of questionnaires (among which the STAI and BDI). This took 15 minutes. Following this, participants were exposed to the second block of subliminal presentations (i.e., same pictures, other picture size). After this second block of trials, subjects were asked during an informal interview whether they had seen recognizable pictures during the preceding trials and if so, whether they could specify them. Next, the two blocks of trials were presented once more and forced choice awareness checks were carried out, for each black separately. Participants were informed that during previous trials, they had been confronted with a target picture (a spider, snake, mushroom, or flower) followed by a meaningless mask. Photographs of each stimulus category and a mask were shown as an example. Participants were now instructed to indicate on each trial what type of target picture they had been exposed to. Participants were stressed to guess if they were not sure about their answer. Throughout the SCR and forced-choice awareness check blocks, target stimuli (i.e., spiders, snakes, mushrooms, and flowers) had a duration of $30 \mathrm{~ms}$. Target stimuli were immediately followed by a mask of $100 \mathrm{~ms}$ duration. After the experiment proper, participants underwent a BAT.

\section{Data reduction and analysis}

Forced choice identification data indicate whether subjects were able to identify the target stimuli above chance (i.e., $25 \%$ ). Both percentage hits (true identifications) and percentage false alarms (false positive identifications) must be taken into account to determine whether subjects are able to identify correctly above chance (Snodgrass, Levy-Berger, \& Haydon, 1985). For example, a 100\% hit level for spider targets that is accompanied by $100 \%$ false alarms for spiders (i.e. identifying every trial as a spider trial) indicates random performance. Accordingly, for each picture category a within-subject comparison has to be made between percentage correct identifications and percentage false alarms. Thus, to determine whether participants identified masked pictures above chance, percentage hits and percentage false alarms were subjected to a 2 Group (between-subjects: spider-fearful / control) $\times 4$ Picture (within-subjects: spider/ snake / mushroom / flower) $\times 2$ Size (withinsubjects: large / small) $\times 2$ Awareness (within-subjects: percentage hits / percentage false alarms) Analysis of Variance (ANOVA). In case of significant main or interaction effects, additional $i$-tests were carried out.

SCR magnitude was measured by scoring the maximal deflection in conductance (in $\mu \mathrm{S}$ ) starting in the 1 to $4 \mathrm{~s}$ interval after onset of each target picture. As even minimal conductance changes could reliably be detected by computer, no minimum SCR value was specified. Following the criteria of Stern, Ray, and Davis (1980), SCRs associated with respiratory irregularities were eliminated from the data set. As a result, $0.9 \%$ of the trials 
was excluded. In order to normalize the distribution, SCRs were square-root transformed.

SCR data were subjected to a 2 Group (spider-fearful / control) $\times 4$ Picture (spider / snake / mushroom / flower) $\times 2$ Size (small / large) ANOVA, with repeated measures on the last two factors. In case of significant main or interaction effects, separate ANOVA's and follow-up $t$-tests were carried out.

Results

\section{Questionnaires and BAT}

Paired $t$-tests showed that fearfuls and controls had similar depression levels [mean BDI scores being 8.5 and 6.5 , respectively: $t(56)=1.16, p>0.2]$. However, fearful participants had higher state anxiety levels than controls [mean STAI scores being 41.5 and 29.2, respectively: $t(52)=4.0, p<0.001$ ]. Mean scores on the Fear of Spiders Questionnaire confirmed that spider-fearfuls were truly fearful whereas controls were not [means being 84.7 and 1.2, respectively: $t(56)=17.2, p<0.001]$. Comparable results were obtained with the Behavioural Approach Test [means being 3.0 and 7.9 , respectively, adjusted $t(29.3)=$ $15.3, p<0.001$. Note that a high BAT score indicates more approach behaviour.

\section{Identification dato}

Informal interviews revealed that there were 4 participants who claimed that they had seen a spider, 3 participants who mentioned a snake, and 10 participants reporting mushrooms and flowers. Thus, a substantial part of the participants (i.e., 29\%) evidenced, what has been termed, 'subjective awareness' (e.g., Cheesman \& Merikle, 1986). As our hypothesis concems pre-attentive processing, the data of these participants were excluded from the analyses. Consequently, ANOVAs were carried out on data of 20 fearful and 22 control participants who were subjectively unaware of the presented stimuli.

Forced-choice identification scores of fearful and control subjects are shown in Table 1. The omnibus ANOVA revealed no main effect of Group: $F(1,40)<1$. However, there was a significant main effect of Awareness: $F(1,40)=27.6, p<0.001$. Overall, percentages hits exceeded percentages false alarms. The interaction of Group and Awareness did not attain significance: $F(1,40)<1$. Neither was there a main effect of Size $[F(1,40)<1]$ or an interaction between Group and Size $[F(1,40)<1]$. Interestingly, a significant main effect of Picture was found: $F(3,120)<0.01$. Post-hoc $t$-tests showed that for flower pictures, percentages hits and false alarms were larger than for snake pictures [ $t(41)=2.1, p<0.05]$ and spider pictures $[t(41)=2.8, p<0.01]$. Similarly, percentages hits and false alarms for mushrooms were larger than those for either snakes $[t(41)=3.2, p<0.01]$ or spiders $[t(41)$ $=3.7, p=0.001]$. The interaction between Group and Picture did not reach significance $[F(3,120)<1]$. Furthermore, no significant interaction emerged between Awareness and Size $[F(1,40)=3.5, p=0.07]$, or between Group, Awareness, and Size $[F(1,40)<1]$. Thus, small pictures were not better identified than large pictures. However, the interaction of 


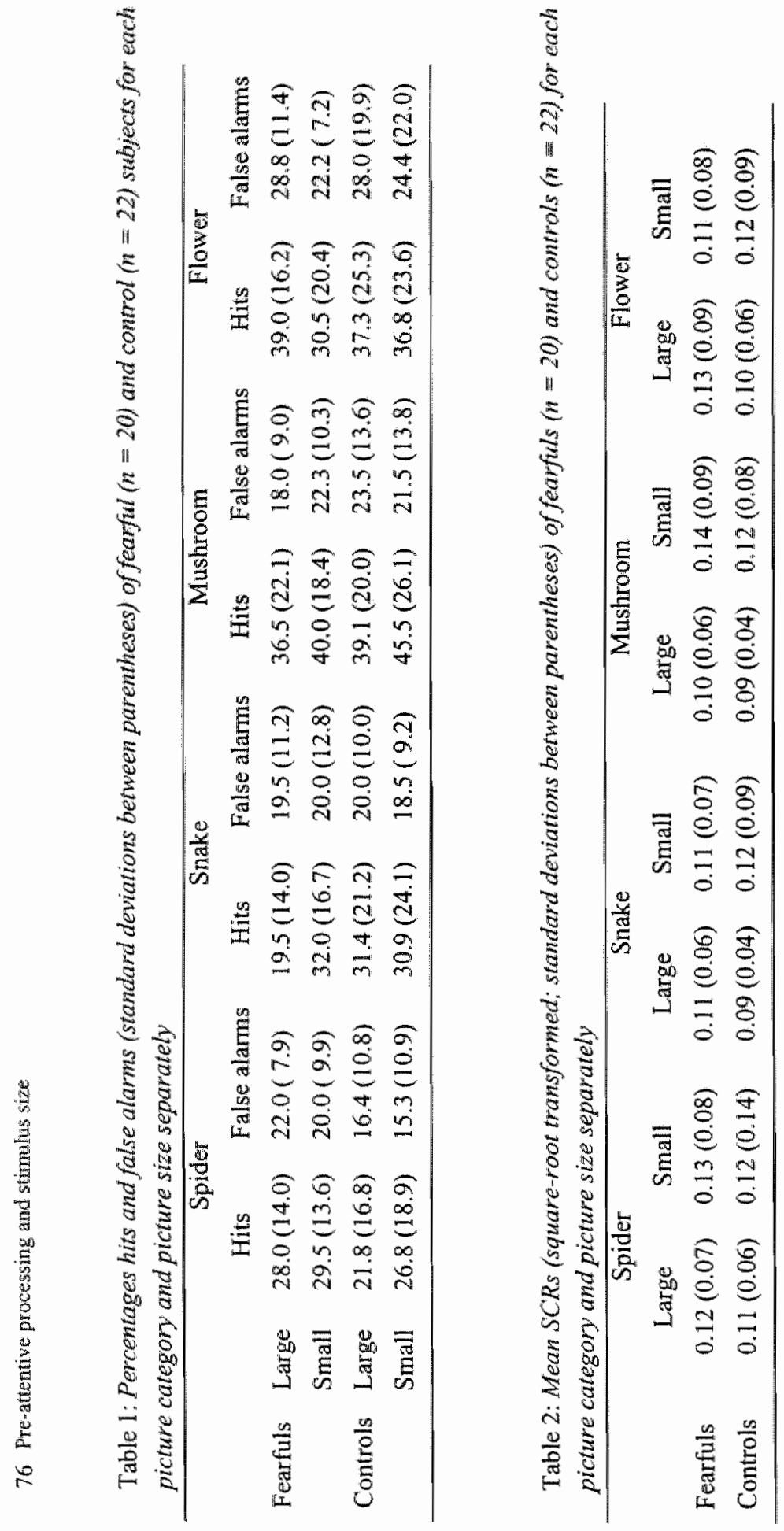


Awareness and Picture did reach significance: $F(3,120)=7.1, p<0.001$. In other words, some pictures were identified more often than others. Post-hoc $t$-tests showed that the discrepancy between hits and false alarms for mushrooms was significantly larger than that for the other pictures [all $i(41)$ 's $>2.8$, all $p$ 's $<0.01$ ], indicating that mushroom pictures were more often consciously perceived than the other pictures. This effect was not modulated by Group, as the Group by Awareness by Picture interaction did not attain significance: $F(3,120)<1$. Furthermore, the interaction of Size and Picture was significant $[F(3,120)=5.1, p<0.01]$ due to the fact that compared to large presentations, small mushroom presentations produced heightened hits and false alarms while the opposite pattern was true for flowers. This effect was modulated by Group since the Group by Size by Picture interaction $[F(3,120)=2.9, p<0.05]$ reached significance. This effect was not modulated by Awareness since the Awareness by Size by Picture interaction $[F(3,120)<$ 1] failed to reach significance. Finally, no significant interaction was found between Group, Awareness, Size, and Picture: $F(3,120)=2.2, p=0.09$. Thus, in conclusion, "objective awareness criteria' indexed by the forced-choice task indicated that mushroom pictures were more often consciously perceived than the other pictures, but this effect was not modulated by Group or Size.

SCRs

Mean SCRs of spider-fearful and control participants are shown in Table 2. The omnibus ANOVA did not yield a significant main effect of Group $[F(1,40)<1]$ or Picture $[F(3,120)$ $<1]$. Neither did the critical interaction between Group and Picture reach significance: $F(3,120)<1$. Thus, there was no differential SCR to spider pictures in the fearful group. Furthermore, no significant main effect emerged for Size: $F(1,40)=1.4, p>0.2$. Also, no significant interactions were found between Group and Size $[F(1,40)<1]$, Picture and Size $[F(3,120)=2.0, p>0.1]$, or Group, Picture, and Size $[F(3,120)<1]$. This pattern indicates that size of target presentations is not a critical factor in obtaining differential responses to masked fear-relevant stimuli. In fact, such a pattem did not show up in both size conditions.

\section{Discussion}

The main results of the present study can be summarized as follows. To begin with, a substantial part of participants indicated to be subjectively aware of some of the masked 30 $\mathrm{ms}$ pictures. After excluding these participants from the analyses, the forced-choice identification data indicated that some backwardly masked pictures still did not remain subliminal in the strict sense of the word (i.e., abjective threshold; see Cheesman \& Merikle, 1986). More specifically, some pictures (especially mushrooms) were detected above chance and this was not modulated by group or size. Thus, both spider-fearfuls and controls identified small and large (mushroom) pictures above chance. This indicates that the backwardly masked $30 \mathrm{~ms}$ presentations of neutral and fear-relevant stimuli used in 
previous studies (e.g., Öhman \& Soares, 1994) were not necessarily subliminal. Secondly, no evidence was found to suggest that size of target pictures is a critical factor in obtaining differential SCRs to masked fear-relevant pictures. Thirdly, spider-fearfuls were not found to display differential SCRs to large or small backwardly masked spider pictures. In conclusion, the present study failed to find support for Öhman's theory about pre-attentive processing of phobic stimuli and there was no hint that this failure was due to the size of the masked fear-relevant stimuli.

It could be argued that the present study must be silent about pre-attentive information processing of threatening material because participants seemed to be aware of at least some target pictures. After all, identifying pictures above chance along with a reduced rate of false positives means that the objective threshold of awareness has been crossed (Cheesman \& Merikle, 1986). However, participants included in the pertinent analyses were at least subjectively unaware of the target pictures. In this context, it can be argued that "... stimuli presented at energy levels between the objective and subjective threshold are unconsciously processed." (Cheesman \& Merikle, 1986, p.345). Thus, it seems fair to conclude that in the final sample, all target pictures fulfilled the criteria for degraded (i.e., unconscious) stimulus material. Nevertheless, no evidence was found for the idea that degraded fearrelevant input does elicit stronger SCRs in fearful than in control subjects.

Öhman's theory of the pre-attentive origins of phobic fear is predicated on the idea that phobic objects represent evolutionary challenges that once required immediate action. Implicit in this evolutionary approach is the idea that spiders, snakes, and other small animals that may serve as objects of animal phobia, once were dangerous to our prehistoric ancestors. However, other authors (e.g., Davey, 1992; 1995; Matchett \& Davey, 1991; Merckelbach, De Jong, Arntz, \& Schouten, 1993) have argued that small animal phobias can be better understood in terms of a disease-avoidance model. By this view, specific phobias and fears often pertain to animals that are perceived as disgusting rather than dangerous. The disgust-evoking status of these animals would derive from their association with disease, dirt, and/or contamination. In line with this, Matchett and Davey (1991) noted that heightened disgusu/contamination sensitivity is related to a stronger fear of animals that generally do not attack or harm humans (e.g., spider, cockroach). These authors also found that disgusticontamination sensitivity is not linked to fear of predatory animals (e.g., tiger, shark). Note that this category of animals is seldomly the object of a specific phobia.

Apart from this theoretical issue, there are indications from other sources that cast doubts on the tenability of Öhman's theory. That is, the findings of the present study add to several other studies (see Globisch, Weike, \& Hamm, 1996; Mayer, Merckelbach, De Jong, \& Leeuw, 1999; see Study 2; Mayer, Merckelbach, \& De Jong, 1999a; see Study 3; Mayer, Merckelbach, \& Muris, 1999b; see Study 5) that were unable to cross-validate the basic phenomenon reported by Öhman and Soares (1994), namely that the physiological component of fear can be activated at a pre-attentive level of information processing. As things stand, it is hard to escape the conclusion that this phenomenon critically depends on subtle parameters. Obviously, stimulus size of masked target pictures do not represent such 
Pre-attentive processing and picture size 79

a parameter. Which parameters are involved in the phenomenon is completely unknown. Unless these parameters are fully understood, it is difficult to assess the explanatory power of Öhman's (1994) account of the 'irrationality' of phobias. 


\section{Study 5}

\section{Spider phobic children do not react with differential skin conductance responses to masked phobic stimuli *}

\section{Summary}

In the present study, spider phobic children $(N=22)$ were exposed to subliminal presentations of spiders, snakes, and mushrooms, while skin conductance responses (SCRs) were measured. In addition, pre- and post-treatment symptom severity data were obtained. As a group, spider phobic children did not react with differential SCRs to masked phobic pictures. In addition, no convincing evidence was found to suggest that individual variation in differential SCRs to phobic stimuli is linked to pre-treatment symptom severity or therapy outcome. These findings cast doubts on the idea that phobics' phenomenal experience of their fear as irrational and uncontrollable is a result of pre-attentive physiological fear activation.

\section{Introduction}

Phobias are unreasonable and intense fears of certain objects or situations (DSM-IV, American Psychiatric Association, 1994). Phobic patients readily admit that their fear is unreasonable but at the same time they experience their fear responses as uncontrollable (see also Mayer, Merckelbach, \& Muris, 1999a; see Study 1). According to Öhman (1994), the uncontrollable character of phobic fear results from pre-attentive information processing mechanisms. By this view, phobic information is initially processed by fast and automatic subcortical processes and so, the initiation of fear responses may occur outside awareness. At the time the phobic patient consciously identifies the phobic object, (s)he already feels bodily sensations.

In their experiments, Öhman and Soares $(1993,1994)$ found support for the notion that threatening stimuli may elicit fear responses before conscious perception comes into play. For example, Öhman and Soares (1994) confronted 16 spider-fearful, 16 snake-fearful and 16 non-fearful undergraduates with very brief presentations (i.e., $30 \mathrm{~ms}$ ) of threatening (i.e., spiders and snakes) and non-threatening (i.e., flowers and mushrooms) pictures. These briefly presented pictures were immediately followed by $100 \mathrm{~ms}$ meaningless pictures (i.e., masks). This masking procedure prevented the subjects from perceiving the target stimuli

\footnotetext{
* This study appeared as an article (Mayer Merckelbach, \&uris) in the Jownal of Pychoparhology and Behovioural Assessment, 21 (1999), $237-248$.
} 
consciously (cf., backward masking; see Marcel, 1983). Although subjects were unable to consciously recognize the presented stimuli, spider-fearful students reacted specifically with large skin conductance responses (SCRs) to masked spider slides, snake-fearful students reacted specifically with large SCRs to masked snake slides, and non-fearful students did not respond differentially to any of the slides. These findings seem to indicate that pre-attentive analyses of threatening stimuli may elicit the physiological component of fear responses (but see Globisch, Weike, \& Hamm, 1996; Mayer, Merckelbach, De Jong, \& Leeuw, 1999; see Study 2; Mayer, Merckelbach, \& De Jong, 1999a; see Study 3).

According to Öhman (1994), pre-attentive information processing of threatening stimuli is an evolutionary based phenomenon. That is, a rapid detection of threat stimuli that functions largely independently of the momentary direction of attention is thought to have survival value. Similarly, effective defence is believed to depend on short latencies. Following this line of reasoning, it is tempting to assume that evolutionary selection has biased the neuronal mechanisms that underly defence and avoidance behaviour in favour of false alarms. Thus, to guarantee that defence or avoidance is elicited in potentially dangerous situations, the information processing system sometimes evokes false alarm reactions to stimuli that subsequently turn out to be harmless (LeDoux, 1994). Such false alarm responses may be understood as "irrational anxiety" (Öhman, 1994).

It is a well-established fact that most specific phobias have their onset in childhood (e.g., Öst, 1987). So, if the evolutionary analysis of phobias provided by Öhman (1994) and LeDoux (1994) is correct, one would expect that the fast and automatic processing of phobic stimuli is also evident in young phobic children. The fact that adults with a clinical phobia or intense fear react with a physiological response to degraded phobic stimuli can, of course, be taken as evidence to support an evolutionary interpretation. Alternatively, this phenomenon may reflect a fear responding system that has become proceduralized due to extensive learning experiences with the phobic object. Compared to adults with specific phobias, children with specific phobias are much closer to the onset of their anxiety disorder and, thus, will not have had many learning experiences yet. The case for an evolutionary interpretation would thus be much stronger if it could be shown that automatic and pre-attentive reactions to degraded phobic stimuli can also be documented in phobic children. The current study employed the paradigm of subliminal presentations of phobic pictures in order to explore whether phobic children display pre-attentive information processing of threatening stimuli. The second goal of the present study has to do with the clinical ramifications of fast and pre-attentive fear processing. If pre-attentive fear processing underlies the phenomenal experience of phobias as uncontrollable, one would expect that children who exhibit a relatively strong version of this type of fear processing have more severe fear symptoms and are more difficult to treat compared to children who do not display such a strong version of this type of fear processing. 
Method

\section{Children}

Twenty-two spider phobic children (all Caucasian girls; mean age: 11.6 years, range 9-14) participated in the study. Although the majority of the girls and their parents seemed to come from the middle-class, no exact information on the socio-economic status was available. Participants were recnuited via articles in local newspapers in which children (and their parents) were invited to participate in the Spider Phobia Project for Children at Maastricht University in return for 'free' treatment. Children were only included if they' fulfilled DSM-III-R criteria for specific phobia, animal type (APA, 1987), and if no comorbid disorders were present. Diagnoses were made by a senior psychologist who interviewed one of the children's parents using the Diagnostic Interview Schedule for Children (DISC; National Institute of Mental Health, 1992).

Mean score on the short 15-item version of the Spider Phobia Questiomaire for Children (SPQ-C; Kindt, Brosschot, \& Muris, 1996) was $9.75(S D=2.0)$, which comes close to the mean score of spider phobic children found in previous studies (e.g., Muris, Merckelbach, Holdrinet, \& Sijsenaar, 1998). In addition, fear of spiders was measured with a Behavioural Approach Test (BAT) and the Self Assessment Manikin (SAM; Hodes, Cook, \& Lang, 1985). The BAT was used to assess children's actual avoidance of spiders. During this test, children were seated behind a large table (ie, $2 \mathrm{~m}$ ) with at the end a movable glass jar containing a medium-size live spider. They were instructed to approach the spider in a stepwise manner. BAT performance was scored on a 10 -point scale $(1=$ spider still at $2 \mathrm{~m}$ distance, $10=$ spider walking on the hand). Thus, a high BAT score reflects more approach behaviour (i.e., less fear). The mean score on the pre-treatment BAT was 3.95 (SD $=2.4$ ); none of the girls was able to touch the spider. On the Self Assessment Manikin participants indicated how they felt (affect: 1 = very positive; 9 -very negative), how anxious they were (anxiety: 1 = not at all anxious; 9 = very anxious), and how powerfil they were (power: 1 = extremely powerful; $9=$ not at all powerful) during the $\mathrm{BAT}$ confrontation with the spider. A total SAM score was calculated, ranging from 3 to 27 , with higher scores reflecting higher levels of spider fear. The mean score of the phobic girls on the SAM was $21.20(S D=3.3)$. Again, BAT and SAM scores were comparable with those found in earlier studies (e.g., Muris et al., 1998).

\section{Stimulus materials and apparatus}

Fifteen colour slides ( $22 \times 34 \mathrm{~mm}$ ) were taken from the International Affective Picture System (LAPS; Lang, Öhman, \& Vaitl, 1988). There were 5 pictures of spiders (i.e., phobic stimuli), 5 pictures of snakes (i.e. fear-relevant stimuil), and 5 pictures of mushrooms (i.e., fear-irrelevant stimuli). Masks consisted of reassembled and rephotographed pieces of these pictures (cf., Öhman and Soares, 1993).

Targets and masks were projected by two Kodak Carousels (Ektapro) equipped with Compur high-speed shutters (EVS-3). This apparatus was located in a room adjacent to the 
sound-attenuated experimental room. Pictures were projected on a white wall approximately $1.5 \mathrm{~m}$ in front of the child. To ensure that masks overlapped target pictures, the size of the mask $(108 \times 70 \mathrm{~cm})$ was slightly larger than the size of the target picture $(100 \times 65 \mathrm{~cm})$. A low-intensity auditory probe signalled the onset of each new trial.

Using the method of constant voltage $(0.5 \mathrm{~V}$ ), skin conductance responses (SCRs) were recorded with a Schwartzer Skin Conductance Coupler (type EDA 48). The coupler was connected to two Beckman $8 \mathrm{~mm} \mathrm{Ag} / \mathrm{AgCl}$ electrodes that were filled with isotonic electrode gel. Electrodes were attached to the thenar and hypothenar eminences of the child's non-dominant hand. Respiration was measured with a Schwartzer respiration belt fastened around the waist of the child. The respiration belt was connected to a PickerSchwartzer ED14 Polygraph. Both SCRs and respiration were recorded on a PickerSchwartzer Polygraph and sampled $(1000 \mathrm{~Hz})$ with a National Instruments AT-mio $16 \mathrm{~A} / \mathrm{D}$ converter.

A Compaq $48633 \mathrm{mHz}$ personal computer controlled the shutters as well as the presentation of warning tones, slides, and masks. A second Compaq 486 computer was used for on-line storage of SCR and respiration data.

\section{Design}

The fifteen slides were presented twice. Accordingly, each child was confronted with 30 target pictures (i.e., 10 phobic, 10 fear-relevant, and 10 fear-irrelevant stimuli). Target pictures had a duration of $30 \mathrm{~ms}$ and were immediately followed by a $100 \mathrm{~ms}$ mask (stimulus onset asynchrony $=30 \mathrm{~ms}$ ). Mean intertrial interval was $20 \mathrm{~s}$ (range $19-21$ ). Sequence of the 30 target pictures was counterbalanced and varied in a quasi-random order with the restriction that no more than two successive presentations of the same slide type occurred.

\section{Procedure}

The experiment proper was carnied out before the children underwent behavioural treatment. Children came to the laboratory in the company of their parents; but were tested individually. They were seated in a dimly lit, sound-attenuated room. After cleaning the thenar and hypothenar with distilled water, electrodes were attached and a respiration belt was put around the waist of the child. Children were told that 30 slides would be presented very fast and that they had to sit quiet and watch carefully. They were instructed that a warning tone was presented $4 \mathrm{~s}$ before onset of the target picture. In the $4 \mathrm{~s}$ before and $6 \mathrm{~s}$ after onset of the target pictures, SCRs and respiration were measured. After children had been exposed to the 30 slides, electrodes and respiration belt were removed and a forcedchoice identification task was carried out. That is, children were confronted with 45 masked pictures of spiders, snakes, and mushrooms. Children were asked to identify the category to which each picture belonged. They were encouraged to guess if they were unsure about the correct response.

After the experiment, children completed the short version of the SPQ-C. Then, they 
were taken to another laboratory room where they underwent the BAT. Furthermore; the SAM was completed. These scores were the pre-treatment scores. Next, children were treated with a combination of eye movement desensitisation and reprocessing (EMDR) and exposure in vivo. In total, treatment lasted for about 3 hours. The effects of the interventions have been described in detail elsewhere (i.e., Muris, Merckelbach, Van Haaften, \& Mayer, 1997). It is important to note that the interventions, in particular the exposure in vivo, resulted in substantial improvements on the symptom measures. Immediately following treatment, children underwent a post-treatment BAT and filled out a post-treatment SAM as well as a post-treatment SPQ-C.

\section{Data reduction and analysis}

Because of equipment failures, data of two children were missing. The forced-choice identification data indicate whether children were able to identify the target pictures above chance (i.e., above $33 \%$ ). To evaluate identification performance, both percentages hits and false alarms should be taken into account (Snodgrass, Levy-Berger, \& Haydon, 1985). Thus, subjects are not performing above chance until percentage hits exceeds both chance level (i.e., 33\%) and percentage false alarms. To determine whether such a pattern occurred, forced-choice data were subjected to a 3 (Picture: spider/snake/mushroom) $\times 2$ (Awareness: hits / false alarms) Analysis of Variance (ANOVA), with repeated measures on both factors.

SCR magnitude was seored as the maximal deflection in conductance (in $\mu S$ ) starting in the 1 to $4 \mathrm{~s}$ interval after onset of the target picture. As even extremely subtle changes could reliably be detected by computer, no minimum scorable value was specified. SCRs were not scored when a trial was accompanied by respiratory irregularities (Stern, Ray, \& Davis, 1980). In order to normalize the distribution, SCR data were square-root transformed. Following this, SCRs were averaged over 5 trials for spider slides, snake slides, or mushroom slides (i.e., blocks of 5 trials). Mean scores were subjected to a 3 (Pictures: spiders / snakes / mushrooms) x 2 (Blocks of five trials) ANOVA, with repeated measures on both factors.

\section{Results}

\section{Forced-choice idenification data}

Data of the forced-choice identification task are summarized in Table 1. Percentages hits and percentages false alarms are shown separately. The ANOVA did neither reveal a significant main effect of Picture $[F(2,38)<1]$ nor a significant interaction of Picture $\mathrm{x}$ Awareness $[F(2,38)=1.17, p=0.32]$. Thus, picture categories did not differ with regard to any of the identification parameters. However, there was a main effect of Awareness: $F(1,19)=39.7, p<0.001$, due to the fact that percentages false alarms were significantly larger than percentages hits. This indicates that pictures were not identified abowe chance. 
SCRs

Mean SCRs of the spider phobic children are summanized in Table 2. The ANOVA did not yield a significant main effect of Picture $F(2,38)<1$. Similarly, the interaction between Picture and Block did not attain significance: $F(2,38)<1$. Thus, no eviderice was found to suggest that spider phobic children display larger SCRs to masked spiders than to masked snakes or masked mushrooms. The only effect that reached significance was the main effect of Block: $F(1,19)=6.05, p<0.05$. That is, SCRs to the pictures were larger during block 1 than during block 2 due to habituation.

Table 1. Mean percentages hits and false alarms (standard deviations between parenheses) for each picture category separately

\begin{tabular}{|c|c|c|c|}
\hline & Spider & Snake & Mushroom \\
\hline Hits & $42.33 \quad(12.29)$ & $44.00(12.12)$ & $36.33(12.51)$ \\
\hline False alarms & $59.00 \quad(16.93)$ & $58.67 \quad(15.39)$ & $59.67(14.10)$ \\
\hline
\end{tabular}

Table 2. Mean SCRs (square-root transformed, standard deviations between parentheses) to masked spider, snake, and mushroom pictures during biock 1 and block 2

\begin{tabular}{lcccccc}
\hline & \multicolumn{2}{c}{ Spider } & \multicolumn{2}{c}{ Snake } & \multicolumn{2}{c}{ Mushroom } \\
\hline Block 1 & 0.27 & $(0.17)$ & 0.28 & $(0.20)$ & 0.24 & $(0.19)$ \\
Block 2 & 0.18 & $(0.13)$ & 0.21 & $(0.20)$ & 0.19 & $(0.17)$ \\
\hline
\end{tabular}

\section{SCRs and therapy outcome}

The results presented above indicate that there was no differential SCR to masked phobic pictures. Nevertheless, we explored relationships between SCR, on the one hand, and pretreatment symptom severity and therapy outcome, on the other hand. To this end, two new SCR variables were constructed: "phobic reactivity" and "fear-relevant" reactivity. Phobic reactivity was defined as the difference between SCRs to phobic targets (i.e., spiders) and the mean SCRs to non-phobic targets (i.e., snakes and mushrooms). Fear-relevant reactivity refers to the difference between the mean SCRs to fear-relevant targets (i.e., spiders and snakes) and the SCRs to fear-irrelevant targets (i.e., mushrooms).

Pearson product-moment correlations were computed between phobic reactivity and fear-relevant reactivity scores, on the one hand, and subjective and behavioural pretreatment measures and therapy outcome measures (i.e., BAT, SAM ${ }^{1}{ }_{\text {, }}$ and SPQ-C), on the other hand. Therapy outcome measures were constructed by subtracting the pre-treatment scores from the post-treatment scores. No significant correlations were found between phobic reactivity and any of the symptom measures. Nor were there significant correlations between fear-relevant reactivity and any of the symptom measures (see Table 3). Thus, no evidence was found to suggest that physiological responsivity to phobic or fear-relevant subliminal targets is linked to symptom severity or therapy outcome. 
Table 3. Pearson product-moment comelations benween "spider reactivity" and "fearrelewant reactivity", on the one hand, and pre-treatment and therapy-outcome measures, on the other hand $(N=20)$

\begin{tabular}{lcccccc}
\hline & SPQpre & SPQout & BATpre & BATout & SAMpre & SAMout \\
\hline Spider reactivity & -0.21 & 0.28 & 0.13 & -0.26 & -0.27 & 0.06 \\
Fear-relevant react. & -0.04 & 0.06 & -0.02 & 0.05 & -0.19 & 0.01 \\
\hline
\end{tabular}

\section{Discussion}

The main results of the current study can be summarized as follows: First, there was no indication that as a group, spider phobic children react with differential SCRs to subliminal phobic target pictures. Second, no convincing evidence was found to suggest that within the phobic sample, individual variation in differential SCRs to phobic pictures is linked to pre-treatment symptom severity or therapy outcome.

Our failure to obtain differential SCRs to masked spider phobic targets is in marked contrast to the findings of Öhman and Soares (1994) who demonstrated that fearful undergraduates do react with differential SCRs to subliminal presentations of their feared object. This discrepancy can be interpreted in either of two ways. One possibility is that differential SCRs to subliminal phobic pictures is a stable and robust phenomenon in adult phobics, but not in phobic children. It is worth noting that recent research on attentional bias and phobias has also revealed remarkable differences between adults and children with regard to the specificity of interference effects in emotional Stroop paradigms. A consistent finding in Stroop studies is that spider phobic adults, but not controls display increased latencies when they are required to colour name spider-related words (e.g., Lavy \& Van den Hout, 1993). In contrast, child studies on the Stroop interference effect report that such an attentional bias for phobia-relevant material is not limited to phobic children, but can also be found in non-fearful control children (Kindt, Bierman, \& Brosschot, 1997; Kindt, Brosschot, \& Everaerd, 1997). On the basis of this finding, Kindt et al. (1997) argue that at early developmental stages, lack of inhibitory control over ernotional responses seems to be a normal phenomenon. If true, this would explain why it might be difficult to obtain differential SCRs to phobic stimuli, if those stimuli are presented along with other (fearrelevant) stimulus material.

Whether or not developmental differences in inhibitory control are responsible for the discrepancies between the current study and that of Ohman and Soares (1994), it should be stressed that our findings are difficult to reconcile with the evolutionary arguments that have been proposed in this context. That is to say, if one assumes that (adult) phobics" phenomenological experience of their fear is a result from a hypersensitive subcortical system that is characterized by an evolutionary-based bias in favour of false alams and which is reflected in differential SCRs to subliminal phobic cues, then it follows that this differential SCR pattern must also be evident in phobic children. Obviously, this prediction 
was not borne out by the curnent data, thereby undermining an evolutionary argument.

A second interpretation of our failure to obtain differential SCR effects to subliminal phobic cues in spider phobic children is that the phenomenon under consideration is weak and unreliable in both adults and children. This interpretation is supported by the fact that several attempts to cross-validate the pertinent finding reported by Ohman and Soares (i.e., phobic participants react with stronger differential physiological responses to subliminal phobic cues) have yielded disappointing results (Gllobisch, Weike, \& Hamm, 1996; Mayer, Merckelbach, De Jong, \& Leeuw, 1999; see Study 2; Mayer, Merckelbach, \& De Jong, 1999a; see Study 3). One could argue that the phenomenon of differential physiological responding to subliminal phobic cues critically depends on technical and procedural details. For example, Öhman and Soares (1994) employed much smaller target pictures than we did in the current experiment. Perhaps, then, large pictures do not fall completely in foveal vision and, as a result, will not elicit differential effects. However, in a recently conducted study (Mayer \& Merckelbach, 1999c; see Study 4), we demonstrated that size of picture is not a critical factor. That is, both relatively large $(90 \times 58 \mathrm{~cm})$ and small $(38 \times 25 \mathrm{~cm})$ masked phobic pictures failed to elicit differential SCRs in fearful participants.

Several limitations of the present study should be acknowledged. First, the number of participants is relatively small (i.e., $N=22$ ). One can argue that, as a result of limited power, definite conclusions cannot be drawn. Note, however, that powerful effects were to be expected as Öhman and Soares (1994) found clear differential effects (i.e., SCRs to the fear-relevant pictures were more than twice as large as the SCRs to the fear-irrelevant pictures) with only 16 spider-fearfull subjects. Second, because no supraliminal condition was included in the current study, one cannot be sure that the spider pictures were threatening enough to elicit fear responses. However, other studies with spider phobics (e.g , De Jong \& Merckelbach, 1991; De Jong, Merckelbach, \& Arntz, 1995) reliably found spider pictures to elicit larger SCRs than control pictures (e.g., mushrooms or weapons). Moreover, it is important to note that we used the same slides as Ohman and Soares (1994). Thus, there seems to be no reason to expect that the phobic pictures used in the present study were not threatening enough to elicit fear responses in spider phobic children. Third, the study relied on a sample of children aged between 9 and 14 years. One could argue that phobias of children of this age are relativelly mild anxiety phenomena, and hence are not severe enough to elicit differential skin conductance responding. Yet, the children in the present study suffered from severe animal phobias and this was confirmed by a reliable structured interview measure (i.e., the DISC). Furthermore, it is important to note that adult animal phobics generally report that their fear began during early childhood years. For example, Ost (1987) found a mean onset age of 7 years for his group of animal phobic patients. These results indicate that most animal phobias begin in early childhood and then continue into the adult years (see for a discussion, Muris \& Merckelbach, 1998).

Several remarks are in order as to the correlations between psychophysiological responding, on the one hand, and symptom severity and therapy outcome, on the other hand. Not only did none of the correlations attain the conventional level of significance, but 
in those cases in which the correlations did approach significance (e.g, the correlation between phobic reactivity and pre-treatment SAM evaluations; see also Footnote 1), the association was in the opposite direction of what was predicted: the stronger the differential reactions to subliminal phobic cues, the lower the SAM evaluations during the BAT. This suggests that physiological reactivity to subliminal phobic cues is not a clinically informative measure. Indeed, our findings cast doubts on Öhman and Soares" claim that physiological fear activation outside awareness underlies phobics' phenomenal experience of their fear as irrational and uncontrollable. It may well be the case that during phobic exposure, phobics tend to attribute catastrophic consequences to the phobic object. By this view, the extent to which phobics experience their fear as irrational and uncontrollable depends on whether or not they are about to be confronted with the phobic object. In the first case, they might consider their fear as rational, while in the latter case they might view it as an irrational and uncontrollable behaviour. According to this analysis, the presence or absence of catastrophizing cognitions rather than unconscious responding underlies the irrationality and uncontrollability of phobic fear. Note that there are reasons to believe that at least under some conditions, phobics do, indeed, have such extreme danger cognitions about their feared object (Thorpe \& Salkovskis, 1995, Amtz, Lavy, Van den Berg, \& Van Rijsoort, 1993).

Over the past few years, interpretations of anxiety disorders in terms of LeDoux"s (1994) quick-and-dirty unconscious response systems have become popular (e.g., McNally, 1998). Due to their physiological and evolutionary connotations, such interpretations are certainly attractive. Meanwhile, the present findings illustrate that the empirical support for such interpretations is, as yet, meagre.

\section{Endnote}

"Following the suggestions of an anonymous reviewer, data were reanalyzed using only the anxiety item of the Self Assessment Manikin. These analyses essentially revealled a similar pattern of results. Correlations between the pre-treatment SAM-fear scale, on the one hand, and spider-reactivity and fear-relevant reactivity, on the other hand, were -0.15 and $-0.49(p<0.05)$, respectively. Correlations between the outcome SAM-fear scalle and spider-reactivity and fear-relevant reactivity were 0.00 and 0.34 , respectively. 


\section{Study 6}

\section{Do subliminal priming-effects on emotion have clinical potential?*}

\section{Summary}

Subliminal primes are able to influence the affective evaluation of subsequent supraliminal stimuli. For example, Murphy and Zajonc (1993) found that Chinese characters are evaluated more positively after they have been preceded by subliminal smiling faces. However, to be therapeutically relevant, sublimnal primes should be able to change strong emotions. The present experiment explored this issue. Spider-fearful $(n=17)$ and nonfearful $(n=14)$ undergraduates were exposed to subliminally presented ( $8 \mathrm{~ms}$ ) positive, negative, and neutral primes. Primes were immediately followed by a picture of a spider or snake $(1500 \mathrm{~ms})$. Subjects then evaluated the affective quality of the picture, using visual analogue scales. No evidence was found to suggest that (un)pleasantness of pictures can be modulated by subliminal priming. In the non-fearful group, spiders were evaluated as more frightening after negative priming. Yet, such an effect was not evident for the fearful group. The findings indicate that subliminal priming only affects the evaluation of relatively neutral stimuli. Thus, subliminal techniques seem to have little or no therapeutic value.

\section{Introduction}

It is widely believed among psychotherapists that psychopathology may be caused but also cured by unconscious processes. For experimental psychologists, however, this assumption is not without problems. The past 10 years or so have seen numerous studies addressing unconscious processes and their influence on emotions (e.g., Bargh, Raymond, Pryor, \& Strack, 1995; Masling, Bornstein, Poynton, Reed, \& Katkin, 1991; Shevrin, 1986). Most of these studies sought to change the emotional status of target stimuli by means of subliminal primes (i.e., stimuli presented beneath the threshold of awareness). At this moment, the question no longer is whether subliminal stimuli are able to affect basal processes involved in emotions (e.g., perception, memory, and learning processes); most experimental psychologists would agree that subliminal stimuli do, in fact, possess this capacity (e.g., Greenwald, 1992; Kihlstrom, 1987; Loftus \& Klinger, 1992). Rather the

* This study appeared as an article (Mayer \& Merckelbach) in Anxjety. Stress, and Coping, 12 (1999), 217.229 . 
question is whether the influence of subliminal primes is substantial enough to suspect that they might play a role in the development and/or treatment of psychopathological tonditions.

In their much cited experiments, Murphy and Zajone (1993) exposed subjects to $4 \mathrm{~ms}$ primes of scowling faces (negative primes) or smiling faces (positive primes). Subliminal primes were immediately followed by supraliminal pictures of neutral Chinese characters. After each prime - Chinese character trial, subjects evaluated the attractiveness of the Chinese character. Murphy and Zajonc found that Chinese characters were evaluated as less attractive when they were preceded by scowling faces than when they were preceded by smiling faces. In short, these authors demonstrated that subliminal primes affect subjects" evaluations of subsequent ambiguous stimuli beyond their awareness. Furthermore, Murphy, Monahan, and Zajonc (1995) as well as Murphy and Zajonc (1993) reported that subjects' evaluation of Chinese characters was only affected if the preceding primes were subiliminal. Under supraliminal priming conditions, primes were unable to change the affective valence of subsequent target material.'

Some authors claim that the influence of subliminal primes is not restricted to the affective modulation of ambiguous stimuli. They contend that subliminal primes are able to provoke a full emotional response. For example, Robles, Smith, Carver, and Wellens (1987) embedded negative images, neutral images, and positive images in three separate, but neutral, videotapes. The embedded images remained unconscious to the subjects. Following exposure to the videotapes, subjects rated their anxiety on several questionnaires. State anxiety was highest in subjects who had been exposed to the negative images, intermediate in the group that had been exposed to the neutral images, and lowest in the group that had been exposed to the positive images. These findings would suggest, then, that subliminal affective stimuli are able to elicit feelings of anxiety. The question arises whether subliminal positive stimuli are also able to inhibit strong negative emotions. In other words, does the subliminal priming technique possess any therapeutic value? According to the manufacturers of so-called "self-help" tapes the answer is a straightforward yes. Self-help tapes are audiotapes that contain subliminal sentences of the "you will be very successful today" type, inserted in calming sounds of nature (e.g., ocean waves). The clam is that these tapes are effective in controlling anxiety, obesity, sexual problems, and the like. Although advertisements promise great results, there is no scientific support for the efficacy of these tapes. As a matter of fact, studies that evaluated the therapeutic value of self-help tapes found that their effects never outperform standard placebo effects (Greenwald, Spangenberg, Pratkanis, \& Eskenazi, 1991; Russell, Rowe, \& Smouse, 1991; see for a review, Mayer \& Merckelbach, 1999a; see Chapter 5).

Better, but still controversial evidence for the therapeutic power of subliminal affective stimuli comes from studies that relied on the Subliminal Psychodynamic Activation (SPA)method of Silverman and colleagues. In several studies, these authors demonstrated that subjects who are subliminally exposed to the sentence "mommy and I are one" subsequently perform better than subjects who are subliminally exposed to the sentence 
"people are walking": These improved performances are found in the domain of weight loss (Silverman, Martin, Ungaro, \& Mendelsohn, 1978), examinations (Hudesman, Page, \& Rautiainen, 1992), and dart-throwing (Silverman, Ross, Adler, \& Lustig, 1978). While the studies of Silverman and colleagues have not gone unchallenged (see Balay \& Shevrin, 1988), they support the idea that subliminal stimuli are able to affect overt behaviour. In order to be therapeutically relevant, however, the crucial question is whether subliminal stimuli may modulate radical emotions and/or pathological behaviour.

Lee, Tyrer, and Hom (1983; see also Lee \& Tyrer, 1980) argue that pathological behaviour can be corrected with help of subliminal stimulation. According to these authors, anxiety patients may benefit from subliminal exposure. In their study, agoraphobic patients were exposed to supraliminal or subliminal agoraphobic film-scenes. Results indicated that both types of exposure are effective in reducing anxiety. Additionally, the authors observed that subliminal exposure is less stressful for patients. Williams, Watts, MacLeod, and Mathews (1997) suggest that subliminal exposure possesses therapeutic potential, since subliminal information cannot be ignored and therefore survives the avoidance manoeuvres of the patient. Referring to the work of Lee and colleagues, Williams et al argue that "while these studies have tended to employ small samples, with only five or six individuals in some groups, such results are certainly encouraiging. They clearly indicate the clinicall potential of exploiting procedures which may directly influence nonconscious processing without either permitting rejection or producing the discomfort which can accompany the conscions representation of aversive stimuli" (p.273). Such a favourable evaluation of the Lee et all. study can also be found in Dixon and Henley (1991). Meanwhile, the Lee et al. study is flawed on several counts. To begin with, visual threshold was only measured before the first session. Therefore, it is far from clear whether agoraphobic scenes remained genuinely subliminal in the subliminal condition. Secondly, to date, no independent replications of the critical effects have been documented. Thirdly, the results are difficult to reconcile with the rationale behind standard exposure treatment. That is, exposure in vivo is thought to be effective because it dictates prolonged confrontation with the phobic object, thereby making people aware of the non-catastrophic consequences of this confrontation (Foa \& Kozak, 1986). It is hard to see how subliminal exposure could have this corrective effect.

The aim of the current study was to explore whether subliminal primes possess therapeutic potential. More specifically, the study addressed the question whether subliminal primes are able to influence radical evaluations and emotions. This requirement should be met before one can attribute therapeutic potential to subliminal stimuli. In the present study, subjects were exposed to subliminal primes and supraliminal target pictures. These target pictures were fear-relevant stimuli (i.e, snakes and spiders). It was tested whether positive primes would reduce the aversiveness of the targets, especially in highly fearful individuals. 


\section{Pilot studies}

To establish adequate parameters for the critical experiment, two pilot studies were conducted. The first pilot study aimed at the selection of suitable stimulus material. The second pilot study sought to calibrate accurate subliminal presentation times.

In the first pilot study, 21 undergraduates evaluated 47 slides of smiling faces (positive primes), scowling faces (negative primes), or slides with geometric configurations that had face-like characteristics (neutral primes). Using $100 \mathrm{~mm}$ Visual Analogue Scales (VASs; $0=$ extremely negative; $100=$ extremely positive), subjects evaluated each slide on 4 affective dimensions (i.e., (un)pleasantness of the emotion that was portrayed, (un)pleasantness of the "person' looking at you that way, feelings of being rejected by that 'person', feelings of being criticized by that 'person'). For the experiment proper, the 6 slides of each category (i.e., negative, neutral, positive) that were most negative, neutral, or positive, respectively, on all 4 dimensions, were selected. ${ }^{2}$

To estimate the most accurate subliminal presentation time, 10 undergraduates ( 5 spiderfearful, 5 non-fearful) underwent a forced-choice identification task. The 18 slides (i.e., 6 smiling faces, 6 scowling faces, and 6 neutral 'faces') selected in the first pilot study served as primes and were presented twice. The primes were presented $10 \mathrm{~ms}$ or $30 \mathrm{~ms}$ and were immediately followed by a masking slide of a snake or a spider with a duration of $1500 \mathrm{~ms}$. After each trial, subjects were exposed to two test faces: the actual prime and an alternative face (with the same emotional expression, see also Murphy \& Zajonc, 1993). Subjects were asked to identify the faces that served as primes. The rationale behind this forced-choice test is that subliminal primes are identified at chance level (objective threshold; see Cheesman \& Merikle, 1986). Results showed that $30 \mathrm{~ms}$ primes were identified above chance. Primes that were presented for $10 \mathrm{~ms}$ could not be identified above chance. ${ }^{3}$ In the actual experiment, an even more conservative strategy was chosen and so prime duration was set at $8 \mathrm{~ms}$.

\section{Method}

\section{Subjects}

Subjects were recruited on the basis of mass testing at the beginning of the academic term. Undergraduates with a score on the Spider Phobia Questionnaire (SPQ; Klorman, Weerts, Hastings, Melamed, \& Lang, 1974) of 13 or more (i.e., spider-fearful) and undergraduates with a SPQ-score of 2 or less (i.e., non-fearful) were selected. As a result, 17 spider-fearful and 14 non-fearful subjects participated in the experiment. Mean scores on the SPQ were $17.2(S D=3.6)$ and $1.5(S D=0.9)$, respectively. Subjects received a small financial compensation for participation.

\section{Apparatus and stimulus material}

Target stimuli were $34 \times 22 \mathrm{~mm}$ colour slides of spiders and snakes. Half of the spider and 
snake slides was taken from the International Affective Picture System (IAPS; Lang, Ohman, \& Vaitl, 1988). The other half of target stimuli was developed for the purpose of this study and was taken from photographes in books and magazines. The latter category of pictures was similar to the LAPS pictures. Subliminal primes were $34 \times 22$ min colour slides of smiling faces, scowling faces, and neutral configurations (see first pilot study). Targets and masks were projected by two Kodak Carousels (Ektapro) equipped with Compur high-speed shutters (EVS-3). The sizes of the projection fields of primes (i.e, 50 $\times 78 \mathrm{~cm}$ ) and targets (i.e., $120 \times 78 \mathrm{~cm}$ ) overlapped each other. A low-intensity auditory probe signalled the onset of each new trial. The onset and offset of probes, primes, and targets were controlled by a Compaq deskpro 486 personal computer. A booklet consisting of 36 pages with 2 VASs on each page was used for evaluation of the target pictures. Subjects had to indicate 1$)$ how (un)pleasant they found each slide $(0=$ very umpleasant; $100=$ very pleasamt), and 2) how fearful they were of each animal $(0=$ wery fearfil; 100 $=$ not fearful at all). Both dimensions were included because stimuli can be negative without eliciting fear. Consequently, it is conceivable that subliminal priming techniques influence affective valence rather than anxiety.

\section{Design}

Subjects were exposed to 9 different pictures of spiders and 9 different pictures of snakes, randomly ordered. Subliminal primes were 6 different pictures of smiling faces, 6 different pictures of scowling faces, and 6 different neutral configurations. Targets and primes were presented twice, resulting in 36 trials. Primes were presented for $8 \mathrm{~ms}$ and immediately followed by a target slide of $1500 \mathrm{~ms}$. Inter-trial intervals were $11 \mathrm{~s}$. To cancel out ordereffects, combinations of primes and target slides were counterbalanced. Subjects were not informed about the preceding primes.

\section{Procedure}

Subjects came to the laboratory individually. They were told that the purpose of the experiment was to evaluate a series of spider and snake slides. Then, subjects were given the booklet with the VASs. Subjects were asked to evaluate each picture on the two VAS dimensions.

Having evaluated all slides, subjects were asked whether they had noticed something strange during stimulus presentation (subjective awareness; see Cheesman \& Merikle, 1986). Next, the priming procedure was explained and subjects participated in a forcedchoice identification procedure (objective awareness). The forced-choice identification procedure involved 18 trials and was similar to the procedure employed during the pillot study. Finally, to get an impression of subjects" fears of snakes, they were asked to complete a 6-item questionnaire about snakes and spiders. That is, subjects had to indicate on a 6-point Likert scale ranging from 0 (not at all) to 5 (extremely) 1) how afraid they were of snakes, 2) how repulsive they found snakes, and 3) how much it bothered them to look at snakes. These three questions were also asked about spiders. 
Results

\section{Forced choice identification}

Forced-choice identification data indicate whether subjects are able to identify the prime pictures above chance (1.e, above $50 \%$ correct). When identification scores of all 29 subjects were summed, 280 out of the 522 (i.e., $18 \times 29$ ) identifications were correct (i.e., $53.6 \%$ ). Binomial calculations indicated that this percentage of correct identifications did not differ significantly $[p>0.1]$ from the expected chance frequency (i.e., 261). In other words, the masking procedure was effective in blocking primes from awareness.

\section{Unpleasantness}

Table 1 shows mean VAS ratings of the target slides for spider-fearful and control subjects as a function of priming conditions. In passing, it is worthy of note that the evaluations of the non-fearful subjects tended to be somewhat more positive than those reported by Lang and Greenwald (1988). The mean ratings for spiders and snakes found in their study circled around 4 on a 9 -point scale $(1=$ very negative; $9=$ very positive $)$.

Table 1: Mean VAS scores (standard deviations between parentheses) of spider-fearful subjects $(n=15)$ and won-fearfwl controls $(n=14)$ for spider and snake targets primed by positive, neutral, or negative subliminal stimuli

\begin{tabular}{llll} 
& & \multicolumn{3}{c}{ Subliminal Prime } & \\
Unpleasantness & Positive & Neutral & Negative \\
$\begin{array}{l}\text { Spider-fearful Ss } \\
\text { Slide Spider }\end{array}$ & $24.1(13.7)$ & $24.0(13.9)$ & $21.9(13.1)$ \\
Snake & $55.5(13.7)$ & $54.6(10.7)$ & $52.2(14.6)$ \\
Control Ss & & & \\
Slide Spider & $50.9(13.6)$ & $52.5(14.5)$ & $49.9(15.7)$ \\
$\quad$ Snake & $60.4(13.2)$ & $58.9(16.2)$ & $57.3(14.2)$ \\
Fearfulnests & & & \\
Spidler-fearful Ss & & & $19.6(12.2)$ \\
Slide Spider & $20.4(11.6)$ & $20.9(12.0)$ & $49.8(21.5)$ \\
$\quad$ Snake & $51.8(22.4)$ & $52.2(18.9)$ & \\
Control Ss & & & $49.3(26.4)$ \\
Slide Spider & $56.1(23.7)$ & $54.1(24.4)$ & $61.4(26.0)$ \\
$\quad$ Snake & $63.1(27.2)$ & $63.4(27.3)$ & \\
\hline
\end{tabular}

Note: low scores indicate a negative evaluation

Due to procedural failures, data of two spider-fearful subjects could not be analyzed. Data were subjected to a 2 Group (between: spider-fearful / non-fearful) x 2 Target (within: spider slide / snake slide) x 3 Prime (within: positive/ neutral / negative) ANOVA. The ANOVA revealed a main effect of Group $[F(1,27)=15.0, p=0.001]$, a main effect of 
Target $[F(1,27)=53.3, p<0.001]$, and a significant interaction between Group and Target $[F(1,27)=19.15, p<0.001]$. That is, control subjects gave more favourable VAS evaluations of the stimuli than fearful subjects, snake slides were evaluated more positively than spider slides, and controls displayed a different pattern of VAS evaluations of the stimuli than spider-fearful subjects. Furthermore, there was only a borderline significant main effect of Prime $[F(2,54)=3.1, p=0.054]$; overall, positive primes tended to evoke a more positive evaluation of targets than did neutral primes, while neutral primes tended to evoke a more positive evaluation of targets than did negative primes. Neither the interaction between Group and Prime, nor that between Target and Prime attained significance: both $F(2,54)$ 's $<1$. In other words, the pattern of the priming-effect was similar for both groups as well as for both types of target slides.

VAS pleasantness ratings were analyzed separately for groups and target slides. For the fearful group, one-way ANOVAs revealed no significant effects of subliminal priming on the pleasantness ratings for snake $[F(2,28)<1, p>0.3]$ or spider slides $[F(2,28)<1, p\rangle$ $0.4]$. Thus, neither for snake slides nor for spider slides did positive primes evoke a different evaluation than neutral or negative primes. Similar results were found for the control group. Control subjects did not evaluate snake slides differently as a function of prime $[F(2,26)=1.6, p>0.2]$. Likewise, no significant priming-effects were found for spider slides $[F(2,26)=1.3, p>0.2]$.

\section{Fearfulness}

A 2 Group (between: spider-fearful / non-fearful) x 2 Target (within: spider slide / snake slide) $\times 3$ Prime (within: positive / neutral / negative) ANOVA, revealed a main effect of Group $[F(1,27)=10.3, p<0.01]$ and a main effect of Target $[F(1,27)=28.2, p<0.001]$. In general, control subjects found the slides less frightening than fearful subjects, and both groups evaluated snake slides as less frightening than spider slides. Furthermore, there was a significant interaction between Group and Target: $F(1,27)=8.0, p<0.01$. A main effect also occurred for Prime: $F(2,54)=3.7, p<0.05$. That is, positive primes evoked less negative evaluations of targets than did neutral primes, while neutral primes evoked less negative evaluations of targets than did negative primes. No significant interactions were found between Group and Prime $[F(2,54)<1]$ or between Target and Prime $[F(2,54)<1]$.

Again, groups and target slides were analyzed separately. For the spider-fearful group, the one-way ANOVA revealed no significant differences between the various priming conditions. This failure to obtain significant differences as a function of priming was true for spider slides $[F(2,28)<1, p>0.7]$ as well as for snake slides $[F(2,28)<1, p>0.4]$. In other words, subjects did not evaluate spiders and snakes as less frightening when they were primed by positive slides compared to when they were primed by negative or neutral slides. For the control group, a significant effect of subliminal priming on the evaluation of spider slides was found: $F(2,26)=4.5, p=0.02$. Post-hoc $t$-tests sliowed that there was no significant difference between spider slides preceded by neutral primes and spider slides preceded by positive primes $[r(13)<1,2, p>0.1]$. Yet, spider slides preceded by neutral 
primes were evaluated as less fear-eliciting than spider slides preceded by negative primes $[t(13)=2.1, p=0.03]$. Additionally, spider slides preceded by positive primes were evaluated as less fear-eliciting than spider slides preceded by negative primes $[t(13)=2.0$, $p=0.02]$. For the evaluation ratings of snake slides, no significant differences were found between the various subliminal priming conditions $[F(2,26)<1, p>0.7]$.

\section{Díscussion}

According to Williams, Watts, MacLeod, and Mathews (1997), subliminal primes may have clinical potential because they are able to affect unconscious processes directly without becoming the focus of cognitive avoidance. A close analysis of the literature shows that the Murphy and Zajone (1993) study is one of the few convincing experiments that may support the position of Williams et al. (1997). In Murphy and Zajonc's study, ambiguous stimuli were evaluated more positively or more negatively depending on whether they were preceded by positive or negative subliminal primes, respectively. Such an effect was not found when primes were presented supraliminally. The fact that an emotional priming-effect only occurred if (affective) primes remained unconscious is, of course, more or less in line with the suggestions of Williams et al. (1997).

In the Murphy and Zajone (1993) study, subliminal primes were able to modulate the evaluation of ambiguous stimuli. But are subliminal priming effects powerful enough to neutralize aversive stimuli? Only if one could demonstrate this, it would make sense to speculate about subliminal priming techniques as treatment tools. The current experiment addressed the issue of whether subliminal affective primes can modulate strong evaluations linked to aversive targets. While it should be admitted that the present study relied on a relativeny small sample size and that its findings shouid therefore be interpreted with

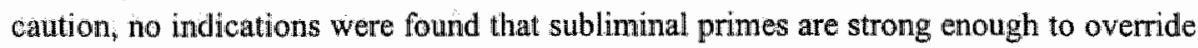
extreme evaluations. The only significant effect that could be found in the present study pertained to control subjects' evaluation of spider slides: subjects who were explicitly not fearful of spiders, rated spider slides as more frightening after negative priming than after positive or neutral priming. This finding fits well with the results of Murphy and Zajonc (1993). Interestingly, the direction of the effect suggests that negative primes have more impact than positive primes. More importantly, such priming-effects were not obtained in the spider-fearful group. In this group, spider slides were evaluated negatively, irrespective of the affective valence of the preceding primes. Apparently, in this group, the affective judgment of spiders is too radicalized to be amenable through subliminal primes.

Surprisingly, no priming-effects were evident for the snake slides. A possible explanation is that most subjects were more or less fearful of snakes. Again, that would imply that the affective evaluations of snake slides were too pronounced to be amenable through subliminal priming. Note that the two groups were selected on the basis of the presence or absence of spider fear. To explore whether extreme snake evaluations played 
a role in our failure to obtain affective priming-effects for this category of slides, the postexperimental questionnaire data on spider and snake fear were analyzed. Reliability of the 6-item questionnaire was favourable $[\alpha=0.84]$ and its total score significantly correlated with the SPQ $[r=0.74, p<0.001]$. A $t$-test showed that the spider-fearful group rated snakes as less fearful than spiders $[t(14)=4.48, p=0.001]$. Meanwhile, this group reported more fear of snakes than did the control group $[t(27)>2.0, p<0.05]$. This suggests that the failure to obtain affective priming-effects with snake slides in the spider-fearful group was, indeed, due to this group's extreme evaluations of snakes. However, such an explanation is not convincing in the case of the non-fearful group. For these subjects, VAS ratings of snakes were just as neutral as their VAS ratings of spiders $[t(13)<1.0]$. Yet, in this group affective priming-effects did occur for spiders, but not for snakes. Perhaps, then, perceptual ambiguity is a critical factor in obtaining affective priming-effects. Thus, it may well be the case that the affective judgments of vague, unclear stimuli are easier to modulate through priming than are judgments of clear, straightforward stimuli. If true, priming-effects would only emerge when primes precede target stimuli that are low in affective valence and that are perceptually ambiguous. Possibly, for the control group, spider slides fulfil these conditions better than do snake slides. While this is a post-hoc explanation, it is open to empirical testing.

In conclusion, as the present study is limited by rather small sample sizes, findings must be interpreted cautiously. Yet, the current data suggest that subliminal priming, at best, influences evaluations of relatively neutral targets. But even with neutral targets, primingeffects seem to be fragile phenomena. Clearly, the precise parameters underlying these priming-effects warrants further study. All in all, the results of the current study suggest that subliminal affective priming have little or no clinical potential.

\section{Endnotes}

'Murphy and Zajonc (1993, Exp. 1) even found that supraliminal primes may produce contrast-effects. That is, supraliminal positive primes induced more negative rather than positive judgments. A comparable contrast-effect of supraliminal stimuli was reported by Masling, Bomstein, Poynton, Reed, and Katkin (1991). In contrast to what one would expect, these researchers found that subliminal affective stimuli elicit larger skin conductance responses (i.e., more arousal) than supraliminal affective stimuli.

${ }^{2}$ For all VASs a low score implies a negative evaluation, whereas a high score means a positive evaluation. Mean values of the 4 scales [i.e., (un)pleasantness of the pictured emotion, (un)pleasantness of the 'person' looking at you that way, feelings of being rejected by that "person', feelings of being criticized by that "person' I for the 3 affective priming categories were as follows: for the negative primes means were $31.1,27.9,31.2$, 
and 29.7 , respectively. For the neutral primes, means were $49.1,48.2,55.2$, and 50.1 , respectively. The positive primes had means of $74.2,74.1,78.0$, and 75.8 , respectively.

${ }^{3}$ Of the 18 primes with a $30 \mathrm{~ms}$ duration, an average of 12.5 primes (range 10-15) was correctly identified. For the 18 primes with a $10 \mathrm{~ms}$ duration, the mean correct identification score was 10.3 (range 8-13). In this experiment, 9 correctly identified primes would represent chance level. Thus, based on the $95 \%$ confidence interval for the binomial distribution, subjects would exceed chance level when they correctly identified more than 12 primes.

${ }^{4}$ Note that duration of subliminal primes in the Murphy and Zajonc (1993) study was $4 \mathrm{~ms}$. 


\section{Chapter 5}

\section{Unconscious processes, subliminal stimulation, and anxiety $^{*}$}

\section{Summary}

Ever since Poetzl's studies, subliminal stimulation has been used as a paradigm to explore the connection between unconscious processes and psychopathology. Inspired by the psychodynamic tradition, folk psychology attributes a dramatic power to subliminal stimulation. In contrast, most modem researchers argue that the effects of subliminal stimulation are rather limited. Does that mean that the unconscious is irrelevant to psychopathology? Not necessarily. Öhman and Soares' hypothesis about the pre-attentive origins of phobic reactions represents a good example of a model in which a 'quick and dirty' unconscious may produce pathogenic effects. While the empirical basis of this model is still meagre, its attractiveness hinges on the assumption that 'quick and dirty' processes that make up the first second of human information processing are essential for higher level analysis and performance. In line with this, recent studies have indicated that the attentional bias that accompanies pathological anxiety, might be an unconscious phenomenon. Theories that focus on the unconscious cognitive processes involved in pathological anxiety are certainly interesting, but it should be emphasized that there are other aspects of automaticity (i.e., involuntariness) that may be as relevant to psychopathology as absence of awareness.

Introduction

The notion that unconscious processes play a causal role in the etiology of mental disorders has a long tradition in psychopathology. Likewise, a recurrent theme in the history of psychiatry is that unconscious processes should be the target of treatiment procedures (see, for historical reviews, Whyte, 1978; Sulloway, 1979). The unconscious as a reservoir containing complex motives, desires, preferences, and so forth, is, of course, one of the cornerstones of classic Freudian theory. The "smart" unconscious implicated in this view has become part of folk psyctiology. Yet, the smart unconscious is not readily accepted by modern cognitive researchers. While these researchers agree that a substantial part of our information processing occurs outside awareness, many of them tend to qualify the unconscious as 'dumb" (e.g., Loftus \& Klinger, 1992).

\footnotetext{
"This chapter appeared as an article (Mayer \& Merckelbach) in Clinical Psychology Review, 19(1999), $571-590$.
} 
It seems intuitively plausible to argue that a dumb unconscious has little or no relevance to psychopathology. This, however, is not necessarily the case. A case in point is Ohman's (1994) analysis of phobic fear. Basically, his proposal is that phobic fear originates from primitive, unconscious processes. Thus, this is an example of modem psychopathology capitalizing on the dumb rather than the smart unconscious. Taking Ohman's hypothesis of phobias as an example, the present chapter attempts to ewaluate how successful such an approach is.

The chapter will be structured in the following way. In the first section, we briefly discuss the unconscious as it is understood in the psychodynamic tradition. In addition, modern cognitive views on the unconscious are summarized. It is emphasized that these views are in conflict with the tendency of folk psychology to attribute a high degree of sophistication to the unconscious. The second section focuses on subliminal perception and modern emotion research. Here, we discuss phenomena such as priming effects and unconscious social influences. The third section outlines recent research on subliminal perception and pathological anxiety. Two lines of research are emphasized: the approach that was initiated by Öhman and that relies on pictorial phobic stimuli and the approach that focuses on threat-relevant verbal stimuli. The shortcomings of these approaches are also discussed. The article concludes with a critical note on the unconscious and its relevance to psychopathology.

Throughout this article, the emphasis will be on one particular technique that is widely used to examine the unconscious: subliminal stimulation. The rationale behind this technique is simple. If a stimulus with ultra-short duration is not consciously perceived by subjects but nevertheless affects their behaviour, there must be an unconscious that mediates these effects. Interestingly, the term 'sublimation' stems from chemistry and is used there to describe a change of a solid state into a gas state without a fluid state in between. It was Freud who first applied the concept to psychology. More specifically, Freud employed the concept of sublimation to refer to a dynamic process in which unconscious sexual energy gives rise to higher cultural expressions such as painting and music (Bengesser \& Walli, 1994). Clearly, then, from the very beginning, the concept of sublimation was associated with powerful effects.

It should be stressed that the subliminal stimulation paradigm represents only one and, indeed, a highly artificial approach to elucidate the way in which unconscious processes affect behaviour. After all, in daily life, we rarely have such extreme restrictions in time for inspection of a stimulus. Note, however, that the artificial nature of subliminal stimulation is the prize that researchers pay for a high degree of experimental control. Meanwhile, there are other approaches to study unconscious determinants of behaviour. Some of these involve a high level of experimental sophistication (e.g., the non-conscious covariation detection paradigm; Lewicki, Hill, \& Czyzewska, 1997), while others rely more on clinical case studies (e.g., Kohut, 1977). As the subliminal stimulation paradigm is a widely used technique on which strong clains are based (e.g., Dixon \& Henley, 1991), these alternative approaches will not be further discussed here. 
1. Psychodynamics, cognitive psychology, and folk psychology

\section{The unconscious and the psychodynamic tradition}

As Whyte (1978) points out, a number of 18 th and 19 th century philosophers speculated about the unconscious antecedents of mental life. However, it was not until the turn of the century that psychiatrists such as Charcot, Janet, and Freud began to connect the unconscious to behavioural aberrations (e.g., phobia, hysteria, etc). In other words, while unconscious processes have been known for more than two centuries, the idea of unconscious processes playing a causal role in psychopathology goes back to fin-desiècle psychiatry. Freud was, of course, the most successful and best known exponent of this psychiatric tradition. He propagated the notion that only a small part of the mind is conscious, like the top of an iceberg. In his view, the unconscious contains motives, emotions, and cognitions that are repressed from the stream of consciousness. He also emphasized that repression of material to the unconscious has a pathogenic effect. Accordingly, in classic psychodynamic theory, psychopathology is mainly the result of unconscious internal conflicts and the main procedure to treat psychiatric disorders is to make these unconscious conflicts conscious.

The physiologist Poetzl was a contemporary of Freud and was well acquainted with psychoanalysis (Shevrin, 1986). With his dream studies in 1917, Poetzl initiated subliminal perception research. He speculated that pictures flashed with ultra short duration (10 ms) would stay in the nervous system in a hidden and inactive form and would only reach consciousness during dreaming. In his experiments, Poetzl, indeed, found evidence to suggest that dream imagery may contain elements of subliminal pictures. However, his results were largely anecdotal and difficult to replicate (e.g., Johnson \& Eriksen, 1961). Nevertheless, since Poetzl, the subliminal technique has become a prominent tool for examining unconscious processes.

As a matter of fact, one of the best known systematic attempts to create an empirical basis for psychodynamic views relied on the technique of subliminal stimulation. To examine the relationship between psychopathology and unconscious conflicts, Silverman and colleagues conducted several experiments in which they employed a method termed "subliminal psychodynamic activation' (SPA). During SPA, subjects are confronted with ultra-short messages (i.e., sentences) that refer to an internal conflict, but remain unconscious. For example, Silverman, Martin, Ungaro, and Mendelsohn (1978) used this approach to "cure" obese women. According to the psychodynamic interpretation, obesity is an unconscious expression of the need to be nourished and cherished by mother. Overeating would meet this need and, therefore, would be fearreducing. In their experiment, Silverman and co-workers worked with two groups of obese women. By means of a tachistoscope, $4 \mathrm{~ms}$ sentences were flashed to both groups. Subjects in the experimental condition were exposed to the message "Mommy" and I are one"; the control condition received the message "People are walking". Both groups also participated in therapy sessions. Weight was measured every week. The results suggested that women who received the subliminal message "Mommy and I are one" lost significantly more weight than women who were exposed to the control 
message "People are walking". Highly similar results were obtained in a SPA study which investigated the effects of activating oedipal motives on competitive activity (Silverman, Ross, Adler, \& Lustig, 1978). In this study, college males were subliminally primed with the sentence "Beating dad is ok" or "Beating dad is wrong". Following this, they had to throw several series of darts. The 'ok'stimulus led to significantly higher dart scores than the 'wrong'stimulus.

Findings such as these have met both positive (e.g., Dixon, 1.981) and negative (e.g., Balay \& Shevrin, 1988) comments. Some of the critics have emphasized that the SPAfindings are extremely difficult to replicate (see, for a review, Weinberger \& Hardaway, 1990), while others have argued that it is very unlikely that complex semantic messages can be fully understood by unconscious processes (Williams, Watts, MacLeod, \& Mathews, 1988). In general, the classic psychodynamic notion that unconscious conflicts produce psychopathology has been heavily criticized for its dubious empirical status throughout the history of academic psychology (e.g., Eysenck, 1985; Hornstein, 1992; Crews, 1996). Note, however, that in modern versions of psychodynamic theory (e.g., object relation theory; Kohut, 1977), attention has shifted from unconscious internal conflicts to dysfunctions in early parent-child interactions and the way in which they might contribute to the etiology of psychopathology. Apart from this, there are also empirical studies that are largely supportive of some psychodynamic key notions that have little to do with the unconscious. Good examples are provided by the work of Luborsky and co-workers on avoidance tendencies (e.g., Luborsky, Blinder, \& Mackworth, 1964) and the empirically based model of Newman, Duff, and Baumeister (1997) on defensive projection.

\section{Unconscious processes and cognitive psychology}

There can be no doubt that unconscious processes are a crucial element of normal, ordinary functioning. Problem solving, writing, listening, learning and so on often do not require consciousness (see also Lewicki et al., 1997). In Erdelyi's (1985; p.59) words, unconscious operations are an "obvious and fundamental feature of human information processing". Even in the more specific domain of subliminal stimulation, the question no longer is whether subliminal stimuli affect behaviour, but rather how profound these effects are. Do subliminal messages affect motives and complex behaviour? Can subliminal messages change attitudes and elicit profound conflicts? Parametric research on subliminal stimulation suggests a disappointing answer to these questions (e.g., Greenwald, Draine, \& Abrams, 1996). This research makes use of semantic activation paradigms in which a subliminal prime (e.g., positive or negative word) is flashed before the target stimulus (e.g., positive or negative words). Subjects are required to categorize the targets in terms of, e.g., pleasantness. Subliminal perception is said to occur when the prime inhibits or facilitates the speed or accuracy of categorization of the target. This paradigm has yielded two important insights. Firstly, effects of subliminal stimulation are short-lived in the sense that they only occur within the $100 \mathrm{~ms}$ time frame after prime onset. Secondly, there are no carry-over effects from one subliminal trial to the next, which indicates that subliminal stimuli have no access 
to memory. On the basis of well-established findings such as these, cognitive psychologists have come to view the unconscious as an unintelligent and crude part of human information processing. For example, Loftus and Klinger (1992; p.764) concluded that "although there is no uniform agreement about how sophisticated these processes are, there seems to be a general consensus that the unconscious may not be as smart as previously believed". Similarly. Greenwald (1992; p.773) argued that "attentionless unconscious cognition is generally quite limited in the sophistication of analyses it can perform". On a related note, Lewicki, Hill, and Czyzewska (1992; p.800) stated that "if intelligent means having its own goals or specific motivations and being able to pursue them by triggering particular actions, such as proposed in the psychoanalytic literature, then the answer (to the question is the non-conscious information-processing system intelligent?") would be $\mathrm{NO}^{\prime \prime}$. So, among many cognitive psychologists there appears to be a consensus that the unconscious (as indexed by subliminal stimulation effects) is dumb.

One could argue that the unconscious cannot be dumb considering the fact that, for instance, people can read or drive without having access to the operations that are involved in these complex behaviours. Clearly, such operations occur outside awareness and it is for that reason that they have been labeled as the 'computational unconscious' (Horowitz, 1988). As a result of learning experiences, belhaviours like reading and driving have become routine activities that are relatively inflexible in the sense that they are applied time after time in mostly the same way (see Loftus \& Klinger, 1992). Yet, the unconscious defined in this way bears little relevance to the topic under consideration because it is difficult to imagine how such proceduralized and affect free behaviour could account for the etiology of psychopathological symptoms.

\section{Subliminal messages and folk psychology}

Still, the clever unconscious does exist: not so much as a scientific fact, but as a strong opinion in the head of lay people. They often tend to interpret their own behaviour and that of others in terms of unconscious motives, repression, and so on. These strong beliefs about the clever unconscious are fuelled and guided by pseudo-scientific claims about the dramatic effects of subliminal stimuli. For example, almost everybody is famillar with the experiment in which cinema visitors were subliminally induced to buy popcom and cola. The experiment itself is dubious (see Loftus \& Klinger, 1992), but since that experiment, the public is convinced of the power of subliminal stimulation and numerous variations on this theme have appeared and keep on appearing.

An interesting example of the alleged power of subliminal stimuli is provided by subliminal self-help tapes. These tapes are advertised as techniques that may produce desirable effects such as weight loss, anxiety reduction, and improvement of sexual functioning. Self-help tapes contain relaxing music or the sound of ocean waves in which subliminal messages are embedded. Messages are affirmations of the "you'll be very successful today" type. In spite of the marketing claims, there is no scientific evidence for the efficacy of self-help tapes. For example, Greenwald, Spangenberg, Pratkanis, and Eskenazi (1991) evaluated the effects of two audiotapes: an "improve 
your memory" tape and an "improve your self-esteem" tape. Labels were detached and then randomly re-assigned to the tapes. As a result, there were subjects who received a self-esteem tape with a memory label and subjects who received a memory tape with a self-esteem label. Subjects were then asked to listen to the tape each day, for a onemonth period. Before and after this month, subjects were tested with regard to selfesteem and memory. Greenwald and colleagues found a huge placebo effect: approximately $50 \%$ of all subjects believed that they had improved in the domain that corresponded to the label of the tape that they had received, compared to only $15 \%$ believing they had improved in another domain than that specified by the label. In other words, while there was no trace of a genuine subliminal content effect, there appeared to be a large suggestion (i.e., placebo) effect of tape label.

Another failure to obtain convincing effects of self-help tapes was reported by Russell, Rowe, and Smouse (1991). These authors were unable to find treatment effects in their study on self-help tapes designed for improvement of academic achievement. After listening to the tape for ten weeks, final exam scores and semester grade points of the experimental subjects were not found to be significantly different from those of control subjects.

The therapeutic effects that are ascribed to subliminal self-help tapes represent a clear case of folk psychology's tendency to overestimate the unconscious. Another illustration of this tendency is provided by the public debate about the effects of backward messages in rack music. This debate reached a climax in 1990, when the rock group Judas Priest was accused of having contributed to a case of teenage suicide by placing the backward message "do it" in one of their songs. Relevant in this context are the experiments of Vokey and Read (1985). These researchers demonstrated that subjects performed above chance level in discriminating between backward masked messages of male and female speakers, between backward masked messages of different male speakers, and between messages in different languages. However, subjects never performed above chance in judging whether a backward message was meaningful or nonsensical. Nor could they judge accurately if a backward message was a nursery rhyme, a Christian message, a satanic message, pornography, or advertising. Similarly, Begg, Needham, and Bookbinder (1993) showed that subjects are not able to recognize the (forward) meaning of backward speech. Clearly, then, people are able to make accurate discriminations with regard to some physical characteristics of backward speech, but not with regard to content of speech.

Another concern of the general public are the subliminal messages embedded in commercials. These messages are thought to persuade people to buy a certain product because 'it feels good'. Several authors have stressed the manipulative power of subliminal advertising (e.g., Key, 1973). Yet, no convincing evidence has been collected to show that subliminal messages can really influence consumer behaviour. For example, Smith and Rogers (1994) added subliminal or supraliminal messages (i.e., "choose this") to television commercials. Subjects were motivated to engage in positive feelings towards the product advertised. However, the authors found that the largest possible effect of subliminal messages is much smaller than that of supraliminal 
messages.

In sum, then, the numerous failures to document straightforward effects of subliminal self-help tapes or backward messages support Moore's (1988) conclusion that there is no evidence that subliminal messages can influence motivation or complex behaviour.

\section{Subliminal perception and emotion research}

\section{Subliminal exposure therapy?}

In most studies cited above, subliminal words and/or sentences were flashed to subjects in order to change minor symptoms (e.g, low self-esteem) or consumer attitudes. The claims of other studies have gone even further. For example, Lee, Tyrer, and Horn (1983) employed subliminal pictorial material as a treatment for agoraphobic patients. During seven sessions, patients were exposed to a series of films containing either agoraphobic or control scenes. Three separate groups were exposed to the phobic film; one group saw the film under degraded brightness (i.e., subliminal) conditions, one group saw it under normal viewing (i.e., supraliminal) conditions, and one group underwent graduate exposure from subliminal to supraliminal viewing levels as the study proceeded (i.e., faded condition). Control patients were exposed to faded neutral scenes. The results from this experiment suggest that both subliminal and supraliminal presentation of phobic films can be effective in reducing agoraphobic behaviour and that both methods are similar in terms of their efficacy. However, several shortcomings of the Lee et al. study preclude a strong interpretation of this finding. To begin with, it is not at all certain that the scenes in the degraded brightness condition were genuinely subliminal, since the visual threshold was measured only before the first session. As Holender (1986) pointed out in his critical review, subjects' visual threshold may vary over successive trials as a result of for example, dark adaption. Consequently, a single pre-experimental trial for determining visual threshold might yield rather inaccurate estimations. Secondly, no independent replications have been reported of the Lee et al. study. Thirdly, it is difficult to see how this subliminal exposure technique relates to the standard exposure techniques that are commonly used by behaviour therapists. Reseren on behavioural exposure treatment strongly suggests that these interventions are successful to the degree that they correct patients' catastrophic ruminations about the phobic stimulus (e.g., Shafran, Booth, \& Rachman, 1993). This is brought about by extensive and consequently supraliminal exposure to the stimulus and it necessarily assumes conscious processing of the non-catastrophic consequences of phobic stimulation. Given this state of affairs, it is hard to believe that subliminal and supraliminal exposure therapy have similar treatment effects.

\section{Priming studies}

The Lee et al. experiment rests on the assumption that by gaining access to patients' unconscious, they might be cured. Such an idea is not far removed from the romantic overestimation of the unconscious that can be found in the psychodynamic tradition and 
in folk psychology. As said before, there is little evidence to support this idea. However, this is not to say that subliminal stimulation is unable to modulate transient emotional preferences and states. An interesting example is provided by Murphy and Zajonc (1993; see also Murphy, Monahan, \& Zajonc, 1995). These researchers found results in line with Zajonc's (1980) proposal that under some conditions, emotions are precognitive. They primed subjects with subliminal pictures of smiling (positive affect) or scowling faces (negative affect). Subliminal pictures were directly followed by supraliminal pichures of a neutral Chinese character. Subjects had to rate the attractiveness of the Chinese characters on a trial-by-trial basis. Murphy and Zajonc demonstrated that the characters preceded by a smiling face were evaluated more positively than those preceded by a scowling face. Thus, the positive and negative feelings provoked by subliminal pictures of faces were found to modulate evaluations of the Chinese characters without subjects being aware of this change.

The technique of priming has also been employed to manipulate state anxiety levels. Robles, Smith, Carver, and Wellens (1987) inserted negative, neutral, or positive subliminal pictures in a videotape. Each subject was confronted with one of the three affective picture types. After watching the video sequence, subjects completed anxiety questionnaires. Anxiety scores of subjects who were confronted subliminally with positive pictures were reliably lower than those of subjects in the neutral condition, while scores of subjects in the neutral condition were lower than those of subjects confronted with negative pictures. In other words, subliminal affective material appears to be able to affect the emotional state of subjects. Similar results were reported by Tyrer, Lewis, and Lee (1978) and Kemp-Wheeler and Hill (1987; 1992).

Some studies have relied on physiological measures to detect the influence of subliminal emotional primes. For example, Làdavas, Cimatti, Del Pesce, and Trozzi (1993) flashed emotional or neutral primes of $10 \mathrm{~ms}$ duration to either the left (right hemisphere) or the right (left hemisphere) visual field of a split-brain patient while heart rate was recorded. Compared to neutral primes, emotional primes elicited a cardioacceleration, but only if they were flashed to the right hemisphere. The magnitude of this cardio-acceleration was moderate, i.e., about three beats per minute. A similar interaction between emotional primes and right hemisphere was found in a study by Wexler, Warrenburg, Schwartz, and Janer (1992). In that study, EEG and EMG served as dependent variables. Again, although statistically significant, the priming effects were small (i.e., $<1 \mu \mathrm{V})$.

\section{A critical evaluation of priming studies}

While the priming studies cited above suggest that subliminal messages may affect transient emotions and preferences without subjects being aware of this, they deserve some critical comments. To begin with, not all studies were successful in documenting subliminal modulation of emotions. For example, Smith (1993) was unable to find an effect of subliminal exposure on physiological anxiety. In his study, subjects were confronted with positive (e.g., smiling animated cartoons), negative (e.g., horrifying 
creatures), or neutral (i.e., a blank frame) subliminal stimuli. All stimuli had a duration of $17 \mathrm{~ms}$ and were inserted 18 times in videotapes consisting of several scenes of Miami Beach. As a physiological index of anxiety, frontalis muscle tension was measured. No significant effects of subliminal exposure on frontalis activity were found. Interestingly, Underwood (1994) found a contrast effect that is difficult to reconcile with traditional opinions about subliminal primes. This researcher presented a $20 \mathrm{~ms}$ subliminal smiling face seven times embedded in a short film on $\mathrm{BBC}$ television. The eastern network regions of the $\mathrm{BBC}$ received the film together with the subliminal frames; the western regions received the same film, but without subliminal. faces. Immediately after the film, viewers were invited to make a judgement about a neutral face. Viewers who were exposed to the subliminal smiling face were less likely to judge the neutral face as being happy than were viewers who saw no subliminal face. Although a prior laboratory study (Underwood, 1994) found little evidence to suggest that the frames could be detected above chance, it cannot be ruled out that the smiling face was above detection threshold for a number of participants. Thus, it is possible that some subjects explicitly used the happy face in the film as a reference point for their judgement of the neutral face that appeared later.

A second critical point has to do with the type of stimuli that Murphy and Zajonc (1993) employed to elicit preference ratings. In their study, subliminal stimuli were found to modulate subjects" evaluations of ambiguous stimuli (i.e. $e_{\text {, }}$ Chinese characters). The question arises whether such a modulation would occur in the case of straightforward emotional cues. With this in mind, we (Mayer \& Merckelbaclh, 1999b; see Chapter 4, Study 6) recently conducted an experiment in which spider-fearful and non-fearful students were primed with subliminal pictures of smiling and scowling faces. The prime pictures were immediately followed by supraliminal pictures of spiders or snakes. Subjective feelings of anxiety were measured with Visual Analog Scales (VAS). In the non-fearful group, primes of smiling faces did produce lower anxiety ratings for spider pictures than primes of negative faces. In the spider-fearful group and for the snake pictures, no significant priming effects were found. It is hard to escape the conclusion that subliminal stimuli are not powerful enough to overrule strong feelings. Thus, it is an over-interpretation of the facts to conclude on the basis of Murphy and Zajonc's (1993) findings that "affective reactions are more likely to be influenced by unconsciously perceived stimuli than by consciously perceived stimuli" (Merikle \& Daneman, 1998; p.9).

A third concern is the alleged mechanism behind subliminal effects on emotion. Even if one accepts that subliminal modulation of emotion exists, the theoretical underpinnings of these effects remain unclear. Subliminal modulation of emotion have been claimed not only on the basis of priming paradigms such as those of Murphy and Zajonc (1993), but also on the basis of experimental set-ups that deviate strongly from priming procedures. For example; Soares and Öhman (1995) conditioned subjects to subliminal fear-relevant pictures by pairing these pictures with aversive, and by implication, supraliminal consequences. That is, masked spiders (or snakes; CS+) were followed by an electric shock, whereas masked snakes (or spiders; CS-) were not. 
During a subsequent extinction phase, skin conductance responses (SCRs) were measured while CS+ and CS-were presented supraliminally. Larger SCRs to the CSt than to the CS - were found. In other words, while subjects had not been aware of the contingency between CS (1e, snake, spider) and shock, they nevertheless responded differentially to CS+ and CS-. Similarly, Martin, Hawryluk, and Guse (1974) ran an experiment in which a compound stimulus consisting of a red light and ultrasound (CS-H) was followed by an electric shock (UCS), while the same red light alone (CS-) was never followed by a shock. During a subsequent extinction phase, CS+ and CSelicited different SCR patterns in subjects, although subjects could not hear the ultrasound. Other researchers have used conditioning procedures in which the UCS rather than the CS remains subliminal. For example, in an evaluative conditioning setup, De Houwer, Baeyens, and Eelen (1994) have shown that neutral target words followed by subliminal positive words subsequently are more positively evaluated than are words followed by subliminal negative words. Thus, although priming paradigms and classical conditioning set-ups differ radically in terms of the temporal dymamics of their stimuli, both approaches have been used to document subliminal modulation of transient emotions and preferences. This point has not been fully recognized by students of subliminal stimulation. As a matter of fact, some have termed their priming studies 'subliminal conditioning' (e.g., Krosnick, Betz, Jussim, \& Lynn, 1992), whille others have described priming techniques in terms of 'backward conditioning' (e.g., De Houwer et al., 1994). Such a cavalier way of relating priming to conditioning does not take away the point that it remains difficult to understand the precise mechanisms that underlie subliminal modulation of emotion.

The studies reviewed so far, at best provide evidence for a small scale effect of subliminal stimuli on subjective ratings and/or autonomic physiology. One could counter that social psychology research offers some good illustrations of subliminal primes affecting complex, emotion-linked behaviour. For example, Bargh and Pietromonaci (1982) exposed their subjects to subliminal words that either had an aggressive or a non-aggressive content. After this, subjects had to evaluate other persons. Aggressive primes lead to a more negative evaluation than did neutral primes. Following a similar procedure, Carver, Ganellen, Froming, and Chambers (1983) exposed subjects to aggressive or non-aggressive primes. Next, subjects were instructed to administer shock to another participant who produced incorrect answers in a learning task. Subjects exposed to subliminal aggressive primes gave longer shock than subjects exposed to control primes. While these studies are impressive, there are two critical points that can be raised. Firstly, it is difficult to see how these findings can be related to the extensive parametric research of Greenwald et al. (1996). As said earlier, their work shows that subliminal effects are short-lived and do not survive a $100 \mathrm{~ms}$ interval. In social psychological studies on subliminal priming, time intervals between prime and task are much longer. Therefore, before concluding that the phenomena documented by these studies are reliable, one would like to see independent replications. Secondly, and most important, in the Bargh and Pietromonaco (1982) study, subjects were invited to come up with social evaluations. Likewise, in the Carver et al. (1983) experiment, 
subjects were explicitly instructed to administer shock. Consequently, these studies do not indicate that subliminal stimulation may elicit spontaneous, emotion-linked behaviour. At best, they show that subliminal stimulation modulates ongoing behaviour, i.e., enhances or reduces the intensity of that behaviour (see also Bargh, Chen, \& Burrows, 1996).

If the emotional effects of subliminal stimulation are limited, does that mean that they are irrelevant to psychopathology? Not necessarily. Recent research on preattentive mechanisms in anxiety disorders provides a case in point. This research employs subliminal stimulation as a technique to explore particular key features of psychopathological anxiety. In contrast to folk psychology, it does not view subliminal stimulation as a real world condition that may elicit or heal psychopathological symptoms (cf., backward messages and subliminal self-help tapes). Rather it treats subliminal stimulation as an artificial technique that may unravel certain basic mechanisms involved in anxiety. There are two research lines that are relevant in this context. The first focuses on the dynamics behind phobic responding. The second is concerned with attentional bias in anxiety disorders. Both types of research are briefly discussed below.

\section{Subliminal perception and pathological anxiety}

\section{Pre-attentive origins of phobic responding}

According to the Diagnostic and Statistical Manual of Mental Disorders (DSM-IV, APA, 1994), persons with a specific or social phobia readily admit that their fear is irrational. Thus, the DSM-IV assumes that, for example, spider phobics know that spiders are harmless, but despite this knowledge react with an involuntary fear response to spiders. In an attempt to account for the involuntary character of phobias, Soares and Öhman (1993a) proposed that a pre-attentive, automatic analysis of phobic cues is sufficient to activate the physiological components of a phobic reaction. According to their view, a physiological fear response is initiated before the person consciously perceives the phobic object. At the moment the phobic person becomes aware of the phobic cue, physiological fear reactions are already on their way. It is plausible to assume that this will contribute to feelings of uncontrollability which, in turn, will enhance fear. Öhman and Soares carried out an impressive series of experiments to test this hypothesis. In their critical experiment, Öhman and Soares (1994) examined whether highly fearful and non-fearful undergraduates differ in autonomic responses to phobic and non-phobic stimuli presented either sub- or supraliminally. Subjects were exposed to $30 \mathrm{~ms}$ pictures of spiders, snakes, mushrooms, and flowers. Masks of 100 ms duration (photographs of fragments of the original pictures) immediately followed these target pictures. This backward masking procedure was used in order to ascertain that the target picture remained subliminal. If a phobic response is initiated before conscious controlled processes come into play, one would expect that fearful subjects but not controls - react to phobic stimuli even when these stimuli are presented ultra 
short (e.g., 30 ms) and backwardly masked. In line with this, Öhman and Soares found that spider-fearful subjects reacted with SCRs to backwardly masked spider pictures, snake-fearful subjects teacted with SCRs to backwardly masked snake pictures, while non-fearful control subjects failed to react to the pictures. This pattern of results seems to indicate that a pre-attentive analysis of fear stimuli is sufficient for a phobic response to occur.

Ohman and Soares' speculations about the pre-attentive (i.e., unconscious) origins of phobic fear fit well with neurobiological findings of LeDoux (1994). In his animal studies, LeDoux found that two different brain pathways contribute to emotional processing: a slowly operating cortical pathway and a quickly operating subcortical pathway. In the first pathway, a thalamo-cortical route relays information to the cortex. At the cortical level a full and conscious analysis of the stimuli is carried out. Next, information is transmitted along the cortico-amygdala line. Eventually, the anygdala activates an emotional response. The second pathway operates in a 'quick and dirty' fashion. Information transmitted along this pathway bypasses the thalamo-cortical and the cortico-amygdala pathway. Stimuli are directly relayed from the thalamus to the amygdala, at which point the fear response is immediately initiated ("quick'). However, by-passing the cortex means that emotional stimuli are not fully analysed ('dirty"). Obviously, the quick and dirty thalamo-amygdala route has survival value in dangerous situations that call for immediate action. It is conceivable that in phobics, the thalamoamygdala route is hypersensitive to certain phobogenic stimuli as a result of aversive conditioning experiences. As an historical note, it should be added that already in the 1930s, the Dutch Pavlov disciple Ten Cate demonstrated that in animals, aversive conditioning can be mediated by primitive, sub-cortical circuits (Merckelbach \& Overduin, 1993).

While the research line initiated by Öhman and co-workers is certainly interesting, some critical remarks are in order. To begin with, attempts to replicate the basic findings of Öhman and Soares have yielded mixed results. In our lab (Mayer, Merckelbach, De Jong, \& Leeuw, 1999; see Chapter 4, Study 2), severe spider phobics and non-phobic control subjects were exposed to phobic slides (spiders) and non-phobic slides (flowers, mushrooms, and snakes) that were presented for $30 \mathrm{~ms}, 20 \mathrm{~ms}$, or $15 \mathrm{~ms}$ and backwardly masked for $100 \mathrm{~ms}$. During each trial, SCRs were measured and following this subjects indicated what they had seen (forced choice awareness check). The awareness check data revealed that only $15 \mathrm{~ms}$ stimuli remained genuinely subliminal, i.e., were not identified above chance. In both the $20 \mathrm{~ms}$ condition and the $30 \mathrm{~ms}$ condition, some stimuli survived backward masking, i.e., were identified above chance. However, spider pictures were never identified above chance. In meither condition, spider phobics responded with larger SCRs then controls to the spider slides in particular. This, then, provides no support for Öhman and Soares' position that subliminal phobic cues elicit stronger autonomic reactions in phobic than in non-phobic subjects (see also Chapter 4, Study 4 and Siudy 5).

Similarly, Globisch, Weike, and Hamm (1996) were unable to find differential eyeblink startle responses to subliminal phobic stimuli. These researchers examined 
whether animal phobics show potentiation of their blink responses to masked phobic stimuli. Animal phobics and control subjects were exposed to fear-relevant, neutral, and pleasant slides that were presented for $20 \mathrm{~ms}$ and backwardly masked for $130 \mathrm{~ms}$. To elicit startle blinks, $50 \mathrm{~ms}$ white noise bursts were presented at various times (i.e., 120 , $300,800,1300$, and $3800 \mathrm{~ms}$ ) after the onset of the masked stimuli. The authors obtained no convincing evidence that phobics' eyeblink responses to the probe stimuli were more potentiated by the emotional content of the subliminal stimuli than those of control subjects (see also Mayer, Merckelbach, \& De Jong, 1999a; Chapter 4, Study 3; but, see Merckelbach, De Jong, Leeuw, \& Van den Hout, 1995).

Apart from this empirical issue, one can raise other critical points with regard to Öhman and Soares' proposal. For example, an important assumption of these authors is that phobias are experienced as involuntary. That is, they assume that the phobic person responds with anxiety to the phobic object, although (s)the knows that his/her fear is inrational. Research of Amtz, Lavy, Van den Berg, and Van Rijsoort (1993) casts doubts on this assumption. Using the Spider Phobia Beliefs Questionnaire (SBQ), these authors reported that spider phobics have a highly developed set of ideas about spiders (e.g., "The spider jumps onto me") and their own reactions when exposed to spiders (e.g., "I will become crazy because of anxiety"). These ideas become especially articulated when phobics anticipate confrontation with spiders. In light of this, it is very unlikely that phobics experience their fear as truly irrational at moments when they are exposed to their feared object (see also Thorpe \& Salkowskis, 1995).

In sum, while the work of Öhman and Soares illustrates that it is, in principle, possible to formulate a theory that relates certain key features of phobias to a quick and dirty' unconscious, the merits of this theory are, at the present, unknown.

\section{Attentional bias and anxiety}

Numerous studies have documented that anxiety disorders are accompanied by attentional bias, i.e., the tendency to attend to fear-relevant stimuli, even if they are not critical to the task in which subjects are involved (see, for a review, Williams, Mathews, \& MacLeod, 1996). Several authors have claimed that attentional bias is not the peripheral by-product of pathological anxiety, but plays a crucial role in the maintenance of this form of psychopathology (e.g., Beck \& Clark, 1997). In short, the idea is that attentional bias leads to a heightened sensitivity to fear-relevant material. As a result, this material is selectively processed and easily accessible. This, in turn, intensifies anxiety, which leads to further attentional bias and so on.

Recent studies have focused on the issue whether or not attentional bias is under intentional control. One way in which this question has been approached is by subliminal stimulation. The underlying idea is that if attentional bias occurs with subliminai stimuli, it must be a preconscious phenomenon. Several studies have found, indeed, that individuals with an anxiety disorder (e.g* generalized anxiety disorder) or with high trait-anxiety exhibit an attentional bias after subliminal stimulation with fearrelevant material (Mogg, Bradley, Millar, \& White, 1995; MacLeod \& Rutherford, 1992). A widely used technique in this context is the modified Stroop colour-task. In 
this task, subjects are primed with an witra short word which is followed by a coloured pattern mask that subjects are required to colour-name. Compared to normals, anxious subjects show a retarded colour-naming latency when they have been exposed to subliminal threat words (e.g., 'stupidity", "lonely').

Interestingly, there are indications that attentional bias elicited through subliminal primes predicts subsequent emotional breakdown. For example, in a study by MacLeod and Hagan (1992), women awaiting gynaecological examination underwent the subliminal Stroop task. A subgroup of women later received a diagnosis of cervical pathology. In these women, interference of colour-naming latency on subliminal threat words was the best predictor of subsequent distress in reaction to the diagnosis (see also Van den Hout, Tenney, Huygens, Merckelbach, \& Kindt, 1995). Thus, it appears that attentional bias reflects vigilance for threat that is not under conscious control and makes people vulnerable to stress.

The attentional bias phenomenon shows some striking parallels with the findings reported by Öhman. In both cases, subliminal threat evokes a larger response in anxious than in normal control subjects. However, there is also a curious difference between the results of both research lines. As noted by McNally (1995), effects of subliminal threat in the Stroop paradigm are generalized in the sense that they are linked to a great variety of negative words. That is to say, they are not restricted to words that are of specific concern to the anxiety patients who are tested (e.g., Mogg, Bradley, Williams, \& Mathews, 1993). In contrast, the effects of subliminal phobic cues in the Öhman paradigm are content-specific. Thus, spider phobics respond to subliminal spider pictures, while snake phobics react to subliminal snake pictures. There is no ready explanation why the subliminal effects in both paradigms differ in their specificity.

As to the subliminal Stroop effects, there is another critical point that should be noted. Fox (1996) demonstrated in a recent series of experiments that effects of subliminal threat critically depend on contextual factors. She found that robust effects of subliminal threat words only occur if they are presented after subjects have been exposed to the supraliminal versions of these threat words. She concludes: "This pattern of results does not support the laypothesis that anxious individuals are characterised by an 'etemally vigilant' preconscious bias to process threat-relevant information. Rather, the results suggest that attentional bias on masked trials was dependent on prior activation of threat-related material. In Bargh's (1989) taxonomy, anxiety-related attentional bias would seem to be best categorised as a postconscious automatic effect" (Fox, 1996; p.476).

\section{Automaticity}

To be sure, there are large differences between the way in which lay persons conceptualize unconscious processes and the way cognitive psychologists view it. Still, both positions have in common a focus on absence of awareness. When the job is to elucidate certain aspects of psychopathological phenomena (e.g., clinical anxiety), this becomes manifest in an emphasis on subliminal stimulation paradigms. However, as things stand, one may ask whether this emphasis represents the only or even the most 
promising starting point for analysing automaticity in pathological behaviour. For instance, Fox (1996) might be correct when she concludes that automatic processing biases are dependent on prior activation by supraliminal threat-related material. If true, it would be misleading to state that anxious individuals are characterized by a preconscious bias to process threat-related information. Therefore, it seems worthwhile to take into account other aspects of automaticity than absence of awareness. Experimental and clinical studies (e.g., Stroop research) suggest that the information processing biases associated with anxiety disorders (i.e., biases in attention, interpretation, and memory) are, indeed, sometimes automatic in the sense of being unconscious, but, most importantly, they are always automatic in the sense of being involuntary. Consider, as an example, interference effects in supraliminal modified Stroop colour-naming tasks. Although subjects are instructed to attend only to the colour, they are unable to ignore the fear-relevant content of the word. This selective processing of threat-relevant material is involuntary rather than unconscious. As McNally (1995; p.751) points out "initiation outside of awareness may alone be insufficient to produce prolonged emotional distress; it is the inability of the patient to terminate fear-generating processing once it starts that is the hallmark of pathological anxiety".

\section{Concluding remarks}

\section{Technical issues}

Many ideas exist about the effects of subliminal stimulation. Not only scientists, but also non-professionals have strong opinions about the nature of unconscious processes. The difference between these views is often dramatic. While lay people are still convinced of the power of subliminal stimulation, researchers are considerably more sceptic about the extent of its effects. Indeed, studies concerned with subliminal stimulation have produced conflicting results: whereas some studies reported robust but small-scale effects of subliminal stimulation, others were unable to document any effects. What is the source of this discrepancy?

To be sure, the occurrence of subliminal effects heavily depends on subtle procedural variations. There is a number of procedural factors that are important in this context (see, for a review, Holender, 1986). First, as Benoit and Roger (1992) pointed out, in several studies that reported positive results of subliminal stimulation, subjects were beforehand informed that they would be exposed to subliminal stimuli. In other words, the expectations of subjects may be a crucial factor. A second procedural difference is the type of threshold that is used in experiments. In some experiments, stimuli were presented below subjective threshold (e.g., Smith \& Rogers, 1994; Tyrer, Lewis, \& Lee, 1978), whereas in other experiments stimuli were presented below objective threshold (e.g., Kemp-Wheeler \& Hill, 1992; Murphy \& Zajonc, 1993). A subjective threshold refers to the level of discriminative responding at which observers claim not to be able to identify or recognize perceptual information (but when forced they might detect it at 
a better than chance level of performance). An objective threshold is the level of discriminative responding corresponding to chance level performance (Cheesman \& Merikle, 1986). Most recent studies on subliminal stimulation have attempted to define the boundary between conscious and unconscious processes in, terms of objective thresholds (e.g., Marcel, 1983). These studies have yielded divergent empirical findings (see Cheesman \& Merikle, 1986). Cheesman and Merikle argue that most methods used to establish objective thresholds in the masked-prime studies are not really capable of distinguishing between objective and subjective thresholds. Therefore, it is always possible to argue that subjective rather than objective thresholds were established. This might be an important source of the contradictory results found in the various maskedprime studies. For this reason, Cheesman and Merikle (1986) believe that the subjective threshold is a better definition of the boundary between conscious and unconscious processes than the objective threshold. They reason that when discriminative behaviour indicates a complete absence of perceptual processing, it may be impossible to demonstrate experimental effects. Some authors have even gone further. For example, Kitayama (1991) proposed that affective input presented under extremely degraded viewing conditions might lead to affective impairment rather than affective enhancement. The reason for this would be that stimuli presented in an extremely impoverished marner might result in a misdirection of attention to irrelevant perceptual codes. All in all, it seems reasonable to argue that the closer the stimulus duration is to the threshold of awareness, the more effect stimuli are likely to have (e.g., Theus, 1994).

Another problem related to thresholds is that in studies of subliminal perception, the awareness threshold is usually fixed for the whole sample (e.g., Öhman \& Soares, 1993; McNally, Amir, \& Lipke, 1996; MacLeod \& Rutherford, 1992). Although a forced choice recognition task at the end of the experiment makes it possible to identify those subjects who recognized stimuli above chance, it seems better to use a pre-experimental assessment procedure in which thresholds are calibrated for each individual subject (e.g., Kemp-Wheeier \& Hill, 1992). But, even then, there might be trial-to-trial variability in subjects' awareness thresholds (Miller, 1991). According to Miller, standard threshold-setting procedures result in threshold estimates that are more conservative than the subject's actual threshold on most trials. Consequently, experimental power is low because there are relatively few trials on which stimulus energy is close enough to the subject's threshold for subliminal effects to occur.

A third technical issue in subliminal perception research is the modality of the stimuli. Visual stimuli presented subliminally appear to have a much higher probability of being cognitively processed by subjects than do auditory stimuli (e.g., Theus, 1994). Therefore, the effect of visual stimuli will be greater than those of auditory stimuli. A fourth factor that seems relevant is the content of the stimulus. For example, familiar words can prime anaesthetised patients during surgery, while unfamiliar words cannot (Bonebakker, 1995).

Finally, the masking procedure is a crucial factor in subliminal stimulation studies (e.g., Kemp-Wheeler \& Hill, 1987). When the stimulus is not masked correctly, subjects will be able to identify the target or prime stimulus. Of course, this may change the 
results dramatically. The best procedure to reduce the probability of conscious detection is central pattern masking with a shor stimulus onset asynchnony (Holender, 1986). A number of studies have followed the procedure of backward masking. For example, most of the subliminal Stroop tasks (e.g., Mogg, Kentish, \& Bradley. 1993; Macleod \& Hagan, 1992; Mogg, Bradley, Wiliams, \& Mathews, 1993) use a string of letters, fragments of letters, or upper-case Xs to mask the varget words. In conditioning studies (e.g., De Houwer, Baeyens, \& Eelen, 1994; Esteves, Dimberg, \& Ohman, 1994; Soares \& Ohman, 1993) or priming studies (e.g., Murphy \& Zajonc, 1993), it is also cormon to use backward masking techniques. On the other hand, there are various studies which have failed to use backward masking. For example, some authors (e.g., Tyrer, Lewis, \& Lee, 1978; Smith \& Rogers, 1994) attempted to induce subliminal effects by reducing the level of illumination of heir stimuli. Other authors (e.g., Henke, Landis, \& Markowitsch, 1994; Silveman, Ross, Adler, \& Lustig, 1978; Kunst-Wilson \& Zajonc, 1980 ) relied on very short durations of the stimuli (e.g., $1 \mathrm{~ms}$ ) to prevent awareness. It is questionable whether with such techniques stimuli remain genuinely subliminal.

\section{Conclusion}

It takes us a full second to articulate and verbalize a message (Levelt, 1993). Nevertheless, numerous cognitive researchers believe that the crucial time scale for human information processing lies well below the one second. As Hofstadter (1985; p.633) said: "everything of interest in cognition happens below the 100-millisecondlevel, the time it takes you to recognize your mother". "Thus, it becomes tempting to argue that dysfunctions in the earliest and therefore unconscious stages of information processing might produce a cascade of effects that ultimately take the form of a psychopathological disorder. From this perspective, we do not need the intelligent unconscious proposed by Freud to argue that unconscious processes are relevant to psychopathology. Ohman and Soares model of phobic reactions represents a clear example of a psychopathologically relevant hypothesis build on the primitive and dumb unconscious. Yet, studies carried out to test such hypotheses are often plagued by a number of procedural problems. When such problems are adequately resolved; - i.e., when effective masking occurs, when subjective expectations are absent, et cetera - it becomes possible to evaluate how well these hypotheses stand up to empirical investigations. As recent research (e.g., Fox, 1996) suggests, it is not at all certain that they will prove to be correct.

Some studies indicate that a strict connection between subliminal stimuli and lack of awareness might be misleading. Germane to this issue is Fox's (1996) work demonstrating a posiconscious rather than a preconscious effect of subliminal stimuli. In contrast, Merikle and Daneman (1998) have argued that research in this domain should not be preoccupied with technical discussions about levels of awareness during subliminal stimulation. According to these authors, a more interesting research strategy is to examine whether subliminal and supraliminal stimuli (or, in their terminology, unconscious and conscious perception) lead to qualitatively different consequences. Meanwhile, there is no point in proving that the effects of subliminal or unconscious 
stimuli differ fundamentally from those of supraliminal or conscious stimuli as long as it remains uncertain whether the subliminal/unconscious cues are truly subliminal/unconscious.

Another point is that it might not longer be very productive to identify the study of unconscious determinants of emotional behaviour with the technique of subliminal stimulation (see also McNally, 1995). In the field of social cognition, there are a number of interesting examples that may serve as a model for studies on unconscious or automatic processes in psychopathology. For example, Bargh, Chen, and Burrows (1996) primed half of their subjects in a scrambled-sentence task with supraliminal words relevant to the elderly stereotype; control subjects were primed with age-nonspecific words: After completing this task, subjects were thanked and debriefed. Another experimenter then recorded the time that the participant took to reach the elevator down the hall. Subjects who were exposed to the elderly-related words were found to walk more slowly to the elevator than control subjects. Thus, the prime did affect behaviour, although subjects were not aware of this carry-over effect. Likewise, in a study that explored the automatic association between power and sex in men, Bargh, Raymond, Pryor, and Strack (1995; Exp. 2) primed men with supraliminal power-related words (e.g., authority, boss). The priming procedure consisted of a wordfragment completion task. Following this, subjects were asked to rate the attractiveness of a female confederate on six rating scales. The results showed that men who score high on sexual aggression feel more attracted to a woman after priming with powerrelated words.

In their review paper, Dixon and Henley $(1991 ;$ p.243) claimed that subliminal paradigms "might play a useful role in the understanding and treatment of various mental disorders". On the basis of the studies reviewed above, our conclusion is considerably less optimistic: the effects of subliminal affective material are either subtle or, in case large effects are claimed, await independent replication. Therefore, the time is ripe to look for different paradigms and techniques. This is not to say that attempts to formulate a contemporary synthesis between (neo)psychodynamic interpretations of the unconscious and concepts from cognitive psychology are doomed to fail. For example, Wegner and Smart (1997) argued that deep cognitive activation (i.e., thoughts that are highly accessible, but not currently conscious) is likely to affect behaviour in an indirect way and that this is especially true for thoughts that are painful and, therefore, targets of intentional suppression attempts. In their words: "These consequences of deep activation, as well as the implications of this state for psychopathology and psychotherapy, echo in some way a long history of psychoanalytic thinking about the unconscious (...). These influences (...) appear to be generated primarily when people try to control their minds (...)" (Wegner \& Smart, 1997; p.993). In sum, then, this suggests that the unconscious should be studied from a top-down (mental control) rather than bottum-up (subliminal perception) perspective.

In conclusion, supraliminal priming can elicit strong automatic effects in people and this shows that automatic modulation of emotion and preferences is not restricted to the domain of subliminall stimuli. One could go even further and speculate that subliminal 
primes at best elicit small-scale effects, while supraliminal automatic phenomena might be able to induce more powerful effects. From a psychopathological point of view, the latter could be more interesting. After all, psychopathology is about strong emotions and radical behaviour. 
$\therefore \quad \therefore \quad \therefore \cdots$ 


\section{Chapter 6}

\section{General discussion}

Chapter 4 described 6 experiments that tested various aspects of Öhman's hypothesis about the pre-attentive activation of phobic fear. Chapter 5 presented an overview of the literature. That chapter made an atternpt to place Öhman's hypothesis in a broader context by critically reviewing the psychological potential of subliminal stimulation. In the current chapter, results of the studies will be recapitulated and discussed. As well, some ideas for future studies will be briefly described.

\section{Recapitulation of the findings}

So far, the findings of Öhman and associates have not been cross-validated. Even the Wong et al. (1994) study which claimed to provide an independent replication of some of the effects described by Öhman and co-workers is, on a closer look, not very convincing. Recall that in the Wong et al. study, SCRs to subliminaliy presented angry face CS+'s did not exceed those to subliminally presented happy face CS+'s, at least when SCRs were defined in terms of magnitude. Also, the theoretical underpinnings of Öhman's hypothesis (i.e., preparedness) are not without problems. Therefore, it is essential to scrutinize his hypothesis very carefully before it can be accepted as an validated part of abnormal psychology. One of his basic assumptions is that phobics experience their fear as automatic (i.e., involuntary). According to his analysis, automatically elicited physiological responses would contribute to phobics experiencing their fear of certain objects as irrational. To examine automaticity and irrationality in phobics at a phenomenological level and to establish whether these two characteristics are, indeed, correlated as Öhman assümes, a questionnaire was developed and administered to spider phobic patients and non-fearful control participants (Chapter 4, Study 1). Results of that study clearly showed that phobics experience their fear responses as automatic reactions which they cannot control. Furthermore, phobics tend to yiew their reactions to spiders as irrational. That is, they admit that their fear cannot be explained by the dangerousness of the spider. Even so, self-reported irrationality and uncontrollability of phobic fear were not significantly correlated with each other. Thus, at the phenomenological level, there is no straightforward connection between the absence of voluntary control and the tendency to view ones fear as irrational. The important point to note here is that there is probably more to phobic fear than just irrationality and uncontrollability. As Davey (1995) points out, phobics may well be able to apply the standards of rationality to their phobic behaviour, but that does not mean that they believe that there will be mo active or dangerous outcomes when actually confronted with phobic cues. As a matter of fact, phobics have a clear cut expectancy bias when confronted with phobic stimuli (e.g.. De Jong, Merckelbach, \& Arntz, 1995) 
and such expectancy bias may guide highly controlled awoidance behaviour. Perhaps, then, the imperfect correlation between irrationality and uncontrollability has to do with a third variable, namely expectancy bias.

In their most critical experiment, Öhman and Soares (1994) showed that spiderfearfuls responded specifically to masked spider slides, snake-fearfuls responded specifically to masked snake slides, and non-fearfuls responded to none of the slides. To cross-validate these findings, a study was carried out that closely followed Öhman and Soares" (1994) experiment (see Chapter 4, Study 2). Thus, SCRs were measured while masked fear-relevant and non-fearful stimuli were presented. However, some procedural modifications were made. First, masked stimuli were presented to clinical phobic patients rather than to fearful undergraduates. Furthermore, for the masked stimuli different presentation times were employed (i.e., 30,20, and $15 \mathrm{~ms}$ ). Finally, physiological and awareness check measurements were obtained in one and the same sample. This study failed to obtain differential SCRs to masked fear-relevant pictures. Thus, we were unable to provide a conceptual replication of Öhman and Soares' (1994) findings. It could be argued that some stimuli in the 30 and $20 \mathrm{~ms}$ conditions were identified above chance, and, thus, did not meet the criteria for the objective threshold of unawareness (i.e., did not remain genuinely subliminal). However, apart from the fact that the phobic stimuli did remain subliminal in all three conditions, it should be stressed that in the $15 \mathrm{~ms}$ condition, all stimuli were genumely subliminal. But even in that condition, differential effects to the phobic stimuli did not occurr. So, what about the "dramatic findings" that Öhman (e.g., 1996) often cites in his review papers? It is hard to escape the conciusion that on closer inspection, they are not dramatic in the sense of robustness.

One could argue that SCRs are not the most sensitive index for measuring fear, as they predominantly reflect orienting and arousal. Probably, a more sensitive measure that may reveal the automatic activation effect proposed by Öhman and Soares, is the startle potentiation phenomenon. Therefore, in the third experiment (Chapter 4 , Study 3), eyeblink startle responses were measured. A substantial number of studies (e.g., Lang, Bradley, \& Cuthbert, 1990, 1992; Bradley, Cuthbert, \& Lang, 1993) has demonstrated that the eyeblink startle reflex is particularly sensitive to emotional valence. A pilot study of Merckelbach et al. (1995) provided some tentative evidence that masked phobic pictures may elicit differential eyeblink startle responses. We sought to replicate that study, but also decided to test whether masked fear-relevant stimuli elicit cognitive interference. The rationale behind this was as follows: If masked phobic stimuli trigger physiological responses but fail to induce cognitive interference, this would support Öhman's hypothesis about the purely automatic and non-cognitive antecedents of phobic fear. In contrast, if masked phobic stimuli elicit cognitive interference, but fail to provoke physiological responses, this would cast doubts on Ohman's hypothesis. Meanwhile, the results of our experiment did not fit one of these patterns. Masked phobic pictures were not accompanied by larger eyeblink startle responses than were masked neutral pictures. In addition, masked phobic pictures did not provoke cognitive interference. Thus, the psychological potential of masked fear- 
relevant pictures seems to be extremely limited. Note, however, that under supraliminal conditions, these pictures did elicit larger eye blink startle responses and more cognitive interference in spider phobics. So, again, no indications were found for pre-attentive activation of fear.

One could argue that a potentially important difference between our studies and that of Öhman and Soares (1994), has to do with the size of the presented stimuli. Whereas these authors used pictures of $21 \times 14 \mathrm{~cm}$ at a distance of 1 meter, the studies described above used pictures of $110 \times 70 \mathrm{~cm}$ at a distance of 2 meters. Large masked pictures might not be capable of eliciting a physiological response, simply because essential parts of them fall outside the range of foveal vision. Accordingly, in the fourth experiment (see Chapter 4, Study 4), size of the target picture was manipulated. It was found that neither large nor small masked fear-relevant pictures (the latter being comparable to the size employed by Ohman and Soares) were able to induce differential SCRs in spider-fearful participants.

Öhman 1994) argued that pre-attentive detection routines for threatening stimuli are an inheritance of our ancestors. If true, one would expect this mechanism also to be present in phobic children. Moreover, as children are much closer to the onset of their phobia, no extensive leaming experiences (which could automatize fear responses) with the phobic object can have taken place. Thus, if a pre-attentive reaction to masked phobic stimuli could be documented in phobic children, an evolutionary interpretation would be much stronger. With this in mind, we confronted spider phobic children with masked fear-relevant and neutral pictures (see Chapter 4, Study 5). SCRs were measured during confrontation with masked spiders, snakes, and mushrooms. Once more, no indiciations for a pre-attentive activation of fear emerged.

Taken together, none of our studies found support for Öhman's hypothesis about preattentive elicitation of the physiological fear response. As a group, they point to the conclusion that whether one finds differential physiological effects of masked fearrelevant stimulation depends on an array of very subtle factors.

A frnal issue that is addressed concerns effects of posinive subliminal stimuli on (subjective) fear. Results of the priming study (Chapter 4 , Study 6) showed that small priming effects did occur in the non-fearful group. That is, in the non-fearful group, subliminal primes of angry faces (i.e., fear-relevant stimuli) did produce higher anxiety ratings for spider pictures than did subliminal primes of neutral or smiling faces (i.e., fear-irrelevant stimuli). Yet, in the spider-fearful group, no such subliminal priming effect was found. The picture that emerges from this experiment is that subliminal stimuli are not powerful enough to overnule strong emotions. As a consequence, positive subliminal stimuli seem to have no therapeutic relevance. The most optimistic conclusion that can be drawn from our priming study is that negative subliminal primes lave more impact on subjective ratings than positive subliminal primes. Broadly speaking, this is in line with Ohman's hypothesis, but it still is a huge step to the idea that subliminal phobic cues may produce full blown physiological responses. 
How to handle contradictory results?

In his commentary on the published version of study 2 ("Skin conductance responses of spider phobics to backwardly masked phobic cues"), Öhman (1999; p.160) argued that this study is "not a contribution to psychological science; it is merely a contribution to confusion". In an attempt to underpin this statement; he raised some methodological points, for example that our study failed to include a non-masked control condition and that our measurements were probably not sensitive enough, so that we only picked up physiological noise. As a take-home message, Öhman stated that a failure to replicate should be ignored unless authors can identify factors that are responsible for such a nonreplication. This puts a premium on authors who claim spectacular results and places those who seek to evaluate the validity of extraordinary claims in an ackward position. In what follows, this point is elaborated.'

Individuals with specific fears of, say, spiders or snakes display an increased latency when they have to colour-name threat words referring to their fears. This robust effect has been termed attentional bias and it can be obtained in fearful people with supra- as well as subliminal presentations of threat words during a so-called emotional Stroop task (e.g., Lavy \& Van den Hout, 1993; Mathews \& MacLeod, 1985; Van den Hout, Tenney, Huygens, \& De Jong, 1997). Many authors have speculated about the clinical ramifications of the attentional bias phenomenon. And, indeed, one would expect that a strong version of this phenomenon can be easilly documented in persons with a fullblown anxiety disorder. However, this is not necessarily the case. For example, Amir et al. (1996) found no attentional bias for social threat words in social phobics. Later on, we address the question as to how to explain this discrepancy between fearful and phobic individuals. For the moment, it is important to note that this 'null finding' of Amir et al. (1996) has been taken seriously and has contributed to the knowledge about information processing in psychopathology. Similarly, for a proper evaluation of Öbman's hypothesis about pre-attentive activation implying that phobic individuals react with physiological fear responses to subliminally presented phobic stimuli, it would be important to see whether such fear-specific responses not only emerge in analogue groups, but can also be found in clinical phobic individuals.

In their crucial experiment, Öhman and Soares (1994) confronted spider-fearful, snake-fearful, and non-fearful control participants with presumably subliminal pictures of spiders, snakes, and neutral material. They found that spider-fearful individuals reacted with a selective skin conductance response (SCR) to masked spider pictures, snake-fearfuls reacted with a selective SCR to masked snake pictures, while non-fearful controls did not exhibit a SCR to any of the pictures. Öhman and Soares $(1994 ;$ p. 238 , $239)$ were quick to point out the clinical significance of their finding: "(..) our data and theoretical interpretations provide a good explanation of the irrationality of phobias" and "(..) even though our results support the psychoanalytic contention that phobias are

\footnotetext{
The remainder of this paragraph appeared as a rejoinder to Öhnan in the Journal of Psychophysiology, $13(1999), 257-259$.
} 
rooted in the unconscious, they do not necessarily support a view of a smart unconscious that may patronize consciousness by deciding what is bad for it".

However, while Öhman and Soares (1994) sometimes refer to their fearful participants as "phobic subjects" (p. 239), their participants were just what they were, namely fearful subjects. So, it makes sense to apply the paradigm outlined by Ömman and Soares to people suffering from a serious clinical phobia to see whether they too react with SCRs to subliminal phobic cues. This is what we sought to do in our study (Mayer, Merckelbach, De Jong, \& Leeuw, 1999; see Chapter 4, Study 2). Note that although Ohman and Soares (1994) suggested that their $30 \mathrm{msec}$ backwardly masked. presentations of phobic and neutral stimull were genuinely subliminal, we will never know whether this was really the case. That is, subliminal thresholds and SCRs were examined in different experiments with different fearful and normal participants. So, we decided in our experiment to obtain awareness check data along with SCRs in one and the same sample of participants. As we had no a priori reasons to believe that $30 \mathrm{~ms}$ presentations would remain subliminal, we included two additional presentations times of shorter durations (i.e., $20 \mathrm{~ms}$ and $15 \mathrm{~ms}$ ). The results were "quite disappointing": we found no indications that truly subliminal phobic pictures may elicit selective SCRs in phobic patients.

According to Öhman (1999), it is impossible to interpret our findings as we failed to include a non-masked control condition. In other words, he questioned whether the spider slides we used were capable of eliciting SCRs in spider phobics at all. To strengthen this argument, he stated that our $30 \mathrm{~ms}$ SOA condition could be regarded as a non-masked control condition in which no heightened SCRs to spider slides occurred. Note, however, that in none of our three time conditions (i.e., $30 \mathrm{~ms}, 20 \mathrm{~ms}$, and $15 \mathrm{~ms}$ ) spider slides were detected above chance. Anyway, although one cannot rule out the possibility of non-responses to our spider slides on the basis of our data, this suggestion is extremely far-fetched. That is, there is abundant evidence that spider fearful individuals react with heightened SCRs to non-masked spider pictures (e.g., Hare \& Blevings, 1975; Fredrikson, 1981; Fredrikson, Sundin, Frankenhaeuser, 1985; Diamond, Matchett, \& Davey, 1995; Hamm, Cuthbert, Globisch, \& Vaitl, 1997). Most important for the issue at stake, we also consistently found enhanced SCRs to spider slides in clinically diagnosed spider phobics (e.g., De Jong \& Merckelbach, 1991; De Jong, Merckelbach, \& Arntz, 1995; De Jong \& Merckelbach, 1999). Moreover, we used the same source to select our slides as was used by Ötman and Soares (i.e., the International Affective Picture System; Lang, Ohman, \& Vaitl, 1988).

In his commentary on our article, Öhman $(1999 ; \mathrm{p} .160)$ argues that our failure to find subliminal activation of physiological responses in phobics does not represent "a contribution to science; it is merely a contribution to confusion". He also suggested that our experiment picked up nothing but physiological noise and that publication of the results was guided by our intention to blow up our CV. Finally, he advocates this rule: "a single instance of alleged failure to replicate should be neglected unless its authors can document the reliability and validity of their procedures and propose factors that determine when the effect is there and when it is not ${ }^{* 3}(p .161)$. 
It is hard to defend oneself against speculations about motives involved in publishing an article. Suffice is to say that writing up disappointing results is not the best way to blow up your $\mathrm{CV}$, dramatic effects do a far better job. An even more remarkable part of Ohman's commentary concerns his rule for handling replicational failures. It is an example of a contradictio in terminis because it boils down to the doctrime that failures to replicate a finding should be ignored unless the authors can document the finding. This rule echoes the Hegelian way of doing science: when the facts fail to support the theory, too bad for the facts.

Ohman $(1999, \mathrm{p} .161)$ continues his commentary by maintaining that "activation of psychophysiological responses to masked stimuli has been demonstrated for many response modalities". Even apart from the fact that there are also examples of studies that failed to find such activation (e.g., Globisch, Weike, \& Hamm, 1996), it is completely irrelevant for the aim of our study: our study was about phobic patients, phobic stimuli, and SCRs.

Returning to Amir et al. (1996), why were these authors unable to replicate the delayed colour-naming latency for phobic material? Well, in this research domain, unexpected and counterintuitive failures have been treated seriously and, thus, have contributed to progress. Most authors now seem to agree that some conditions can ovenide attentional bias phenomena. If, for example, the prospect of being confronted with the phobic object elicits extremely high anxiety levels in patients, their processing priorities may change in such way that threatening test stimuli loose their ability to elicit Stroop interference. Testing theories in independent laboratories and establishing the boundary conditions for phenomena by reporting and examining failures, is an essential part of science. Especially in psychopathology, this point has historical backing: theories about the "refrigerator" mother as a cause of autism or frontal lobotomy as a treatment for schizophrenia have fortunately disappeared due to failures to replicate.

\section{The saga of Smith and Jones}

In his by now classic article on "progress in clinical psychology", Rosenthal (1995) rightly pointed out that in clinical psychology many failures to replicate, in fact, represent pseudo-failures to replicate, due to relatively small effect sizes of the phenomenon under consideration and/or relatively small sample sizes involved in replicational attempts. Rosenthal refers to this situation as the Smith and Jones saga: Smith reports a significant result $(t=2.2, N=80)$, but then Jones appears and claims a failure to replicate Smith on the basis of a study with an $N$ of, say, 20 . No doubt, such failures to replicate contribute to the impression that clinical psychology progresses very slowly, if at all. The important question to be asked in such situations is whether Jones failure to replicate is a true failure or a pseudo-failure. In other words, what is the effect size reported by Smith and what is the sample size used by Jones? If we know the answers to these two questions, we are in a better position to evaluate the disappointing findings of Jones.

What about the effect size in the original Öhman and Soares (1994) study? Of course, Ohman (1994, p.16) claimed that "the results were quite dramatic"; but it is 
really hard to arrive at a precise estimate of the effect size. That is; the critical $F$-test corresponding to a 3 (groups) $\times 4$ (stimuli) ANOVA for the SCRs in the masked condition is simply not reported. Therefore, let us take the ormibus F-test (involving both masked and ummasked conditions) that Ohman and Soares specify as the best available parameter to calculate effect sizes: $F(1,45)=9.33$. In the absence of any information about means and standard deviations, Rosenthal's (1995) correlation effect size is the only effect size index that can be calculated. It takes on the value of $.41^{2}$, which corresponds to a medium rather than a large effect (Cohen, 1992). Now, to successfully replicate such an effect with power set at .90 and $\alpha$ fixed at .05 , a sample size of 45 would suffice (Abramson \& Gahlinger, 1993). The studies 2, 3, and 4 described in Chapter 4 relied on sample sizes that amply surpass the 45 participants required ( $N=88, N=46$, and $N=58$, respectively). Thus, unless the non-reported statistics were less dramatic as Öhman wants us to believe, there is little reason to assume that a lack of statistical power was responsible for our null findings.

\section{Technical obstacles}

Subliminal studies like those described in the present dissertation critically depend on a number of rather "technical" issues (see Holender, 1986; Marcel, 1983). To begin with, the duration of stimulus presentation is a crucial procedural factor. Results can vary widely when stimuli are presented (too) long (i.e., supraliminal; e.g., Murphy \& Zajonc, 1993), or (too) short (e.g., Kitayama, 1991; see also Theus, 1994). For example, Murphy and Zajonc (1993, Exp. 1) noted that supraliminal affective primes provoked effects that were almost the opposite of those of subliminal affective primes, possibly as a result of conscious contrast-effects. As another example, Kitayama (1991) noted that extremely degraded stimuli led to affective impaiment rather than affective enhancement, possibly as a result of a misdirection of attention to irrelevant perceptual codes. Most importantly, there is no consensus over what exactly constitutes a subliminal stimulus. That is, some authors (e.g.,Cheesman \& Merikle, 1986) argue that the subjective threshold should be met, while others recommend objective threshold of awareness (e.g., Kemp-Wheeler \& Hill, 1992). The subjective threshold refers to stimulus durations at which observers claim not to be able to identify perceptual information. However, when forced they might detect the stimulus at a better than chance level of performance. The objective threshold is the level of discriminative responding corresponding to chance level performance. Apart from the discussion about the type of threshold, there seems to be a wide variety in awareness thresholds between subjects (see Holender, 1986) and even within subjects (Miller, 1991). As a result, it is notoriously difficult to establish a uniform awareness threshold for all trials in all subjects. Note that there are even authors who argue that automatic processing cannot accur at all without perceiving the stimulus consciously. A fine example is provided by the Stroop study of Tzelgov, Porat, and Henik (1997). These authors found that the magnitude of the Stroop effect was correlated with subjects' ability to report the

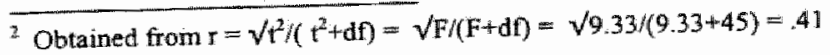


stimulus meaning in identified trials, while this effect was absent on trials where subjects failed to report the stimulus meaning. In a similar vein, Fox (1996) argued that the preconsciouis effect reported by a number of subliminal Stroop studies is probably better described as a postconscious effect. That is, Fox only found evidence for automatic processing when masked versions of stimuli followed unmasked versions of those stimuli.

Another technieal issue that might need some consideration is the subliminal stimulus itself Ohman hypothesized that the physical features of a stimulus serve as the triggers for a physiological response. This implies that complex stimuli such as words will go undetected by Öhman's pre-attentive system. Likewise, LeDoux (1986) documented that only simple perceptual stimuli can be processed without cortical mediation. Thus, one could speculate that the stimuli presented in our studies were perceptually too complicated, which might explain our failure to observe straightforward physiological effects. Note, however, that the pictures employed in our work were more or less similar to those used by Ohman and co-workers (i.e., slides of the International Affective Picture System; Lang, Ohman, \& Vaitl, 1988). Admittedly, in one of our studies (Chapter 4, Study 3), different spider pictures were used. However, these spider pictures were even more simplified and had very clear stimulus features. Thus, in that study, straightforward differential physiological responses to phobic stimuli were anticipated. However, this was not borne out by the data. Interestingly, in a recent study, Van den Hout, De Jong, and Kindt (in press) found that spider phobics do react with differential SCRs to subliminal fear-related words. Obviously, there is no survival value of responding pre-attentively to threat words. Most importantly, this study suggests that the arousal system may be activated by subliminal stimuli that possess no perceptual characteristics of the feared cues. Apparently, the arousing effects of subliminally presented threat words must be due to some intermediate semantic analysis (Van den Hout et al, in press). Even so, the question arises why the present studies were unable to document physiological responses of phobics to subliminal fearrelevant pictures, whereas Van den Hout et al. (in press) succeeded in documenting physiological phobic responses to subliminal fear-relevant words. One distinct possibility is that fear-relevant pictures have more reality constraints than fear-relevant words. Thus, it is conceivable that under subliminal conditions, phobics are not able to classify a fear-relevant picture as a threatening exemplar, whereas this is more easy to accomplish with the highly associative meaning that fear-relevant words possess (e.g., Tesser, 1976). If this line of reasoning is correct, it is precisely because of their higher semantic value that subliminal threat words are superior in evoking autonomic arousal compared to subliminal fear-relewant pictures.

A closely related issue concems the categories of stimuli that may be processed automatically. As Logan (1985) argued, automaticity is a continuum with new, unskilled activities at the 'conscious control' end and familiar, highly practiced activities at the 'automatic control' end (see also Underwood \& Everett, 1996; Kahneman \& Chajzyck, 1983). By this view, automatization will progress with practice. One could argue that for automatic information processing, "practice" is also needed. In 
that case, familiar stimuli can be processed automatically, but unfamiliar, novel stimuli cannot; novel stimuli will need attention. This is in line with findings of Bonebakker (1995) who found that anaesthesised patients can be primed by familiar words, but not by unfamiliar words. Thus, one could speculate that the stimuli presented in our studies were completely novel (i.e, subjects had not seen the pictures before) and, therefore, could not be processed automatically. In contrast, in the majority of the Öhman et al. studies, subjects were conditioned to supraliminal versions of pictures before they were confronted with subliminal versions of those pictures. Likewise, words, as presented in the Van den Hout et al. (in press) study, are highly familiar stimuli. Note that this analysis fits nicely with Fox's (1996) concept of postconscious effects. Admittedly, these considerations are speculative, but they are open to empirical testing. It would be easy to conduct a study in which novelty versus familiarity of subliminal stimuli is manipulated to examine to what extent this dimension is responsible for whether or not one obtains physiological effects.

Taken together, technical obstacles in subliminal research preclude firm conclusions about the potential of subliminal phobic cues to elicit physiological phenomena. Indeed, the precise factors that underly subliminal or pre-attentive activation of fear remain largely unknown. What can be stated with some confidence, though, is that this effect at least depends on rather subtle factors (e.g., objective versus subjective thresholds, novelty versus familiarity). A comparable conclusion about the effects of subliminal stimuli can be found in Shanks and St. John's (1994) extensive review of dissociable learning systems. These authors argue that, although various studies examining learning with subliminal stimuli (e.g., under general anaesthesia) have obtained evidence of reliable amounts of learning, these studies are matched by a comparable number of negative results. In their opinion, this patten of results has two different indications. That is, on the one hand, it might indicate that learning under anaesthesia is a genuine phenomenon, but that subtle methodological factors determine whether it can be obtained or not. Note, however, that Andrade (1995) was unable to find clear factors that deternined whether subtumal learning occurred or not. On the other hand, the positive resuls migh have been due to inadequately auministered anaesthetic, leaving the patients at least partially conselous. Consequenty, Shanks and St John (1994; $p, 371$ end ap wh the conclusion that st would be prenature to conchde from the avalable sudies that unconsious leaming is feasible".

\section{Awowatic processes and psychopahology}

One may question whether the technque of subliminal stimulation is well-sulted for examining automaticity of infomation processing in psychopathology. Apart from the technical abstacles as described above, "there is not enough compelling empirical evidence that automatic processing can be based on subliminal stimul" (Tzelgov, 1997; p. 44). Also, automaticity is a broad concept that cannot be taken as an equivalent of lack of awareness. For decades, it was widely believed that automatic processes were capacty-free, anconscious, and involuntary. Bargh (1989), however, noted that these atributes of awomatrity do not always covary and suggested that there are varieties of 
automaticity. The common factor to all automatic processes is that they run to completion once started, without the need of conscious monitoring (Bargh, 1992; see also Tzelgov, 1997 ). So, it is possible to have automatic processes that are accompanied by conscious and capacity-using operations. Following this line of reasoning, McNally (1995; p.751-752) stated that "the phenomenology of pathological anxiety suggests that processing biases are automatic in the sense of being involuntary rather than being capacity free or necessarily unconscious. [...] It is the obligatory character of these processes that prompt the characterization of phobias, panic attacks, and so forth as being "irrational" Processing of threat information may, indeed, occur outside of awareness, and therefore qualify as automatic under this criterion. But initiation outside of awareness may alone be insufficient to produce prolonged emotional distress; it is the inability of the patient to terminate fear-generating processing once it starts that is the hallmark of pathological anxiety." Thus, if automaticity of phobic responding is at stake, it might be more fruitful to examine the involuntary aspects than to focus on unconscious aspects:

There are studies that clearly show that conscious (i.e., unmasked) stimuli may elicit an involuntary, automatic process. Supraliminal emotional Stroop studies provide a good example. These studies demonstrate that fearful subjects simply cannot ignore the contents of fear-related words, which results in longer colour-naming latencies (e.g., Lavy \& Van den Hout, 1993; Mathews \& MacLeod, 1985). Other demonstrations of automaticity in the presence of consciousness can be found in the domain of social psychology. For instance, in a supraliminal priming study, Bargh, Raymond, Pryor, and Strack (1995; Exp. 2) showed that men who scored high on sexual aggression felt more attracted to a female confederate when primed with power-related words (e.g., "authority") than when primed with neutral words. Thus, although these men were exposed to supraliminal versions of the power-related primes, they were unaware of the automatic effect that these primes had on their behaviour. Likewise, participants primed with supraliminal elderly-related material (words like "Florida" and "wrinkle"), subsequently were found to behave in line with these primes. That is, they walked more slowly down the hallway after leaving the experiment than control participants (Bargh, Chen, \& Burrows, 1996). Other good examples can be found in studies that address the automatic activation effects of stereotyping and prejudice. For example, Banaji and Greenwald (1995) showed that social category (gender) is implicitly used (i.e., automatically activated stereotyping) in judgments of fame. That is, familiar male names were more likely judged to be famous than equally faniliar female names. Likewise, Banaji and Hardin (1996) showed that reading the word nurse or mechanic antomatically activated social category (gender), which was demonstrated by the facilitation of the judgment of gender congruent male and female pronouns. These studies demonstrate that automatic processes (which remain unconscious to the individual) can be perfectly studied by means of supraliminal stimuli. 


\section{Suggestions for future research}

Theories that assume that bodily responses are faster than conscious thoughts are not new. As early as in 1884, James proposed that emotions are the outcomes of bodily changes (e.g., "I cry thus I am sad"). Apart from Öhman's hypothesis, another recent example of such an approach can be found in Damasio's (1994) somatic marker hypothesis. Damasio contends that physiological indices (the so-called somatic markers) regulate people's decision-making process. In his view, the body responds preattentively (i.e., outside the focus of attention) to certain cues, making decisions "feel" right or wrong. These feelings of right and wrong then guide decision-making processes in such way that, when certain cues activate aversive emotions, a number of alternatives is automatically eliminated. As a result, fewer options are left for the decision-maker to consider.

The somatic marker hypothesis is supported by findings of Bechara, Damasio, Tranel, and Damasio (1997; Bechara, Damasio, Damasio, \& Anderson, 1994; see also Damasio, 1994). With a real-life decision-making task (i.e., a gambling task), these authors demonstrated that normal subjects start choosing advantageously before they consciously realize which strategy works best. More specifically, subjects were motivated to choose cards from four different decks. They could win or loose money. Two decks were advantageous to choose from (i.e., overall benefit) and two decks were disadvantageous to choose from (i.e., overall loss). Normal subjects started avoiding the "loss"decks before knowing consciously that these were disadvantageous. Moreover, subjects developed anticipatory SCRs to these decks before knowing consciously that they were disadvantageous. Thus, it could be argued that in these subjects, their body reacted with an alarm response before they consciously identified the situation as disadvantageous and in this way, bodily responses contributed to their decision-making process.

It is tempting to speculate whether this experimental design can be used to study automatic processes in phobia. Consider an experiment in which spider phobics and non-fearful controls have to sample from decks containing various frequencies of instructions to approach a spider (e.g., "You have to put a spider on your arm"). One would anticipate that normal subjects are sensitive to this frequency information and base their decisions to sample one or the other deck on this information. In contrast, spider phobics would be expected to disregard frequency information and to display a decisional process that is irrational (i.e., random sampling), because their information processing becomes dysregulated when confronted with spider-related information. That is, they will respond automatically to each deck because, for them, each deck is disadvantageous.

In a pilot experiment, we confronted spider-fearful $(n=29)$ and non-fearful control $(n=29)$ women with three decks of 40 cards each (i.e., deck A, B, and C). Each deck consisted of cards containing spider-related instructions (e.g., "Put your hand in a box with spiders"), cards containing financial benefits (e.g." "You win a dollar"), and cards containing financial losses (e.g., "You loose 50 cents"). The crucial difference between the decks was the percentage spider cards: deck A contained 10\% spider cards, deck B 
contained $25 \%$ spider cards, and deck C contained $40 \%$ spider cards. The remaining cards in each deck were always composed of $20 \%$ "loose"cards and $80 \%$ "win"cards. Subjects had to select one card at the time, from any of the three decks, until they were told to stop. They had to stop after 80 cards, which was not mentioned beforehand. Participants were told that the instructions written on the cards had to be performed after the experiment. After the first 20 eards, subjects were asked whether they had any ideas or speculations about the decks ("Do you know what is going on?"). This question was repeated after each set of 10 cards. This was done in order to establish whether subjects could verbalize (i.e., knowing consciously) the difference in the frequency of "spider approach instructions" between the three decks.

Results of this pilot study showed that spider-fearfuls and non-fearful controls did not differ in their pattern of card selection. Both spider-fearful and control participants failed to display a preference for one of the three decks. It was hypothesized that spiderfearfuls would not develop a preference for one of the decks because their information processing would be dysregulated by phobic information. On the contrary, controls would prefer the deck with the smallest percentage (i.e., $10 \%$ ) of spider instructions. However, the latter was not borne out by the data. This null finding may be interpreted in several ways. First; participants might not have recognized that more spider instructions were included in one deck than in another. Probably, the percentages of spider instructions in decks A, B, and C (i.e., 10\%, 25\%, and $40 \%$, respectively) did not vary enough. Another possibility is that participants may have recognized differences between the decks, but were not bothered by them. Perhaps, they did not believe the instructions, and, as a result, did not experience the spider instructions as disadvantageous. In post-experimental interviews, some subjects, indeed, indicated that they did not believe that the instructions really had to be carried out. Altogether, this null finding is yet another illustration of difficulties that arise when studying automatic information processing in psychopathology. But, perhaps, Bechara et al.'s (1997) decision-making task can be optimalized, such that it is suitable for documenting and qualifying the automatic antecedents of abnormal behaviour.

Another line for future research is suggested by the paradigm of change perception. People are not very good at detecting changes in the visual world. An important issue in this respect is saccade blindness: people are not able to detect changes in a picture when these changes occur during a saccade (e.g., Grimes, 1996). Blackmore, Brelstaff, Nelson, and Troscianko (1995) provided a very useful technique to investigate saccadecontingent blindness. In their technique, a picture is quickly extinguished and displayed again in another location at the moment that a change in the picture occurs. As a result, subjects have to move their eyes (i.e., make a saccade) to see the picture and detect changes. Blackmore et al. (1995) used pictures of real-world scenes, for example a street with or without a person. After each movement of picture, subjects had to report whether or not they had seen a change. It was found that when people had to move their eyes, their detection of change was close to chance. In other words, there was no perception of change. 
It is conceivable that this so-called change blindness occurs for changes in unattended, uninteresting parts of ant inage, but not for changes in the centre of attention. To investigate whether change blindness also occurs for an object that is in the centre of attention, Levin and Simons (1997) wsed parts of fulms. In their films, the object of attention (i.e, an actor) changed fron one shot to another. Subjects were not explicitly anstructed to look for changes. It tamed out that only a minority of subjects (i.e., $33 \%$ ) reported the charige af actor. So, even when attention is paid to an object, this is no guarantee for perception of change.

The change perception paradigm might be a useful tool to study automatic information processing in phobias. That is, one can think of an experiment atong the lines of Blackmore et al. (1995) in which spider phobics and controls are confronted with changing pictures that do or do not include spiders. Subjects are required to indicate whether the content of the pictures changed or not. For example, subjects could be confronted first with a pichure of a wooten ganden chair in a thowery garden, and then, when the picture changes, there is the same wooden chair in the flowery garden but now with a spider on it. As a control condition, one coutd flash another picture depicting a window with plants on the windowsill. Then, during the changed version of this picture, the window with plants on the windowsill is still there, but with one plant missing. Of course, apart from trials with changes, there should be also trials without changes.

As people appear not to be good at change perception, one would expect control participants to perform at chance level in indicating whether pictures changed or not. In contrast, if spider phobics autonatically process phobic information, one would expect that their attertion will be automatically drawn to the spiders that suddenly appear in an old context. As a result, they will detect changes when spiders are involved (cf., attentional bias). The attractiveness of the change detection paradigm is clear: this is about real-life scenes that are presented dynamically and supraliminally, but nevertheless allow for the measurement of automatic processes.

\section{Final remarks}

Stroop studies have convincingly shown that phobic stimuli are processed automatically. Evidence for the assumption that automatically processed phobic stimuli trigger physiological fear responses is, however, less convincing. Furthermore, no support has been obtained for the hypothesis that an automatic and pre-attentive activation of phobic fear underlies its irrational and uncontrollable character. Irrationality and uncontrollability of phobias seem to be the results of the imvoluntariness of automatic processes. In Bargh's (1992) definition, antomatic processes are processes that run to completion once started, without the need of conscious monitoring.

Automaticity of behaviour is not the exclusive domain of psychopathology. Most of people's everyday life is based on automatic processes. That is, our behaviour is seldornly determined by conscious intentions and deliberate choices. Instead, most of the time, our behaviour is a function of mental processes that operate outside of 
conscious awareness and guidance (Bargh \& Chartrand, 1999). According to Bargh and Chartrand (1999), these automatic processes are put into motion by features of the environment. As an example, people will tend to discriminate when they are confronted with stereotypes that are triggered by a person's skin colour. Or, as a less negative example, subjects will persist longer on a certain task when their achievement goal is primed (Bargh, Gollwitzer, \& Lee-Chai, 1999). Of course, these automatically triggered processes do not know the source of their actions and behave the same way regardless of where the commands come from. So, once these processes are put in motion, they operate as if they have been consciously intended (see Bargh \& Chartrand, 1999). Although these automatic mental processes sometimes have negative consequences, they are of great use to human functioning. That is, they free our limited conscious attentional capacity from tasks in which this capacity is no longer needed. In the words of Bargh and Chartrand (1999, p.476), "these processes are in our service and best interests", and "they are, if anything, "mental butlers' who know our tendencies and preferences so well that they anticipate and take care of them for us, without having to be asked."*

To sum up, then, unconscious processing is only one and for that matter a relatively narrow aspect of automaticity, while automaticity is not necessarily a sign of psychopathology. Automatic guidance of behaviour is the default in the absence of clear choices and explicit goals (e.g., Dijksterhuis, Bargh, \& Miedema, 2000). On the other hand, social psychologists have pointed out that normal subjects have the ability to override automatic behaviour whenever the situation requires a careful selection from several behavioural options. This may provide us with quite a different perspective on the role of automaticity in, for example, phobias: It is not the "quick and dirty" bottomup processes that function as the primary antecedents of phobic fear. Rather it is the inability to override such automatic influences that makes phobic fear different from nomal behaviour. 


\section{References}

Abramson, J.H. \& Gahlinger, P.M. (1993). Power of a test comparing two samples. PEPI program, version 3.0.

Agras, S., Sylvester, D., \& Oliveau, D. (1969). The epidemiology of common fears and phobia. Comprehensive Psychiatry, 10, 151-156.

American Psychiatric Association (1987). Diagnostic and Statistical Manual of Mental Disorders, Third Edition, Revised. Washington D.C.: American Psychiatric Association.

American Psychiatric Association (1994). Diagnostic and Statistical Manual of Mental Disorders, Fourth Edition. Washington D.C.: American Psychiatric Association.

Amir, N., McNally, R.J., Riemann, B.C., Burns, J., Lorenz, M., \& Mullen, J.T. (1996). Suppression of the emotional Stroop effect by increased anxiety in patients with social phobia. Behaviour Research and Therapy, 34, 945-948.

Andrade, J. (1995). Learning during anaesthesia: A review. British Journal of Psychology, 86, 479-506.

Arntz, A., Lavy, E., Van den Berg, G., \& Van Rijsoort, S. (1993). Negative beliefs of spider phobics: A psychometric evaluation of the spider phobia beliefs questionnaire. Advances in Behavior Research and Therapy, 15, 257-277.

Arrindell, W.A., Pickersgill, M.J., Merckelbach, H., Ardon, A.M., \& Comet, F.C. (1991). Phobic dimensions III. Factor analytic approaches to the study of common phobic fears; an updated review of findings with adult subjects. Advances in Behaviour Research and Therapy, 13, 73-130.

Balaban, M.T. \& Taussig, H.N. (1994). Salience of fear / threat in the affective modulation of the human startle blink. Blological Psychology, $0,1-15$.

Balay, J. \& Shevrin, H. (1988). The subliminal psychodynamic activation method: A critical review. American Psychologist, 43, 161-174.

Banaji, M.R. \& Greenwald, A.G. (1995). Implicit stereotyping in judgments of fame. Journal of Personality and Social Psychology, 65, $272-281$.

Banaji, M.R. \& Hardin, C. (1996). Automatic gender stereotyping. Psychological science, 7, 136-141.

Banaji, M.R., Hardin, C., \& Rothman, A. (1993). Implicit stereotyping in person judgment. Joumal of Personality and Social Psychology, 65, 272-281.

Bargh, J.A. (1989). Conditional automaticity: Variaties of automatic influence in social perception and cognition. In J.S. Uleman \& J.A. Bargh (Eds.), Unintended thought. New York: Guilford.

Bargh, J.A. (1992). The ecology of automaticity: Toward establishing the conditions needed to produce automatic processing effects. American Jowrnal of Psychology, 105,18 i-199. 
Bargh, J.A. \& Chartrand, T.L. (1999). The unbearable automaticity of being. American Psychologist, 54, 462-479.

Bargh, J.A., Chen, M., \& Burrows, L. (1996). Automaticity of social behavior: Direct effects of trait construct and stereotype activation on action. Joumal of Personality and Social Psychology, 71, 230-244.

Bargh, J.A. \& Pietromonaco, P. (1982). Automatic information processing and social perception: The influence of trait information presented outside of conscious awareness on impression formation. Journal of Personality and Social Psychology, 43,437.449.

Bargh, J.A., Raymond, P., Pryor, J., \& Strack, F. (1995). Attractiveness of the underlying: An automatic power $\rightarrow>$ sex association and its consequences for sexual harassment and aggression. Joumal of Personality and Social Psychology, 68, 768-781.

Barlow, D.H. (1988). Anxiety and its disorders: The nature and treatment of anxiety and panic. New York: Guilford Press.

Bechara, A., Damasio, A.R., Damasio, H. \& Anderson, S.W. (1994). Insensitivity to future consequences following damage to human prefrontal cortex. Cogmition, 50, 7-15.

Bechara, A., Damasio, H., Tranel, D., \& Damasio, A.R. (1997). Deciding advantageously before knowing the advantageous strategy. Science, 275, 1293 1294.

Beck, A.T. \& Clark, D.A. (1997). An information processing model of anxiety: Automatic and strategic processes. Behaviour Research and Therapy, 35, 49-58.

Beck, A.T., Emery, G., \& Greenberg, R.L. (1985). Anxiety disorders and phobias: $A$ cognitive perspective. New York: Basic Books.

Beck, A.T. \& Steer, R.A. (1987). Beck Depression Inventory mamwal. San Antonio, TX: The Psychological Corporation.

Begg, I. M., Needlham, D. R., \& Bookbinder, M. (1993). Do backward messages unconsciously affect listeners? No. Canadian Journal of Experimental Psychology, 47, 1-14.

Bengesser, G. \& Walli, J. (1994). Suggestive measures involving exposure to phobias. European Journal of Pychiatry, 8, 205-208.

Benoit, S. \& Roger, T. (1992). The influence of expectancy in subliminal perception experiments. The Journal of General Psychology, 119, 335-341.

Blackmore, S.J., Brelstaff, G., Nelson, K., \& Troscianko, T. (1995). Is the richness of our visual world an illusion? Transsaccadic memory for complex scenes. Percepiion, 24, 1075-1081.

Boelhouwer, A.J.W. \& Blumenthal, T.D. (1993). The electrically elicited eyeblink as a measure for social anxiety. Psychophysiology, 30,518.

Bonebakker, A. (1995). Memory during general anaesthesia: variations in stimulus characteristics. Delft: Eburon P\&L. 
Bourdon, K.H., Boyd, J.H., Rae, D.S., Burns, B.J., Thompson, J.W., \& Locke, B.Z. (1988). Gender differences in phobias: Results of the ECA community survey. Joumal of Anxiery Disorders, 2, 227-241.

Bower, G.H. (1981). Mood and memory. American Psychologist, 36, 129-148.

Bradley, M.M., Cuthbert, B.N., \& Lang, P.J. (1990). Startle reflex modification: Emotion or attention? Psychophysiology, 27, 513-522.

Bradley, M.M., Cuthbert, B.N., \& Lang, P.J. (1993). Pictures as prepulse: Attention and emotion in startle modification. Psychophysiology, 30, 541-545.

Britt, T.W. \& Blumenthal, T.D. (1993). Social anxiety and latency of response to startle stimuli. Joumal of Research in Personality, 27, 1-14.

Carver, C., Gamellen, R., Froming, W., \& Chambers, W. (1983). Modelling: An analysis in terms of category accessibility. Jownal of Experimental Social Psychology, 19, 403-421.

Chapman, T.F. (1997). The epidemiology of fears and phobias. In: G.C.L. Davey (Ed.) Phobias. A handbook of theory, research and treatment. Wiley \& Sons: New York.

Cheesman, J. \& Merikle, P. M. (1986). Distinguishing conscious from unconscious perceptual processes. Canadian Jowmal of Psychology, 40, 343-367.

Cohen, J. (1988). Statistical power analysis for the behavioral sciences ( $2^{\text {nd }}$ ed.). Hillsdale, NJ: Erlbaum.

Cook III, E.W., Hawk, L.W., Davis, T.L., \& Stevenson, V.E. (1991). Affective individual differences and startle reflex modulation. Journal of Abnormal Psychology, 100, 5-13.

Cornelius, R.R. \& Averill, J.R. (1983). Sex differences in fear of spiders. Joumal of Personality and Social Psychology, 45, 377-383.

Costello, C. G. (1982). Fears and phobias in women: A community study. Journal of Abnomal Psychology, 91, 280-286.

Crews, F. (1996). The verdict on Freud. Psychological Sicience, 7, 63-68.

Curtis, G.C., Magee, W.J., Eaton, W.W., Wittchen, H.-U., \& Kessler, R.C. (1998). Specific fears and phobias. British Journal of Psychiatry, 173, 212-217.

Cuthbert, B.N., Bradley, M.M., \& Lang, P.J. (1996). Probing picture perception: Activation and emotion. Psychophysiology, 33, 103-111.

Damasio, A.R. (1994). Descartes' error. Emotion "reason, and the human brain. New York: Putnam.

Davey, G.C.L. (1992). An expectancy model of laboratory preparedness effects. Jowmal of Experimental Psychology: General, 121, 24-40.

Davey, G.C.L. (1992). Characteristics of individuals with fear of spiders. Anxiety Research, 4, 299-314.

Davey, G.C.L. (1995). Preparedness and phobias: Specific evolved associations or a generalized expectancy bias? Behavioral and Brain Sciences, 18, 289-297.

Davey, G.C.L., Forster, L., \& Mayhew, G. (1993). Familial resemblances in disgust sensitivity and animal phobias. Behaviour Research and Therapy, 31,41-50. 
Davis, M. (1992). The role of the amygdala in conditioned fear. In J.P. Aggleton (Ed), The amygdala: Neurobiological aspects of emotion, memory and mental diysfunctions. New York: Wiley.

Davis, M, Hitchcock, J.M, \& Rosen, J.B. (1987). Anxiety and the amygdala: Pharmacological and anatomical analysis of the fear-potentiated startle paradigm. In G.H. Bower (Ed.), The psychology of learning and motivation. San Diego: Academic Press.

Dawson, M., Schell, A., \& Filion, D. (1990). The electrodermal system. In J.T. Cacioppo \& L.G. Tassinary (Eds.), Principles of psychophysiology: Physical, social, and inferential elements (pp. 295-324). Cambridge: Cambridge University Press.

De Jong, P.J. \& Kindt, M. (1999). Finding the face in the crowd: Anger superiority effects and social anxiety. Manuscript under review.

De Jong, P.J. \& Merckelbach, H. (1991). Covariation bias and electrodermal responding in spider phobics before and after behavioural treatment. Behaviour Research and Therapy, 29, 307-314.

De Jong, P.J. \& Merckelbach, H. (1999). Covariation bias in phobia: a cold or hot phenomenon? Manuscript under review.

De Jong, P.J., Merckelbach, H., \& Arntz, A. (1991). Eyeblink startle responses in spider phobics before and after treatment: A pilot study. Journal of Psychopathology and Behavioral Assessment, 13, 213-223.

De Jong, P.J., Merckelbach, H., \& Arntz, A. (1995). Covariation bias in phobic women: The relationship between a priori expectancy, on-line expectancy, autonomic responding, and a posteriori contingency judgment. Journal of Abnormal Psychology, 104, 55-62.

De Jong, P.J., Visser, S., \& Merckelbach, H. (1996). Startle and spider phobia: Unilateral probes and the prediction of treatment effects. Journal of Psychophysiology, 10, 150-160.

De Houwer, J., Baeyens, F., \& Eelen, P. (1994). Verbal conditioning with undetected US presentations. Behaviour Research and Therapy, 32, 629-633.

Diamond, D., Matchett, G., \& Davey, G.C.L. (1995). The effect of prior fear levels on UCS-expectancy ratings to a fear-relevant stimulus. Quarterly Journal of Experimental Psychology: Human Experimental Psychology, 48A, 237-247.

Dijksterhuis, A., Bargh, J.A., \& Miedema, J. (2000). Of men and mackerels: Attention and automatic social behavior. In H. Bless \& J. Forgas (Eds.), Subjective experience in social cognition and behavior. Philadelphia: Philadelphia press.

Dimberg, U. \& Öhman, A. (1983). The effects of directional facial cues on electrodermal conditioning to facial stimuli. Psychophysiology, 20, 160-167.

Dixon, N.F. (1981). Preconscious processing. New York: Wiley \& Sons.

Dixon, N.F. \& Henley, H.A. (1991). Unconscious perception: Possible implications of data from academic research for clinical practice. Journal of Nervous and Mental Disease, 179, 243-252. 
Ehlers, A. (1993). Interoception and panic disorder. Advances in Behaviour Research and Therapy, 15, 3-21.

Ehlers, A., Margraf, J., Davies, $S_{*}$ \& Roth, W.T. (1988). Selective processing of threat cues in subjects with panic attacks. Cognition and Emotion, 2, 201-219.

Erdelyi, M.H. (1985). Psychoanalysis: Freud"s cogmitive psychology. New York: Freeman.

Esteves, F, Dimberg, U., \& Ôhman, A. (1994). Automatically elicited fear: Conditioned skin conductance responses to masked facial expressions. Cognition and Emotion, 8, 393-413.

Esteves, F., Parra, C., Dimberg, U., \& Öman, A. (1994). Nonconscious associative leaming: Pavlovian conditioning of skin conductance responses to masked fearrelevant facial stimuli. Psychophysiology, 31, 375-385.

Eysenck, H. J. (1985). Decline and fall of the Freudian empire. New York, Viking.

Foa, E.B. \& Kozak, M.. (1986). Emotional processing of fear: Exposure to corrective information. Psychological Bulletin, 99, 20-35.

Fox, E. (1996). Selective processing of threatening words in anxiety: The role of awareness. Cognition and Emotion, 10, 449-480.

Foy, M.R., Stanton, M.E., Levine, S, \& Thompson, R.F. (1987). Behavioral stress impairs long-term potentiation in rodent hippocampus. Behavioral and Neural Biology, 48, 138-149.

Fredrikson, M. (1981). Orienting and defensive reactions to phobic and conditioned fear stimuli in phobies and normals. Psychophysiology, 18,456-465.

Fredrikson, M., Annas, P., Fischer, H., \& Wik, G. (1996). Gender and age differences in the prevallence of specific fears and phobias. Behaviour Research and Therapy, 34, 33-39.

Fredrikson, M., Hugdahl, K., \& Öhman, A. (1976). Electrodermal responding to potentially phobic stimuli in male and female subjects. Biological Psychology, 4, 305-314.

Fredrikson, M., Sundin, O., \& Frankenhaeuser, M. (1985). Cortisol excretion during the defense reaction in humans. Psychosomatic Medicine, 47, 313-319.

Freud, S. (1909; 1984). Analyse der Phobie eines funfiahrigen Knaben. Gesammelte Werke VII. Frankfurt am Main: Fischer Taschenbuch Verlag.

Garcia, J. \& Koelling, R.A. (1966). Relation of cue to consequence in avoidance leaming. Psychonomic Science, 4, 123-124.

Globisch, J., Hamm, A.O., Esteves, F., \& Öhman, A. (1999). Fear appears fast: Temporal course of startle reflex potentiation in animal fearful subjects. Psychophysiology, 36, 66-75.

Globisch, J., Weike, A., \& Hamm, A.O. (1996). Startle reflex modulation during unconscious processing of fear-evoking slides in animal phobics. Psychophysiology, 33, 541 [Abstract].

Greenwald, A. G. (1992). New Look 3. Unconscious cognition reclaimed. American Psychologist, 47, 766-779. 
Greenwald, A., Draine, S., \& Abrams, R. (1996). Three cognitive markers of unconscious semantic activation. Science, 273, 1699-1702.

Greenwald, A.G., Spangenberg, E.R., Pratkanis, A.R. \& Eskenazi, J. (1991). Doubleblind tests of subliminal self-help audiotapes. Psychological Science, 2, 119-122.

Grimes, J. (1996): On the failure to detect changes across saccades. In K. Akins (Ed.), Perception (pp. 89-110). New York: Oxford University Press.

Hamm, A.O., Cuthbert, B.N., Globisch, J., \& Vaitl, D. (1997). Fear and the startle reflex: Blink modulation and autonomic response patterns in animal and mutilation fearful subjects. Psychophysiology, 34, 97-107.

Hampton, C., Purcell, D.G., Bersine, L., Hansen, C.H., \& Hansen, R.D. (1989). Probing 'pop-out': Another look at the face-in-the-crowd effect. Bulletin of the Psychonomic Society, 27, 563-566.

Hansen, C.H. \& Hansen, R.D. (1988). Finding the face in the crowd: An anger superiority effect. Journal of Personality and Social Psychology, 54, 917-924.

Hare, R.D. \& Blevings, G. (1975). Defensive responses to phobic stimuli. Biological Psychology, 3, 1-13.

Henke, K., Landis, T. \& Markowitsch, H. (1994). Subliminal perception of words and faces. International Journal of Newroscience, 75, 181-187.

Hitchcock, J.M. \& Davis, M. (1991). Efferent pathway of the amygdala involved in conditioned fear as measured with the fear-potentiated startle paradigm. Behavioral Neuroscience, 105, 826-842.

Hodes, R.L., Cook, E.W., \& Lang, P.J. (1985). Individual differences in autonomic response: Conditioned association or conditioned fear? Psychophysiology, 22, 545-560.

Hofstadter, D. (1985). Metamagical theme's. New York, Basic Books.

Holender, D. (1986). Semantic activation without conscious identification in dichotic listening, parafoveal vision, and visual masking: A survey and appraisal. The Behavioral and Brain Sciences, 9, 1-66.

Hornstein, G.A. (1992). The return of the repressed. Psychology's problematic rellations with psychoanalysis, 1909-1960. American Psychologist, 47, 254-263.

Horowitz, M.J. (1988). Psychodynamics and Cognition. Chicago: University of Chicago Press.

Hudesman, J., Page, W., \& Rautiainen, J. (1992). Use of subliminal stimulation to enhance learning mathematics. Perceptual and Motor Skills, 74, 1219-1224.

Hugdahl, K. (1978). Electrodermal conditioning to potentially phobic stimuli: Effects of instructed extinction. Behaviour Research and Therapy, 16, 315-321.

Hugdahl, K. (1989), Simple phobias. In G. Turpin (Ed); et-al. Handbook of clinical psychophysiology. Wiley psychophysiology handbooks (pp. 283-308). Chichester, England: John Wiley \& Sons.

Hugdahl, K., Fredrikson, M., \& Öhman, A. (1977). "Preparedness" and "arousability" as determinants of electrodermal conditioning. Behaviour Research and Therapy, 15, 345-353. 
Hugdahi, K. \& Öhman, A. (1977). Effects of instruction on acquisition and extinction of electrodermal responses to fear relevant stimuli. Jownal of Experimental Psychology: Human Learning and Memory, 3, 608-618.

Isen, A.M, Daubman, K.A., \& Nowicki, G.P. (1987). Positive affect facilitates creative problem solving. Journal of Personality and Social Psychology, 52, 1122-1131.

Iwata, J., LeDoux, J.E., Meeley, M.P., Americ, S., \& Reis, D.J. (1986). Intrinsic neurons in the anygdaloid field projected to by the medial geniculate body mediate emotional responses conditioned to acoustic stimuli. Brain Research, $418,183-188$.

Jacobs, W.J. \& Nadel, L. (1985). Stress-induced recovery of fears and phobias. Psychological Review, 92, 512-531.

James, W. (1884). What is emotion? Mind, 9, 188-205.

Johnson, H. \& Eriksen, C.W. (1961). Preconscious perception: A reexamination of the Poetzl phenomenon. Journal of Abnormal and Social Psychology, 62, 497. 503.

Kahneman, D. \& Chajczyk, D. (1983). Tests of the automaticity of reading: Dilution of Stroop effects by color-irrelevant stimuli. Joumal of Experimental Psychology: Human Perception and Performance, 9, 497-509.

Kapp, B.S., Pascoe, J.P., \& Bixler, M.A. (1984). The amygdala: A neuroanatomical systems approach to its contributions to aversive conditioning. In N. Buttlers and L.R. Squire (Eds.), Neuropsychology of memory. New York: Guilford.

Katkin, E.S. \& Hoffman, L.S. (1976). Sex differences and self-report of fear: A psychophysiological assessment. Journal of Abnormal Psychology, 85, 607-610.

Kemp-Wheeler, S.M. \& Hill, A.B. (1987). Anxiety responses to subliminal experience of mild stress. British Journal of Psychology, 78, 365-374.

Kemp-Wheeler, S.M. \& Hill, A.B. (1992). Semantic and emotional priming below objective detection threshold. Cogmition and Emotion, 6, 113-128.

Kessler, R.C., McGonagle, K.A., Zhao, S., Nelson, C.B., Hughes, M., Eshleman, S., Wittchen, H.U., \& Kendler, K.S. (1994). Lifetime and 12-month prevalence of DSM-II-R psychiatric disorders in the United States. Archives of General Psychiatry, 51, 8-19.

Key, W.B. (1973). Subliminal seduction. Englewood Cliffs, New York: Signet.

Kihlstrom, J.F. (1987). The cognitive unconscious. Science, 237, 1445-1452.

Kindt, M., Bierman, D., \& Brosschot, J.F. (1997). Cognitive bias in spider fear and control children: Assessment of emotional interference by a card format and a single-trial format of the Stroop task. Joumal of Experimental Child Psychology, 66, 163-179.

Kindt, M., Brosschot, J.F., \& Everaerd, W. (1997). Cognitive processing bias of children in a real life stress situation and a neutral situation. Joumal of Experimental Child Psychology, 64, 79-94. 
Kindt, M., Brosschot, J.F., \& Muris, P. (1996). Spider Phobia Questionnaire for Children (SPQ-C): A psychometric study and normative data. Behaviour Research and Therapy, 34, 277-282.

Kitayama, S. (1991). Impairment of perception by positive and negative affect. Cognition and emotion, 5, 255-274.

Klormaa, R., Weerts, T.C., Hastings, J.E., Melamed, B.G., \& Lang, P.J. (1974). Psychometric description of some specific fear questionnaires. Behavior Therapy, $5,401-409$.

Kohut, H. (1977). The restoration of the self. New York: International Universities Press.

Krosnick, J.A., Betz, A.L., Jussim, L.J, \& Lynn, A.R. (1992). Subliminal conditioning of attitudes. Personality and Social Psychology Bulletin, 18, 152162.

Kunst-Wilson, W. \& Zajonc, R. (1980). Affective discrimination of stimuli that cannot be recognized. Science, 207, 557-558.

Ladavas, E., Cimatti, D., Del Pesce, M., \& Tvozzi, G. (1993). Emotional evaluation with and without conscious stimulus identification: Evidence from a split-brain patient. Cognition and Emotion, 7, 95-114.

Lang, P.J., Bradley, M.M., \& Cuthbert, B.N. (1990). Emotion, attention, and the startle reflex. Psychological Review, 97, 377-395.

Lang, P.J., Bradley, M.M., \& Cuthbert, B.N. (1992). A motivational analysis of emotion: Reflex-cortex connections. Psychological Science, 3, 44-49.

Lang, P.J., Öhman, A., \& Vaitl, D. (1988). The International Affective Picture System. Gainesville, Fl.: Center for Research in Psychophysiology, University of Florida, Gainesville.

Last, C.G. (1987). Simple phobias. In L.Michelson \& M.L. Ascher (Eds.), Anxiety and stress disorders: Cognitive-behavioral assessment and treatment (pp. 176190). New York: Guilford Press.

Lavond, D.G., K.im, J.J., \& Thompson, R.F. (1993). Mammalian brain substrates of aversive classical conditioning. Annual Review of Psychology, 44, 317-342.

Lavy, E, \& Van den Hout, M.A. (1993). Selective attention evidenced by pictorial and linguistic Stroop tasks. Behavior Therapy, 24, 645-657.

Lavy, E.H., Van den Hout, M.A., \& Amtz, A. (1993). Attentional bias and facilitated escape: A pictorial test. Advances in Behaviour Research and Therapy, 15, 279289.

LeDoux, J.E. (1986). Sensory systems and emotion: A model of affective processing. Integrative Psychiatry, 4, 237-243.

LeDoux, J.E. (1987). Emotion. In F. Plum (Ed.), Handbook of physiology. I: The nervous system. Bethesda, MD: American Physiological Association.

LeDoux, J.E. (1990). Information flow from sensation to emotion: Plasticity in the neural computation of stimulus value. In M. Gabriel and J. Moore (Eds.), Learning and computational neuroscience: Foundations of adaptive networks. Cambridge, MIT Press. 
LeDoux, J.E. (1992). Brain mechanisms of emotion and emotional learning. Current Opinion in Neurobiology, 2, 191-198.

LeDoux, J.E. (1994). Emotion, memory and the brain. Scienific American, 32-39.

LeDoux, J.E. (1995). Emotion: Clues from the brain. Anmual Review of Psychology, 46, 209-235.

LeDoux, J.E., Ruggiero, D.A., \& Reis, D.J. (1985). Projections to the subcortical forebrain from anatomically defined regions of the medial geniculate body in the rat. Journal of Computational Neurology, 242, 182-213.

LeDoux, J.E., Sakaguchi, A, Iwata, J, \& Reis, D.J. (1986). Interruptions of projections from the medial geniculate body to an archi-neostriatal field disrupts the classical conditioning of emotional responses to acoustic stimuli in the rat. Neuroscience, 17,615-627.

LeDoux, J.E., Sakaguchi, A., \& Reis, D.J (1984). Subcortical efferent projections of the medial geniculate nucleus mediate emotional responses conditioned by acoustic stimuli. Journal of Neuroscience, 4, 683-698.

Lee, I. \& Tyrer, P.J. (1980). Responses of chronic agoraphobics to subliminal and supraliminal phobic motion pictures. Joumal of Nervous and Mental Disease, $168,34-40$.

Lee, I., Tyrer, P. \& Hom, S. (1983). A comparison of subliminal, supraliminal and faded phobic cine-films in the treatment of agoraphobia. British Joumal of Psychiatry, 143, 356-361.

Levelt, W.J.M. (1993). Speaking: From intention to articulation. Cambridge, Mass. MIT press.

Levin, D.T. \& Simons, D.J. (1997). Failure to detect changes to attended objects in motion pictures. Psychonomic Bulletin and Review, 4, 501-506.

Lewicki, P., Hill, T., \& Czyzeweska, M. (1992). Nonconscious acquisition of information. American Psychologist, 47, 796-801.

Lewicki, P., Hill, T., \& Czyzeweska, M. (1997). Hidden covariation detection: A fundamental and ubiquitous phenomenon. Journal of Experimental Psychology: Leaming, Memory, and Cognition, 23, 221-228.

Loftus, E.F. \& Klinger, M.R. (1992). Is the unconscious smart or dumb? American Psychologist, 47, 761-765.

Logan, G.D. (1985). Skill and automaticity: Relations, implications, and future directions. Canadian Joumal of Psychology, 39, $367-386$.

Luborsky, L., Blinder, B., \& Macworth, N. (1964). Eye fixation and recall of pictures as a function of GSR responsivity. Perceptual and Motor Skills, 16, 469-483.

MacLeod, C.M. (1991). Half a century of research on the Stroop effect: An integrative review. Psychological Bulletin, 109, 163-203.

MacLeod, C. \& Hagan, R. (1992). Individual differences in the selective processing of threatening information, and emotional responses to a stressful life event. Behaviour Reseanch and Therapy, 30,151-161.

MacLeod, C. \& Rutherford, E. (1992). Anxiety and the selective processing of emotional information: Mediating roles of awareness, trait and state variables, and 
personal relevance of stimulus materials. Behaviour Research and Therapy, 30 , 479-491.

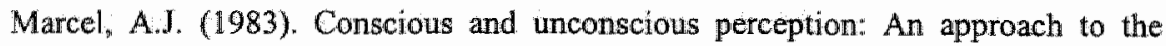
relations between phenomenal experience and perceptual processes. Cognitive Psychology, 15, 238-300.

Masling, J.M., Bornstein, R.F., Poynton, F.G., Reed, S. \& Katkin, E.S. (1991). Perception without awareness and electrodemal responding: A strong test of subliminal psychodymamic activation effects. Journal of Mird and Behavior, 12 , $33-48$.

Matchett, G. \& Davey, G.C.L. (1991). A test of a disease-avoidance model of animal phobias. Behaviour Research and Therapy, 29,91-94.

Mathews, A. \& MacLeod, C. (1985). Selective processing of threat cues in anxiety states. Behowiour Research and Therapy, 23, 563-569.

Mayer, B. \& Merckelbach, H. (1999a). Unconscious processes, subliminal stimulation, and anxiety. Clinical Psychology Review, 19, 571-590.

Mayer, B. \& Merckelbach, H. (1999b). Do subliminal priming effects on emotion have clinical potential? Anxiety, Stress, and Coping, 12, 217-229.

Mayer, B. \& Merckelbach, H. (1999c). Do differential SCRs to masked fearfun stimuli depend on stimulus size? Submitted for publication.

Mayer, B., Merckelbach, H., \& De Jong, P.J. (1999a). Subliminal phobic stimuli, eyeblink startle reflexes, and cognitive interference. Submitted for publication.

Mayer, B., Merckelbach, H., \& De Jong, P.J. (1999b). How to handle contradictory results? Discount the data or refine the theories? A reply to Öhman. Journal of Psychophysiology, 13, 257-259.

Mayer, B., Merckelbach, H., De Jong, P.J. \& Leeuw, I. (1999). Skin conductance responses of spider phobics to backwardly masked phobic cues. Joumal of Psychophysiology, 13, 152-159.

Mayer, B., Merckelbach, H., \& Muris, P. (1999a). Automaticity and irrationality in spider phobia. Submitted for publication.

Mayer, B., Merckelbach, H., \& Muris, P. (1999b). Spider-phobic children do not react with differential skin conductance responses to masked phobic stimuli. Joumal of Psychopathology and Behavioral Assessment, 21, 237-248.

MoNally, R. (1987). Preparedness and phobias: A review. Psychological Bulletin. $101,283-303$.

McNally, R. (1989). On "stress-induced recovery of fears and phobias". Psychological Review, 96, 180-181.

McNally, R. (1995). Automaticity and the anxiety disorders. Behaviour Research and Therapy, $33,747-754$.

McNally, R. (1998). Information-processing abnormalities in anxiety disorders: Implications for cognitive neuroscience. Cognition and Emotion, 12, 479-495.

McNally, R, Amir, N., \& Lipke, H. (1996). Subliminal processing of threat cues in posttraumatic stress disorder? Joumal of anxiety disorders, 10, 115-128. 
McNally, R. \& Foa, E.B. (1986). Preparedness and resistance to extinction to fearrelevant stimuli: A failure to replicate. Behoviour Research and Theropy, 24, 529 . 535 .

McNally, R., Riemann, B.C., \& Kim, E. (1990). Selective processing of threat cues in panic disorder. Behaviour Research and Therapy, 28, 407-412.

McNally, R. \& Steketee, G.S. (1985). The etiology and maintenance of severe animal phobias. Behaviour Research and Therapy, 23, $431-435$.

Merckelbach, H., De Jong, P.J., Arntz, A., \& Schouten, E. (1993). The role of evaluative learning and disgust sensitivity in the etiology and treatment of spider phobia. Advances in Behaviour Research and Therapy, 15, 243-255.

Merckelbach, H., De Jong, P.J., Leeuw, 1, \& Van den Hout M.A. (1995). Startle responses of spider phobics to masked stimuli: A pilot study. Intermational Journal of Neuroscience, $8,169-175$.

Merckelbach, H., De Jong, P.J., Muris P., \& Van den Hout, M.A. (1996). The etiology of specific phobias: A review. Clinical Psychology Review, 16, 337-361.

Merckelbach, H, Kenemans, J.L., Dijkstra, A., \& Schouten, E. (1993). No attentional bias for pictoral stimuli in spider-fearful subjects. Jowrnal of Psychopathology and Behavioral Assessment, 15, 197-206.

Merckelbach, H. \& Overduin, J. (1993). Een nederlandse Pavloviaan: J. ten Cate (1887-1967). De Psycholoog, 28, 67-70.

Merckelbach, H., Van den Hout, M.A., Jansen, A., \& Van der Molen, G.M. (1988). Many stimuli are frightening but some are more frightening than others: The contributions of preparedness, dengerousness, and unpredictability to making a stimulus fearful. Journal of Psychopathology and Beñavioral Assessment, 10, 355-366.

Merckelbach, H., Van der Molen, G.M., \& Van den Hout, M.A. (1987). Electrodermal conditioning to stimuli of evolutionary significance: Failure to replicate the preparedness effect. Journal of Psychopathology and Behaviomal Assessment, 9, 313-326.

Merikle, P.M. \& Daneman, M. (1998). Psychological investigations of unconscious perception. Joumal of Conscionsness Studies, 5, 5-18.

Miller, J. (1991). Threshold variability in subliminal perception experiments: Fixed threshold estimates reduce power to detect subliminal effects. Journal of Experimental Psychology, 17,841-851.

Mogg, K., Bradley, B., Millar, B., \& White, J. (1995). A follow up study of cognitive bias in generalised anxiety disorder. Behaviour Research and Therapy, 33, 927935 .

Mogg, K., Bradley, B., Williams, R., \& Mathews, A. (1993). Subliminal processing of emotional information in anxiety and depression. Joumal of Abnormal Psychology , 102, 304-311.

Mogg, K., Kentish, J., \& Bradley, B. (1993). Effects of anxiety and awareness on colour-identification latencies for emotional words. Behaviour Research and Therapy, 31, 559-567. 
Mogg, K., Mathews, A., \& Weinman, J. (1989). Selective processing of threat cues in anxiety states: A replication. Behaviour Research and Therapy, 27, 317-323.

Moore, T. E. (1988). The case against subliminal manipulation. Psychology and Marketing, 5, 297-316.

Morris, J.S., Öhman, A., \& Dolan, R.J. (1998). Conscious and unconscious emotional learning in the human amygdala. Nature, 393, 467-470.

Morris, J.S., Öhman, A., \& Dolan, R.J. (1999). A subcortical pathway to the right amygdala mediating "unseen" fear. Proceedings of the National Academy of Sciences of the United States of America, 96, 1680-1685.

Mulkens; S.A.N., De Jong, P.J., \& Merckelbach, H. (1996). Disgust and spider phobia. Journal of Abnormal Psychology, 105, 464-468.

Muris, P. \& Merckelbach, H. (1996). A comparison of two spider fear questionnaires. Journal of Behavior Therapy and Experimental Psychiatry, 27, 241-244.

Muris, P. \& Merckelbach, H. (1998). Specific phobias. In A.S. Bellack and M. Hersen (Eds.), Comprehensive Clinical Psychology. New York: Pergamon Press.

Muris, P. \& Merckelbach, H. (2000). The etiology of childhood specific phobia: A multifactorial model. In M.W. Vasey \& M. Dadds (Eds), The developmental psychopathology of anxiety. Oxford: Oxford University Press.

Muris, P., Merckelbach, H., Holdrinet, I., \& Sijsenaar, M. (1998). Treating phobic children: Effects of EMDR versus exposure. Journal of Consulting and Clinical Psychology, 66, 193-198.

Muris, P., Merckellbach, H., Van Haaften, H., \& Mayer, B. (1997). Eye movement desensitisation and reprocessing versus exposure in vivo: A single-session crossover study of spider-phobic children. British Journal of Psychiatry, 171, 8286.

Murphy, S., Monahan, J., \& Zajonc, R. (1995). Additivity of nonconscious affect: Combined effects of priming and exposure. Journal of Personality and Social Psychology, 69, 589-602.

Murphy, S. \& Zajonc, R. (1993). Affect, cognition, and awareness: affective priming with optimal and suboptimal stimulus exposures. Journal of Personality and Social Psychology, 5, 723-739.

Myers, J.K. et al. (1984). Six-month prevalence of psychiatric disorder in three communities: 1980 to 1982. Archives of General Psychiatry, 41, 959-967.

National Institute of Mental Health (1992). Diagnostic Interview Schedule for Children (DISC). Version 2.3. New York: New York State Psychiatric Institute, Division of Child and Adolescent Psychiatry.

Nelson, C.A. (1995). The ontogeny of human memory: A cognitive neuroscience perspective. Developmental Psychology, 31, 723-738.

Newman, L.S., Duff, K.J., \& Baumeister, R.F. (1997). A new look at defensive projection: Thought suppression, accessibility, and biased person perception. Journal of Personality and Social Psychology, 72, 980-1001. 
Ohmman, A. (1979). The orienting response, attention, and learning: An information processing perspective. In H.D. Kimmel \& J.F. Orlebeke (Eds), The orienting reflex in humans. Hillsdale, NJ: Erlbaum.

Ohman, A. (1986). Face the beast and fear the face: Animal and social fears as prototypes for evolutionary analyses of emotion. Psychophysiology, 23, 123-145.

Öhman, A. (1988). Preattentive processes in the generation of emotions. In V. Hamilton et al. (Eds), Cognitive Perspectives on Emotion and Motivation. Kluwer Academic Publishers.

Öhman, A. (1993). Fear and anxiety as emotional phenomena: Clinical phenomenology, evolutionairy perspectives, and information processing mechanisms. In M. Lewis \& J.M. Haviland (Eds.), Handbook of emotions. New York: Guilford.

Öhman, A. (1994). The psychophysiology of emotion: Evolutionary and nonconscious origins. In $G$. d'Ydewalle, P. Eelen \& P. Bertelson (Eds.), International perspectives on psychological science, vol.2, The state of the ant (pp. 197-227). Hove, England: Erlbaum.

Ohman, A. (1996). Preferential preattentive processing of threat in anxiety: Preparedness and attentional biases. In R.M. Rapee (Ed.), Current controversies in the amiety disorders. New York: Guilford Press.

Öhman, A. (1999), Contribution to confusion rather than to knowledge: A commentary on Mayer et al. Joumal of Psychophysiology, 13, 160-162.

Öhman, A. \& Dimberg, U. (1978). Facial expressions as conditioned stimuli for electrodermal responses: A case of "preparedness"? Journal of Personality and Social Psychology, 36, 1251-1258.

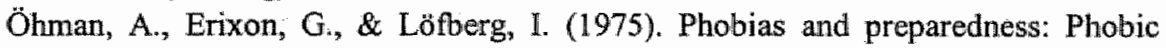
versus neutral pictures as conditioned stimuli for human autonomic responses. Journal of Abnormal Psychology, 84, 41-45.

Öhman, A., Esteves, F., \& Soares, J.J.F. (1995). Preparedness and preattentive associative leaming: Electrodemal conditioning to masked stimuli. Jownal of Psychophysiology, 9, 99-108.

Ohman, A., Fredrikson, M., Hugdahl, K., \& Rimmo, P.-A. (1976). The premise of equipotentiality in human classical conditioning: Conditioned electrodermal responses to potentially phobic stimuli. Journal of Experimental Psychology: General, 105, 313-337.

Öhman, A. \& Soares, J.J.F. (1993). On the automatic nature of phobic fear: Conditioned electrodermal responses to masked fear-rellevant stimuli. Journal of Abnormal Psychology, 102, 121-132.

Öhman, A. \& Soares, J.J.F. (1994). "Unconscious anxiety": Phobic responses to masked stimuii. Journal of Abnormal Psychology, 103, 231-240.

Öhman, A. \& Soares, JJ.F. (1998). Emotional conditioning to masked phobic stimul: Expectancies for aversive outcomes following nonrecognized fearrelevant stimuli. Joumal of Experimental Psychology: General, 127, 69-82. 
O'Keefe, J. Nadel, L. (1978). The hippocampus as a cognitive map. London: Oxford University Press.

Ost. L.G. (1987). Age of onset in different phobias. Joumal of Abnormal Psychology, 96, 223-229:

Ost, L.-G. (1989). One-session treatment for specific phobias. Behaviour Research and Therapy, $27,1-7$.

Ost, L.-G., Salkovskis, P.M., \& Hellström, K. (1991). One-session therapist directed exposure ws self-exposure in the treatment of spider phobia. Behavior Therapy, $22,407-422$.

Page, A.C. (1991). Simple phobias. International Review of Psychiatry, 3, 175-187.

Parra, C., Esteves, F., Flykt, A. \& Ohman, A. (1997). Pavlovian conditioning to social stimuli: Backward masking and the dissociation of implicit and explicit cognitive processes. Europian Psychologist, 2, 106-117.

Parrott, W.G.\& Schulkin, J. (1993). Neuropsychology and the cognitive nature of the emotions. Cognition and Emotion, 7, 43-59.

Purcell, D.G., Stewart, A.L., \& Skov, R.B. (1996). It takes a confounded face to pop out of a crowd. Perception, 25, 1091-1108.

Robins, L.N. \& Regier, D.A. (1991). Psychiatric disorders in America: the epidemiologic catchment area study. New York: Free Press.

Robles, R., Smith, R., Carver, C.S., \& Wellens, A.R. (1987). Influence of subliminal visual images on the experience of anxiety. Personality and Social Psychology Bulletin, 13,399-410.

Rosenthal, R. (1995). Progress in clinical psychology: Is there any? Clinical Psychology: Science and Practice, 2, 133-150.

Russell, T.G., Rowe, W. \& Smouse, A.D. (1991). Subliminal self-help tapes and academic achievement: An evaluation. Journal of Counselling and Development, $69,359-362$.

Seligman, M.E.P. (1970). On the generality of the laws of learning. Psychological Review, 77, 406-418.

Seligman, M.E.P. (1971). Phobias and preparedness. Behavior Therapy, 2, 307-320.

Shafran, R., Booth, R., \& Rachman, S. (1993). The reduction of claustrophobia: Cognitive analyses. Behaviour Research and Therapy, 31,75-85.

Shanks, D. \& St. John, M.F. (1994). Characteristics of dissociable human learning systems. Behavioral and Brain Sciences, 17, 367-447.

Shevrin, H. (1986). Subliminal perception and dreaming. The Joumal of Mind and Behavior, 7, 379-396.

Shors, T.J., Levine, S., \& Thompson, R.F. (1990), Opioid antagonist eliminates the stress-induced impaiment of long-term potentiation (LTP). Brain Research, 506, 316-318.

Silverman, L.H., Martin, A., Ungaro, R., \& Mendelsohn, E. (1978). Effect of subliminal stimulation of symbiotic fantasies on behavior modification treatment of obesity. Journal of Consulting and Clinical Psychology, 46, 432-441. 
Silverman, L.H., Ross, D.L., Adler, J.M., \& Lustig, D. A. (1978). Simple research paradigm for demonstrating subliminal psychodynamic activation: Effects of oedipal stimuli on dart-throwing accuracy in college males. Jownal of Abnormal Psychology, 87, 341-357.

Smith, K.H. \& Rogers, M. (1994). Effectiveness of subliminal messages in television commercials: Two experiments. Joumal of Applied Psychology, 79, 866-874.

Smith, T.B. (1993). Effects of subliminal stimuli on unconscious processing of anxiety: An examination of implicit perception. Perceptual and Molor Skills, 77 . 899-904.

Snodgrass, J., Levy-Berger, G., \& Haydon, M. (1985). Human Experimental Psychology. Oxford: Oxford University Press.

Soares, J.J.F. \& Öhman, A. (1993a). Backward masking and skin conductance responses after conditioning to nonfeared but fear-relevant stimuli in fearful subjects. Psychophysiology, 30, 460-466.

Soares, J.J.F. \& Ohman, A. (1993b). Preattentive processing, preparedness and phobias: effects of instruction on conditioned electrodermal responses to masked and nonmasked fear-relevant stimuli. Behaviour Research and Therapy, 31, 8795.

Soares, J.J.F. \& Öhman, A. (1995). Nonconscious emotional learning: Conditioning of skin conductance responses to masked snakes and spiders. Poster presented at the World Congress of Behavioural and Cognitive Therapies, $J$ wh, Copenhagen, Denmark.

Speltz, M.L. \& Bemstein, D.A. (1976). Sex differences in fearfulness". Verbal report, overt avoidance and demand characteristics. Journat of Behavior Therapy and Experimental Psychiatry, 7, 117-122.

Spielberger, C.D., Gorsuch, R.L., \& Lushene, R.E. (1974). Manual for the StateTrait Anxiety Inventary. Palo Alto, CA: Consulting Psychologists Press.

Squire, L.R. \& Zola-Morgan S. (1988). Memory: Brain systems and behavior. Trends in Neurosciences, 11, 170-175.

Stein, D.J. \& Bouwer, C. (1997). A neuro-evolutionary approach to the anxiety disorders. Journal of Anxiety Disonders, 11, 409-429.

Stern, R.M., Ray, W.J., \& Davis, C.M. (1980). Psychophysiological Recording. Oxford: Oxford University Press.

Sturgis, E.T. \& Scott, R. (1984). Simple phobia. In S.M. Turner, et al. (Ed), Behavioral theories and treatment of anxiety. (pp. 91-141). New York: Plenum Press.

Sulloway, F. J. (1979). Freud, biologist of the mind. New York, Basic Books.

Szymanski, J. \& O'Donohue, W. (1995). Fear of spiders questionnaire. Journal of Behavior Therapy and Experimental Psychiatry, 26, 31-34.

Tesser, A. (1976). Attitude polarization as a function of thought and reality constraints. Journal of Research in Personality, 10, 183-194.

Teyler, T.J. \& DiScenna, P. (1987). Long-term potentiation. Anmual Review of Neuroscience, 10, 131-161. 
Theus, K.T. (1994). Subliminal advertising and the psychology of processing unconscious stimuli: A review of research. Psychology and Marketing, 11, 271-290.

Thorpe, S.I. \& Salkovskis, P.M (1995). Phobic beliefs: Do cognitive factors play a role in specific phobias? Behaviour Research and Therapy, 33, 805-816.

Thorpe, S. \& Salkovskis, P. (1997). Information processing in spider phobics: The Stroop colour naming task may indicate strategic but not automatic attentional bias. Behaviour Research and Therapy, 35, 131-144.

Thyer, B.A., Parrish, R.T, Curtis, G.C., Nesse, R.M., \& Cameron, O.G. (1985). Ages of onset of DSM-III anxiety disorders. Comprehensive Psychiatry, 26, 113122.

Tolin, D.F., Lohr, J.M., Sawchuk, C.N., \& Lee, T.C. (1997). Disgust and disgust sensitivity in blood-injection-injury and spider phobia. Behaviour Research and Therapy, 35, 949-953.

Tyrer, P., Lewis, P. \& Lee, I. (1978). Effects of subliminal and supraliminal stress on symptoms of anxiety. The Journal of Nenous and Mental Disease, 166, 88-95.

Tzelgov, J. (1997). Automatic but consciousness: That is how we act most of the time. In R. Wyer (Ed), Advances in Social Cognition (Vol.10, pp. 217-230). Mahwah, NJ: Erlbaum.

Tzelgov, I., Porat, Z, \& Henik, A. (1997). Automaticity and consciousness: Is perceiving the word necessary for reading it? American Journal of Psychology, $110,429-448$.

Underwood, G. (1994). Subliminal perception on TV. Science, $370,103$.

Underwood, G. \& Everatt. J. (1996) Automatic and controlled information processing: The role of attention in the processing of novelty. In 0 . Neumann \& A.F. Sanders. Handbook of Perception and Action, Volume 3: Attention. London: Academic Press.

Van den Hout, M.A., De Jong, P.J., \& Kindt, M. (in press). Subliminally presented fear words produce increased SCRs. An anomaly for Ohman"s theory of preattentive processing in anxiety. Psychophysiology.

Van den Hout, M.A., Tenney, N., Huygens, K., \& De Jong, P.J. (1997). Preconscious processing bias in specific phobia. Behaviour Research and Therapy, 35, 29-34.

Van den Hout, M.A., Tenney, N., Huygens, K., Merckelbach, H., \& Kindt, M. (1995). Responding to subliminal threat cues is related to trait anxiety and emotional vulnerabillity: A succesful replication of MacLeod and Hagan. Behaviour Research and Therapy, 33, 451-454.

Vokey, J.R. \& Read, J.D. (1985). Subliminal messages. Between the devil and the media. American Psychologist, 40, 1231-1239.

Vrana, S.R., Spence, E.L., \& Lang, P.J. (1988). The startle probe response: A new measure of emotion? Joumal of Abnormal Psychology $97,487-491$.

Watts, F.N., McKenna, F.P., Sharrock, R., \& Trezise, L. (1986). Colour naming of phobia-related words. British Journal of Psychology, 77, 97-108.

Webb, K. \& Davey, G.C.L. (1992). Disgust sensitivity and fear of animals: Effect of exposure to violent or revulsive material. Anxiety, Stress, \& Coping, 5, 329-335. 
Wegner, D.M. \& Smart, $\mathbb{L}$. (1997). Deep cognitive activation: A new approach to the unconscious. Jowmal of Consulting and Clinical Psychology, 65, 984-995.

Weinberger, J. \& Hardaway, R. (1990). Separating science from myth in subliminal psychodynamic activation. Clinical Psychology Review, 10, 727-756.

Wexler, B.E., Warrenburg, S., Schwartz, G.E. \& Janer, L.D. (1992). EEG and EMG responses to emotion-evoking stimuli processed without conscious awareness. Neuropsychologica, 30, 1065-1079.

Whalen, P.J., Rauch, S.L., Etcoff, N.L., Mchemey, S.C., Lee, M.B., \& Jenike, M.A. (1998). Masked presentations of emotional facial expressions modulate amygdala activity without explicit knowledge. The Jownal of Nenroscience, $18,411-418$.

Whyte, L.L. (1978). The Unconscious before Freud. London: Julian Friedmann Publishers.

Williams, J.M.G., Mathews, A., \& MacLeod, C. (1996). The emotional Stroop task and psychopathology. Psychological Bulletin, 120,3-24.

Williams, J.M.G., Watts, F.N., Macleod, C., \& Mathews, A. (1988). Cognitive psychology and emotional disorders. Chichester, Wiley.

Wolpe, I. \& Rachman, I. (1973). The current status of systematic desensitization. American Journal of Psychiatry, 130, $961-965$.

Wong, P.S., Shevrin, H., \& Williams, W.J. (1994). Conscious and nonconscious processes: An ERP index of an anticipatory response in a conditioning paradigm using visually masked stimuli. Psychophysiology, 31,87-101.

Zajonc, R.B. (1980). Feeling and thinking: Preferences need no inferences. American Psychologist, 35, $151-175$. 
$\therefore: \cdots$

का

\& 


\section{Summary}

A phobia is a "marked and persistent fear that is excessive or unreasonable, cued by the presence or anticipation of a specific object or situation" (DSM-IV, American Psychiatric Association, p.410). Exposure to the phobic object or situation almost invariably provokes an immediate fear response. Although phobic patients recognize that their fear is excessive or unreasonable, they cannot control fear responses. Why?

According to Öhman (1988; 1994), hamans possess a perceptual monitoring system that can monitor fear-relevant stimuli automatically and simultaneously by many perceptual channels, independent of the subject's focus of attention. When the system identifies potential threat by recognizing the features, there is an automatic switch of attention that brings the stimulus into the focus of conscious attention. Simultaneously, the defense response would start to be recruited. Thus, as Ohman (1994, p.211) states, "this analysis implies that fear responses are activated even before the eliciting stimulus is consciously perceived". For a phobic patient, this would mean that the phobic object would always enter consciousness against a background of rising physiological activation. According to Ohman (1994), this provides a good theoretical account of the "irrationality" of phobias. That is, this perspective emphasizes that phobic fear originates from automatic processes which would explain why phobics are unable to control their fear by means of rational reasoning. As this is a promising explanation for the irrational and uncontrollable character of phobias, we subjected this hypothesis to empirical testing.

To examine whether a pre-attentive analysis of threatening stimuli is sufficient for a physiological fear response to occur, Öhman and associates carried out several experiments using the backward masking technique (see Marcel, 1983). For this matter, Öhman and co-workers presented two pictures very briefly and immediately after each other. As a result, the first picture (i.e., the target) is masked by the second picture (i.e., a meaningless mask), and is therefore kept out of conscious awareness. In their most crucial experiment, Öhman and Soares (1994) selected spider-fearful, snake-fearful, and non-fearful subjects and exposed them to backwardly masked fear-relevant (i.e., spiders and snakes) and neutral (i.e., mushrooms and flowers) stimuli. Results showed that spider-fearfuls responded with larger skin conductance responses (SCRs) to masked spider pictures, snake-fearfuls responded with larger SCRs to masked snake pictures, while the non-fearful controls did not respond specifically with large SCRs to any of the masked pictures. Thus, the authors claimed that although subjects were not consciously aware of the target stimuli, they responded with larger SCRs to specifically their feared stimulus. These findings suggest, indeed, that autonomic responses associated with fear can be elicited merely after a pre-attentive analysis of a fear-relevant stimulus. While the studies conducted by Öhman and co-workers have yielded impressive results, several critical points can be raised as to their interpretation. For example, with a few exceptions (Wong et al., 1994), the findings of Öhman and Soares have not been cross- 
valiclated ${ }$ they were not obtained in clinical phobics, and it is not sure whether the stimuli were genuinely subliminal. Moreover, the theoretical underpinnings of Öhman's hypothesis, and especially its heavy reliance on evolutionary "preparedness" notions, are not without problems (e.g., see McNally, 1987).

In the present thesis, Öhman's hypothesis about the pre-attentive activation of fear was examined in some detail. One of the basic assumptions of Öhman's idea is that phobics experience their fear response as automatic (i.e., involuntary). As a result of their automatically elicited physiological response, phobics would experience their fear of certain objects as irrational. To examine automaticity and irrationality in phobics at a phenomenological level and to determine whether these two characteristics are correlated as Öhman assumes, a questionnaire was developed and administered to spider phobic patients and non-fearful control participants (Study1). Results of this study showed, indeed, that phobics experience their fear response as an automatic reaction which they cannot control. Furthermore, phobics tended to view their reactions to spiders as irrational. That is, they admitted that their fear could not be explained by the dangerousness of the feared object. Even so, these two characteristics of phobic fear were not significantly correlated. Thus, at the phenomenological level, there was no straightforward connection between the absence of voluntary control and the tendency to view ones fear as irrational.

In their most critical experiment, OHman and Soares (1994) showed that spiderfearfuls responded differentially to masked spider slides, snake-fearfuls to masked snake slides, and non-fearfuls to none of the slides. To cross-validate these findings, a study was carried out following the lines of Öhman and Soares' (1994) experiment (see Study 2). Thus, SCRs were measured while masked phobic and control stimuli were presented. However, some changes in the experimental set-up were made. First, masked stimuli were presented to clinical phobic patients rather than to fearful undergraduates. Furthermore, as there was no guarantee that $30 \mathrm{~ms}$ presentations were genuinely subliminal, various presentation times for the masked stimuli were employed (i.e., 30, 20 , and $15 \mathrm{~ms}$ ). Finally, physiological measurement and awareness check trials were carried out in one and the same sample. This study failed to obtain differential SCRs to masked phobic pictures. Thus, the findings of Ohman and Soares (1994) could not be cross-validated.

One could argue that the SCR is not the most sensitive index for measuring fear as it is more a measure that reflects orienting and arousal. Perhaps, then, a more sensitive dependent variable could bring up the proposed effects. Therefore, in study 3 , eyeblink startle responses were measured. These responses are known to be sensitive to emotional valence (e.g., Lang, Bradley, \& Cuthbert, 1990; 1992). Furthermore, we measured whether masked phobic stimuli were able to elicit cognitive interference. That is, if masked phobic stimuli would elicit physiological responses whereas they would fail to elicit cognitive interference, this would have supported Öhman's hypothesis because this hypothesis predicts physiological effects in the absence of cognitive processes. In contrast, if masked phobic stimuli would elicit cognitive interference whereas they would fail to provoke physiological responses, this would make Öhman's 
hypothesis less likely to be true. Results showed that masked phobic pictures did not elicit larger eyeblink startle responses than masked control pictures. In addition, masked phobic pictures did not provoke cognitive interference. Note, however, that these pictures did elicit larger eyeblink startle responses and more cognitive interference in spider phobics when presented supraliminally. So far, masked phobic pictures seem not be able to elicit differential psychophysiological responses in spider phobic patients. Thus, no indications were found for the existence of a pre-attentive analysis mechanism for threatening stimuli.

One could argue that a potentially important difference between our studies and the study of Öhman and Soares (1994) pertains to the size of the projected stimuli. Whereas these authors used pictures of $21 \times 14 \mathrm{~cm}$ at a distance of 1 meter, the above described studies employed pictures of $110 \times 70 \mathrm{~cm}$ at a distance of 2 meters. Large masked pictures might not be capable of eliciting a physiological response because they probably do not fall completely within foveal vision. Consequently, picture size was manipulated in the fourth experiment (see Study 4). It was found that neither the large nor the small masked phobic pictures were able to induce differential SCRs in spiderfearful participants, although the small pictures had proportions that were quite comparable to those used by Öhman and co-workers.

Öhman argued that the pre-attentive analysis mechanism for threatening stimuli is an inheritance of our ancestors. If true, one would expect this mechanism also to be present in phobic children. Moreover, as children are much closer to the onset of their phobia, no extensive learning experiences (which can automatize the response) with the phobic object will have taken place. Accordingly, if Öhman's line of reasoning is correct, one would expect to find pre-attentive elicitation of physiological responses in phobic children. Then, an evolutionary explanation would be much stronger. To test this idea, we confronted in study 5 phobic children with masked phobic and control pictures. SCRs were measured while the children were exposed to these pictures. However, the results were disappointing in that no indications were found for pre-attentive activation of fear in spider phobic children.

Taken together, none of the presented studies found support for Öhman's hypothesis about pre-attentive elicitation of fear. It is hard to escape the conclusion that whether or not one finds differential physiological effects of masked fearful stimulation depends on an array of subtle factors. What about the subliminal manipulation of subjective fear? And what about the effect of positive masked stimuli? Results of a priming study (Study 6) showed that small priming effects can be found in a non-fearful group. That is, in the non-fearful group of that study, subliminal angry faces did produce higher anxiety ratings for spider pictures compared to anxiety ratings for spider pictures that followed primes of neutral or smiling faces. In the spider-fearful group, however, no subliminal priming effects were found. Thus, subliminal stimuli seem not to be powerful enough to overnule strong feelings.

To be sure, a number of technical problems arise when one uses subliminal stimuli to study unconscious determinants of behaviour (see Holender, 1986; Marcel, 1983). For example, establishing precise awareness thresholds for all trials in all subjects is 
notoriously difficult. The technical obstacles make it hard to draw firm conclusions about the power of subliminal stimuli. Indeed, it remains unclear what exactly is the mechanism behind pre-attentive elicitation of phobic fear. What can be stated with some confidence is that the effect is small and depends on subtle factors that are largely unknown.

One may ask whether research addressing these factors may learn us something about real-life phobias. Also, it is questionable whether the technique of subliminal stimulation is well-suited for examining automaticity of information processing in psychopathology. Apart from the technical obstacles, "there is not enough compelling empirical evidence that automatic processing can be based on subliminal stimuli" (Tzelgow, 1997; p.444). Besides, automaticity is a broad concept that not only and always involves lack of awareness. In this context, MoNally (1995) noted that "the phenomenology of pathological anxiety suggests that processing biases are automatic in the sense of being involuntary rather than being capacity-free or necessarily unconscious". As sociall psychologists have pointed out, normal subjects have the ability to override automatic behaviour whenever the situation requires a careful selection from several behavioural options. Thus, the 'quick and dirty' bottom-up processes seem not to be the primary antecedents of phobic fear. Rather it is the inability to override the automatic influences that makes phobic fear different from normal behaviour. 


\section{Samenvatting}

Volgens het handboek voor de classificatie van psychopathologie (DSM-IV; American Psychiatric Association, 1994) is een fobie een irrationele angst voor bepaalde objecten (bijwoorbeeld honden) of situaties (bijvoorbeeld nauwe ruimten). Omdat confrontatie met een fobische stimulus onvermijdelijk leidt tot een angstrespons zal een fobicus er alles aan doen om de fobische stimulus te vermijden. Ondanks dat fobici erkennen dat ze inderdaad niet bang zouden hoeven te zijn voor die betreffende stimulus, kunnen zij de angstrespons niet onderdrukken. Hoe komt dit?

Volgens de Zweedse onderzoeker Öhman $(1988 ; 1994)$ bezitten mensen een waarnemingssysteem waarmee stimuli die ons fysiek bedreigen (zoals bijvoorbeeld slangen) antomatisch worden waargenomen. Dit waarnemingssysteem werkt onafhankelijk van de aandacht van de persoon (i.e., pre-attentief). Zodra dit systeem een potentieel bedreigende stimulus identificeert, wordt automatisch de aandacht getrokken en het lichaam in gereedheid gebracht om zo snel mogelijk te kunnen vluchten (i.e., de angstrespons). Dus, stelt Ohman, angstresponsen ontstaan reeds voordat de bedreigende stimulus bewust is waargenomen. Voor een fobicus betekent dit dus dat wanneer het fobisch object het bewustzijn bereikt het lichaam al in een angsttoestand is. Hierdoor is het logisch dat de fobicus zijn of haar angst ervaart als automatisch en oncontroleerbaar. Volgens Öhman biedt dit mechanisme een theoretische verklaring voor de irrationaliteit van fobieën. Omdat dit een veelbelovende theorie lijkt ter verklaring van de irrationaliteit en automaticiteit van fobieen, is het interessant om deze theorie uitvoeriger te onderzoeken.

Om na te gaan of een pre-attentieve analyse van bedreigende stimuli reeds voldoende is om een angstrespons uit te lokken, hebben Öhman en collega's in hun experimenten gebruikgemaakt van een maskeertechniek (zie Marcel, 1983). Hierbij presenteerden zij heel kort ( 30 milliseconden) twee dia's snel achter elkaar. Het gevolg hiervan is dat de eerste dia wordt gemaskeerd door de tweede, waardoor die eerste dia niet bewust is waar te nemen. In hun belangrijkste experiment onderzochten Öhman en Soares (1994) eerstejaarsstudenten die bang waren voor spinnen of slangen en studenten die hier niet bang voor waren. Deze studenten werden geconfronteerd met gemaskeerde angstrelevante dia's (spinnen en slangen) en angstirrelevante dia"s (paddestoelen en bloemen). De resultaten van dit onderzoek lieten zien dat de studenten die bang waren voor spinnen, hoge huidgeleidingsresponsen vertoonden op de gernaskeerde spinnendia's, maar niet op de andere dia's. Bij de studenten die bang waren voor slangen, vond men verhoogde huidgeleidingsresponsen specifiek op de gemaskeerde slangendia's. De niet-angstige studenten reageerden op geen enkele gemaskeerde dia met een verhoogde huidgeleidingsrespons. Dus, zeggen de auteurs, hoewel de proefpersonen de dia's niet bewust hebben waargenomen, reageerden zij specifiek met een verhoogde huidgeleidingsrespons op de voor hen bedreigende stimulus. Deze 
bevinding suggereert dat angstresponsen inderdaad uitgelokt kunnen worden door een pre-attentieve analyse van bedreigende stimuli.

Hoewel de studies van Öhman en Soares indrukwekkende resultaten tonen, zijn er enkele kritische kanttekeningen bij te plaatsen. Bijvoorbeeld, de resultaten van Öhman en Soares zijn niet of nauwelijks gerepliceerd in andere, onafhankelijke laboratoria. Tevens zijn ze niet verkregen bij echte fobici, maar bij angstige studenten. Bovendien was het ook niet zeker of de stimuli werkelijk onbewust waren gebleven, omdat er geen zogenaamde bewustzijnscheck was uitgevoerd in deze groep. Ten slotte zijn ook de grondbeginselen van de hypothese (i.e., 'preparedness') niet zonder problemen (e.g., McNally, 1987).

In dit proefschrift wordt Öhmans hypothese over pre-attentieve activatie van fobische angst uitgebreider onderzocht. Een van de belangrijkste veronderstellingen van Öhman is dat fobici hun angstrespons ervaren als automatisch (onvrijwillig). Als gevolg van deze automatisch opgewekte fysiologische respons hebben fobici een irrationele angst voor bepaalde objecten of situaties. Om te onderzoeken of de gevoelens van automaticiteit en irrationaliteit bij fobici daadwerkelijk samenhangen, hebben we een vragenlijst ontwikkeld en verspreid onder spinfobici en niet-angstige controlepersonen (zie Hoofdstuk 4, Studie 1). Uit de data bleek dat fobici hun angstrespons inderdaad ervaren als iets waarover ze geen controle hebben (cf. automaticiteit). Ook gaven zij aan dat hun angstrespons niet verklaard kan worden door gevaar van het gevreesde object (cf. irrationaliteit). Deze twee kenmerken van fobische angst waren echter niet significant gecorreleerd. Dus, op subjectief niveau kon er geen duidelijke relatie worden gevonden tussen de afwezigheid van controle en de tendens de angst te zien als irrationeel.

Om Öhman en Soares" (1994) belangrijkste bevindingen te valideren in een onafhankelijk lab, hebben we een vergelijkbare studie uitgevoerd (zie Hoofdstuk 4, Studie 2). Er zijn echter een paar veranderingen aangebracht. Ten eerste zijn er spinfobische patiënten onderzocht in plaats van angstige studenten. Verder zijn de gemaskeerde dia's met verschillende tijden gepresenteerd (namelijk 30, 20 of $15 \mathrm{~ms}$ ), omdat er geen aanleiding was om te veronderstellen dat gemaskeerde presentaties van $30 \mathrm{~ms}$ werkelijk onbewust zouden blijven. Ten slotte is de bewustzijnscheck in dezelfde groep uitgevoerd als waarvan de fysiologische metingen (huidgeleidingsresponsen) zijn verkregen. In onze studie lokten de gemaskeerde spinnendia's geen verhoogde huidgeleidingsresponsen uit bij de spinfobische patiënten. Met andere woorden, de bevindingen van Öhman en Soares konden niet gevalideerd worden.

Ondat huidgeleiding eigenlijk meer een maat is voor oriëntatie dan voor angst, is het misschien niet de sensitiefste maat om angst te meten. Een gevoeligere maat zou misschien de gezochte effecten wel boven tafel krijgen. Derhalve zijn in het derde experiment (zie Hoofdstuk 4, Studie 3) oogknipperreflexen gemeten. Van de oogknipperreflex is bekend dat deze gevoelig is woor de emotionele lading van een stimulus (e.g., Lang, Bradley, \& Cuthbert, 1990; 1992): hoe negatiever de stimulus, hoe sterker de oogknipper. Ook is er gemeten of de gemaskeerde fobische stimuli in staat waren om cognitieve effecten uit te lokken. Öhmans hypothese impliceert namelijk dat 
er eerder fysiologische dan cognitieve effecten worden ontlokt. Dus als de gemaskeerde fobische stimuli well in staat zijn om fysiologische responsen wit te lokken maar geen cognitieve effecten, dan zou dit Öhmans hypothese ondersteunen. Als daarentegen gemaskeerde stimuli geen fysiologische maar wel cognitieve effecten uitlokken, dan zou dat Öhmans hypothese minder aamemelijk maken. De resultaten van deze studie laten zien dat de gemaskeerde fobische stimuli geen grotere oogknipperreflexen uitlokten dan gemaskeerde neutrale stimuli. Tevens lokten de gemaskeerde fobische stimuli geen cognitieve effecten uit. Deze stimuli lokten daarentegen wel grotere oogknipperreflexen en cognitieve effecten uit toen ze bewust waarmeembaar werden. gepresenteerd. Opnieuw zijn er dus geen aanwijzingen gevonden voor het bestaan van een pre-attentief analysemechanisme voor bedreigende informatie.

Er zou beweerd kunnen worden dat een belangrijk verschil tussen het experiment van Öhman en Soares (1994) en onze studies de afmetingen van de dia's is. Öhman en Soares gebruikten dia's met een afmeting van $21 \times 14 \mathrm{~cm}$ op een afstand van een meter, de bovenstaande studies gebruikten dia's met een grootte van $110 \times 70$ op een afstand van 2 meter. Het zou kunnen zijn dat grote dia's niet in staat zijn om pre-attentief een fysiologische respons uit te lokken ondat deze dia's gewoonweg niet volledig in het zicht vallen. Om deze reden is in het vierde experiment de afmeting van de dia's gemanipuleerd (zie Hoofdstuk 4, Studie 4). Hierbij werden spinangstige en niet-angstige proefpersonen blootgesteld aan zowel grote als kleine gemaskeerde dia's van spinnen, slangen, paddestoelen en bloemen. Zowel de grote als de kieine gemaskeerde fobische dia's bleken niet in staat een werhoogde huidgeleidingsreactie uit te lokken.

Öhman beweert dat het pre-attentieve analysemechanisme voor bedreigende informatie een evolutionaire erfemis is; onze voorouders die uitgernst waren met dit analysemechanisme, hadden een grotere overlevingskans. Als dit het geval is dan zou je dit mechanisme ook moeten aantreffen bij fobische kinderen. In tegenstelling tot volwassen fobici kan bij fobische kinderen de automaticiteit van de angstrespons zeker niet verklaard worden door een jarenlange leerervaring. Derhalve zal een evolutionaine verklaring aannemelijker worden indien het analysemechanisme aangetroffen wordt bij fobische kinderen. Voor dit doel zijn spinfobische kinderen geconfronteerd met gemaskeerde dia's van spinnen, slangen en paddestoelen, waarbij huidgeleidingsresponsen werden gemeten. Ook in dit experiment zijn er geen aanwijzingen gevonden voor een pre-attentieve activatie van de angstrespons.

Kortom, geen van de beschreven studies was in staat steun te vinden voor Öhmans hypothese over de pre-attentieve activatie van angst. Blijkbatar hangt het vinden van fysiologische effecten van gemaskeerde bedreigende stimuli af van hele subtiele factoren. Hoe zit het dan met het vinden van subjectieve effecten van gemaskeerde stimuli? En hoe zit het met de effecten van positieve gemaskeerde stimuli? Een primingstudie (zie Studie 6) liet zien dat er kleine primingeffecten gevonden konden worden in een niet-angstige groep. In deze groep werden plaatjes van spinnen als angstaanjagender beoordeeld wanneer er gemaskeerde boze gezichten aan vooraf waren gegaan dan wanneer er gemaskeerde neutrale of blije gezichten aan vooraf waren gegaan. In de spinangstige groep werden deze primingeffecten niet gevonden. Hier 
werd de beoordeling van de spinnenplaatjes niet beĭnvloed door de voorafgaande gemaskeerde positieve, neutrale of negatieve prime. Deze bevinding wijst erop dat gemaskeerde stimuli niet sterk genoeg zijn om sterke gevoelens te veranderen. Gebaseerd op deze resultaten kan geconcludeerd worden dat negatieve gemaskeerde primes meer effect hebben dan positieve. Alhoewel dit in de lijn ligt van Öhmans hypothese, zorgen de consistente nulbevindingen van de andere experimenten toch voor twijfel aan de juistheid van de hypothese.

Er zijn echter wel enkele technische moeilijkheden die een rol spelen bij de aanbieding van gemaskeerde stimuli (zie Holender, 1986; Marcel, 1983), zoals de instelling van een juiste (on)bewustzijnsdrempel. Dit soort technische obstakels maakt het moeilijk eenduidige conclusies te trekken over de kracht of zwakte van gemaskeerde stimulatie. Vooralsnog blijft het daardoor onduidelijk wat precies het werkingsmechanisme is achter pre-attentieve uitlokking van de fobische angstrespons. Wel blijkt duidelijk dat het gaat om een effect dat afhangt var erg subtiele factoren. Om te beginnen kan men zich hierbij afvragen hoe relevant deze factoren dan zijn bij levensechte fobieën. Tegelijkertijd rijst de vraag of de techniek van gemaskeerde stimulatie wel de meest aangewezen manier is om automaticiteit van informatieverwerking in psychopathologie te onderzoeken. Naast de hoeveelheid aan technische problemen is er volgens Tzelgov (1997) namelijk niet genoeg empirisch bewijs dat automatische processen gebaseerd kunnen zijn op gemaskeerde stimuli. Daarnaast is automaticiteit een breed concept dat niet alleen het gebrek aan bewustzijn omvat. Zo beweerde McNally (1995) dat pathologische angst suggereert dat biases in de informatieverwerking automatisch zijn in de zin van onvrijwillig en niet zozeer in de zin van onbewust. Daarom is het misschien zinvoller om in plaats van het onbewuste aspect, het onvrijwillige aspect van automatische informatieverwerking verder te onderzoeken.

Automaticiteit van gedrag is niet exclusief het terrein van psychopathologie. Ons dagelijks leven bestaat voor het grootste deel uit automatische processen. We hoeven niet meer na te denken hoe we moeten lopen, fietsen of tandenpoetsen. Automatische processen zijn dan ook van groot belang voor het functioneren van de mens. Zij zorgen er namelijk voor dat onze gelimiteerde capaciteit om bewuste aandacht te geven vrij blijft voor zaken waarvoor zij echt nodig is. Normaal gesproken is de mens in staat om deze automatische processen te doorbreken wanneer de situatie aandacht vereist. Denk bijvoorbeeld aan de automobilist die zijn gesprek even staakt wanneer hij een ingewikkelde verkeerssituatie nadert. Misschien is een essentieel verschil tussen fobische angst en normaal gedrag gelegen in de onmogelijkheid om dit soort automatische processen te doorbreken. 


\section{Dank...}

Het dankwoord is een mooie afsluiting van een proefschrif, maar meer nog van een promotieperiode. Het is de gelegenheid on iedereen die in die jaren heef meegewerkt en/or meegeleefd, daar eindelijk eens voor te bedanken. Bij deze dus.

Harald Merckelbach, promotor en begeleider, jouw enthousiasme voor onderzoek zorgde steeds opnieuw voor leuke ideeën en vlot becommentarieerde stukken. De hoeveelheid rood was even wemnen, marar ik heb er veel van geleerd. Terwijl ikzelf door de talloze afwijzingen steeds pessimistischer werd over de kwaliteit en publiceerbaarheid van de artikelen, bleef jij - terecht, zo bleek - altijd optimistisch over de goede afloop. Hartelijke dank daarvoor.

Marcel van den Hout, als student-assistent werkte ik altijd al met plezier voor jouw club: een stel jonge enthousiaste onderzoekers onder leiding van een bevlogen man. Ik heb dan ook met heel veel plezier jaren deel uitgemaakt van deze club; veel dank voor je gastwrijheid.

Peter de Jong, collegavriend, jij hebt mij wegwijs gemaakt in het psychofysiologisch lab, waar we heel wat geëxperimenteerd, dropjes gegeten en leugens gedetecteerd hebben. Het samen spinnenvangen op de kinderboerderij en de congresvakanties zal ik missen, maar je gezellige borreluurtjes hopelijk niet.

Ineke Wessel en Iris Engelhard (alias Nelissen), mijn kamergenootjes, en Anja Meijboom en Guus Smeets, de buurvienden. Ik heb met jullie vooral veel gelachen. Ook hebben jullie echter mijn tranen en frustraties meegemaakt. Steeds opnieuw wisten jullie van deze slechte tijden toch weer goede tijden te maken!

Het pingpongcohort; gaandeweg de jaren is de samenstelling flink veranderd, maar onveranderd bleven het (ont)spannende partijen. Ik zou graag weer mijn lunch opofferen en meedoen.

Onmisbare technische, statistische en onderzoekshulp heb ik gekregen van respectievelijk Theo van Aerts, Erik Schouten en Annie Raven. Ondanks dat ik jullie hulp bijna altijd onaangekondigd en per direct nodig had, stonden jullie steeds onmiddellijk klaar. Jullie waren geweldige collega's!

Alle andere collega's van DMKED; jullie hebben gezorgd voor een erg leuke werkkring met een zeer goede sfeer. De herinneringen zijn goed.

Schaduwcollega's van Experimentele Psychologie; het was gezellig dat ik af en toe kon aanvoeren dat ik er als oio van Harald ook een beetje bij hoorde.

Alle bange en niet-bange proefpersonen; hartelijke dank voor het meewerken aan voor jullie erg saai onderzoek, jullie zagen immers meestal niets.

Dank ook aan Marga van den Oever en Robert Horselenberg; jullie assistentie bij het dataverzamelen was behalve deskundig ook vooral erg gezellig.

Sandra Daems, je hebt een geweldig omslag voor dit boekje gemaakt; gaaf! 
Dick Disselkoen, dank dat je op het laatste moment je treinreis hebt willen besteden aan het controleren van inconsequenties in de tekst; wat er nu nog in zit, is mijn eigen slordigheid. Marja Hortulanus en Sandra Mulkens, paranimfen, dank voor vele uren gezelligheid en de af en toe broodnodige steun. Ik moet jullie missen als collega's, maar gelukkig niet als wriendinnen. Ik ben er onwijs trots op dat jullie straks met mij op het podium willen staan. Papa en mama, dank dat jullie vroeger bij elk goed schoolcijfer al riepen dat ik maar moest gaan studeren; het is me goed bevallen!

Zusjes, vrienden, lieve Peter, zonder jullie had ik het proefschrift waarschijnlijk ook wel voltooid, maar éen ding is zeker: het was absoluut een heel stuk minder leuk geweest! Nu is thet dan eindelijk echt af; laten we feesten! 


\section{Curriculum vitae}

Birgit Mayer werd op 30 mei 1969 geboren in Haarlem. In 1988 behaalde zij het VWOdiploma aan de Lorentz Scholengemeenschap te Arnhem. Hierna ging zij Gezondheidswetenschappen studeren aan de Universiteit Maastricht. In het voorjaar van 1994 behaalde zij het doctoraaldiploma met als afstudeerrichting Geestelijke gezondheidkunde. Per oktober 1994 werd zij aangesteld als onderzoeker in opleiding bij de toenmalige vakgroep Differentiële en Experimentele Psychologie van de Universiteit Maastricht. In die periode heeft zij het onderzoek uitgevoerd waarop dit proefschrift is gebaseerd. Sinds 1 maart 1999 is zij voor de periode van vier jaar aangesteld als universitair docent aan de faculteit Sociale wetenschappen van de Open Universiteit Nederland. 